Florida International University FIU Digital Commons

3-27-2014

\title{
Influence of Chemical Composition and Water on the Bulk Modulus of Pyrope
}

Shu Huang

shuan004@fiu.edu

DOI: $10.25148 /$ etd.FI14040883

Follow this and additional works at: https://digitalcommons.fiu.edu/etd

Part of the Mineral Physics Commons, and the Other Materials Science and Engineering Commons

\section{Recommended Citation}

Huang, Shu, "Influence of Chemical Composition and Water on the Bulk Modulus of Pyrope" (2014). FIU Electronic Theses and Dissertations. 1185.

https://digitalcommons.fiu.edu/etd/1185

This work is brought to you for free and open access by the University Graduate School at FIU Digital Commons. It has been accepted for inclusion in FIU Electronic Theses and Dissertations by an authorized administrator of FIU Digital Commons. For more information, please contact dcc@fiu.edu. 
FLORIDA INTERNATIONAL UNIVERSITY

Miami, Florida

\section{INFLUENCE OF CHEMICAL COMPOSITION AND WATER \\ ON THE BULK MODULUS OF PYROPE}

A dissertation submitted in partial fulfillment of the

requirements for the degree of

DOCTOR OF PHILOSOPHY

in

MATERIAL SCIENCE AND ENGINEERING

by

Shu Huang

2014 
To: Dean Amir Mirmiran

College of Engineering and Computing

This dissertation, written by Shu Huang, and entitled Influence of Chemical Composition and Water on the Bulk Modulus of Pyrope, having been approved in respect to style and intellectual content, is referred to you for judgment.

We have read this dissertation and recommend that it be approved.

$\begin{array}{r}\text { W. Kinzy Jones } \\ \hline \text { Yu Zhong } \\ \hline \text { Grenville Draper } \\ \hline \text { Jung-Fu Lin } \\ \hline \text { Jiuhua Chen, Major Professor }\end{array}$

Date of Defense: March 27, 2014

The dissertation of Shu Huang is approved.

Dean Amir Mirmiran

College of Engineering and Computing

Dean Lakshmi N. Reddi

University Graduate School

Florida International University, 2014 
CCopyright 2014 by Shu Huang All rights reserved. 


\section{ACKNOWLEDGMENTS}

I would like to express my deepest gratitude to my advisor, Prof. Jiuhua Chen, for his excellent guidance of this dissertation and encouragement throughout this project. I would like to thank my committee members for their support and patient. I wish to thank CeSMEC people, Prof. Saxena, Dr. Durigin and Dr. Drozd for their help in experiments. 


\begin{abstract}
OF THE DISSERTATION
INFLUENCE OF CHEMICAL COMPOSITION AND WATER
\end{abstract}

ON THE BULK MODULUS OF PYROPE

by

Shu Huang

Florida International University, 2014

Miami, Florida

Professor Jiuhua Chen, Major Professor

Garnets are major silicates from the upper mantle to the transition zone. Elastic properties of garnets are essential to interpret the variation of seismic velocities at different depths and construct a model of the Earth's composition. Due to the chemical flexibility at octahedron sites of the crystal structures, garnets usually exist with multiple components and have many composition variations. Pyrope is an important member in the garnet group. $\mathrm{Fe}^{2+}-\mathrm{Mg}^{2+}$ substitution in pyrope is one of the common solid solutions. We have synthesized and measured three synthetic solid solutions samples ( $\mathrm{Py}_{83} \mathrm{Alm}_{17}, \mathrm{Py}_{54} \mathrm{Alm}_{46}$ and $\mathrm{Py}_{30} \mathrm{Alm}_{70}$ ). Equations of state yielded their isothermal bulk moduli $\mathrm{K}_{0}$ to be 172(4)GPa, 174(2)GPa, and 183(2)GPa, respectively, which confirmed that almandine content $\left(\mathrm{Fe}^{2+}\right.$ substitution) increased the bulk modulus of the garnet. A relation between the bulk modulus and the almandine mole fraction $(n)$ was derived to be $K_{0}=170+15 n$, showing it is a nearly ideal mixing model. 
Another factor that also significantly influences the elasticity of pyrope is water. Water is transported to the deep Earth by subduction slabs and mainly exists in nominally anhydrous minerals (NAM) as hydroxyl $\left(\mathrm{OH}^{-}\right)$. Its content in minerals varies as depth increases. We therefore investigated pressure influence on water solubility in pyrope. A suite of pyrope single crystals was synthesized in a water-saturated environment at 6, 7,9 and $12 \mathrm{GPa}$ and water was characterized by FTIR. IR spectra showed a typical peak at $3630 \mathrm{~cm}^{-1}$. At 9 and $12 \mathrm{GPa}$, new peaks at $3572 \mathrm{~cm}^{-1}$ and $3504 \mathrm{~cm}^{-1}$ appeared and indicated that a new substitution mechanism, other than hydrogarnet substitution $\mathrm{SiO}_{4}=(\mathrm{OH})_{4}$, was adopted in the pyrope crystal structure. Water solubility in pyrope reached $0.2 \mathrm{wt} \%$ at $7 \mathrm{GPa}$. From $4-7 \mathrm{GPa}$, water solubility increased. At $9 \mathrm{GPa}$, water content dropped to $0.07 \mathrm{wt} \%$ and increased to $0.3 \mathrm{wt} \%$ at $12 \mathrm{GPa}$, where a cubic to tetragonal phase transition was observed. Water showed a weakening effect on the bulk moduli of hydrous pyrope. Their bulk moduli were $166 \mathrm{GPa}, 173 \mathrm{GPa}$ and $161 \mathrm{GPa}$ with water contents of $0.07 \mathrm{wt} \%, 0.1 \mathrm{wt} \%$ and $0.2 \mathrm{wt} \%$, respectively. An approximate linear relationship was proposed about the bulk modulus as a function of water content. 


\section{TABLE OF CONTENTS}

CHAPTER

PAGE

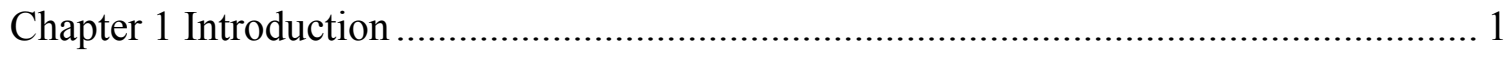

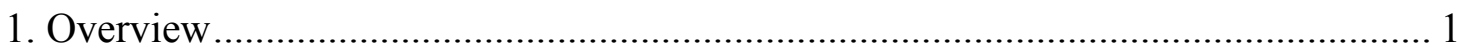

2. Specific Statement of Research Questions/Objectives .............................................. 2

3. Content of chapters ………………………………….................................. 3

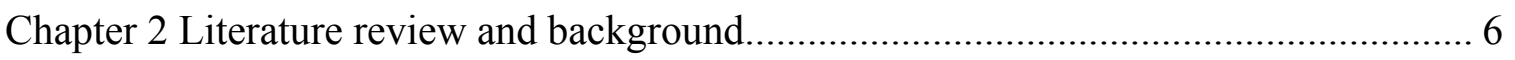

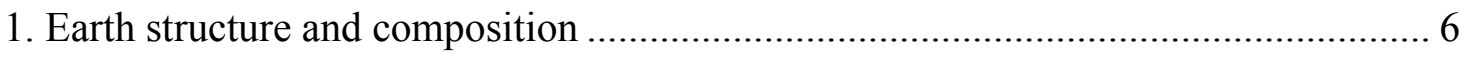

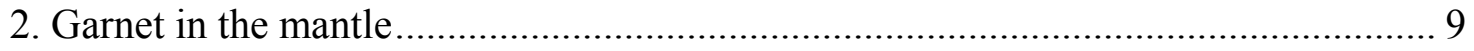

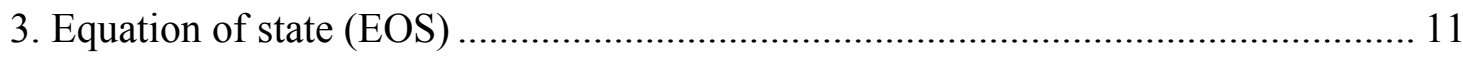

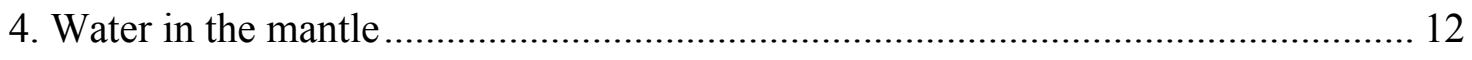

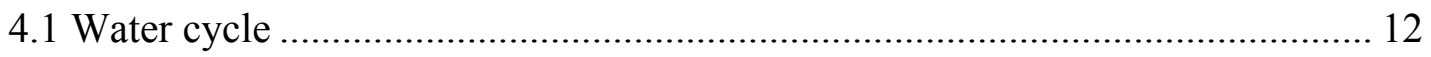

4.2 water in nominally anhydrous minerals ......................................................... 14

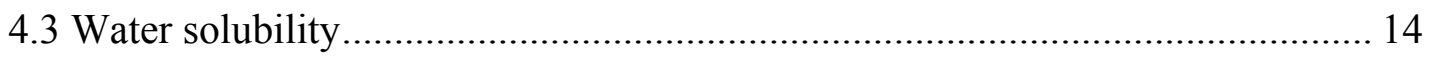

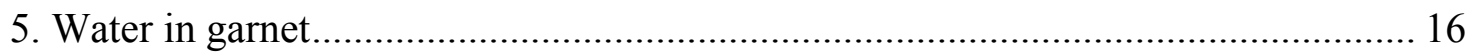

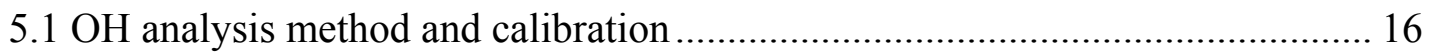

5.2 IR spectra features of hydrous garnet ........................................................... 19

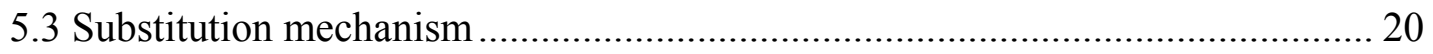

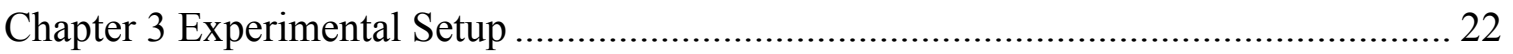

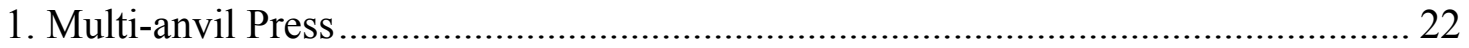

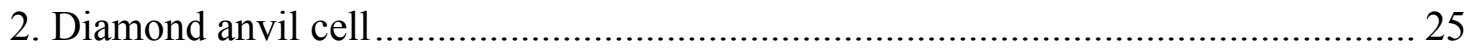

3. Fourier transform infrared spectroscopy-FTIR ………....................................... 29

4. Analysis of single crystal X-ray diffraction data .................................................. 30

Chapter 4 Chemical composition influence on the bulk modulus of pyrope..................... 35

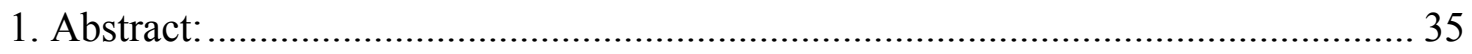

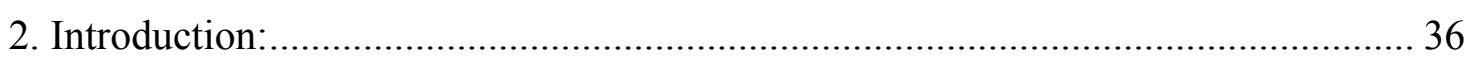

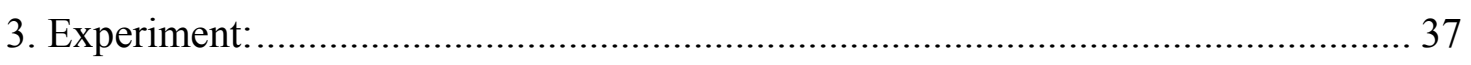

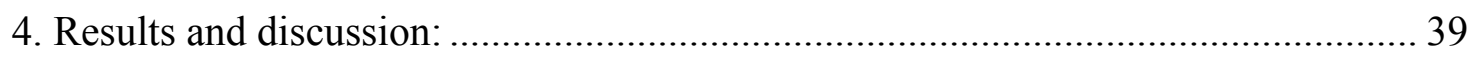

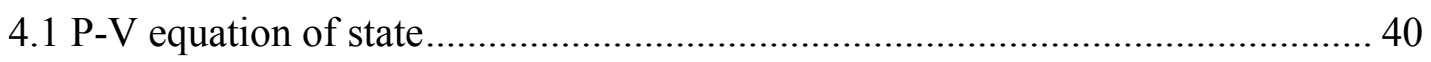

$4.2 \mathrm{Mg}^{2+}-\mathrm{Fe}^{2+}$ substitution effect on bulk modulus ............................................... 41 
Chapter 5 Water solubility in synthetic pyrope at high temperature and high pressure ... 48

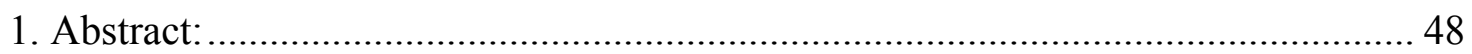

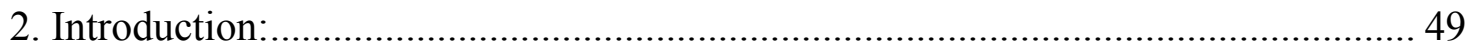

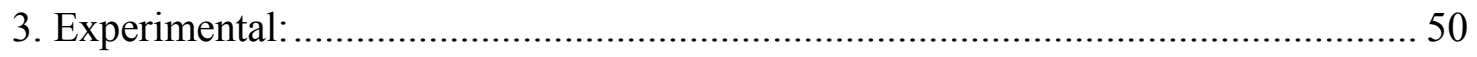

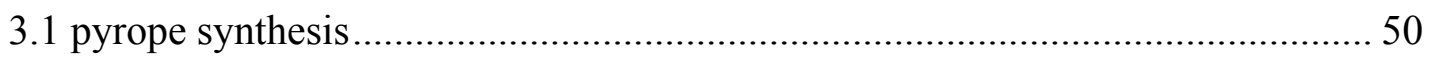

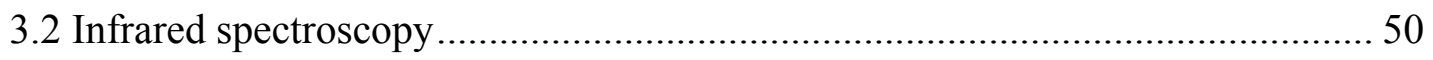

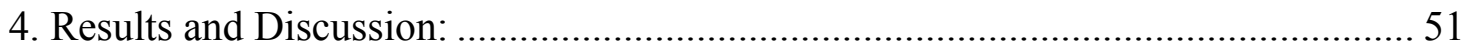

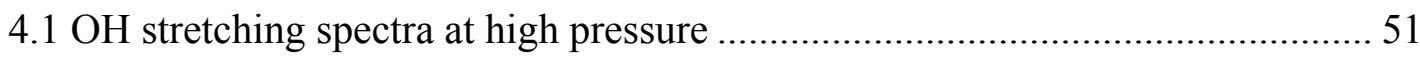

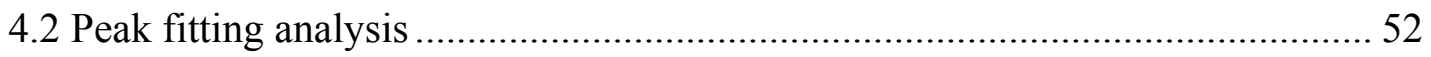

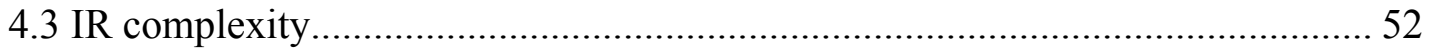

4.4 Water solubility in pyrope under high pressure ……........................................ 52

4.5 Water in grossular garnet and incorporation mechanism ................................... 53

4.6 Tetragonal polymorph of pyrope at 12GPa ..................................................... 54

Chapter 6 Water influence on Equation of state of hydrous Pyrope.................................. 59

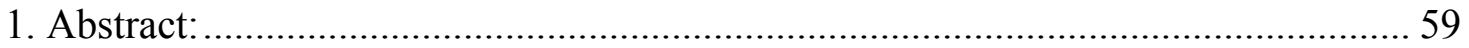

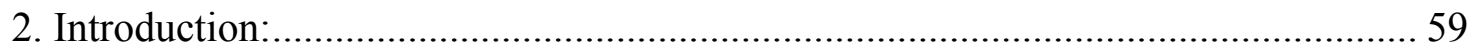

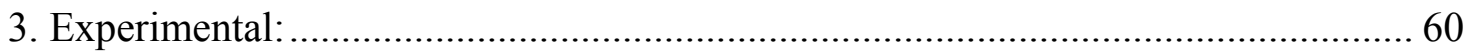

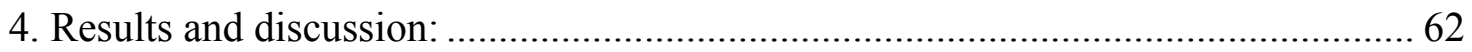

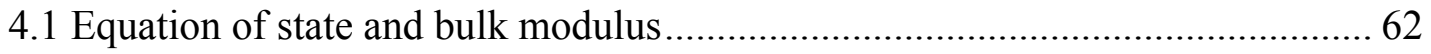

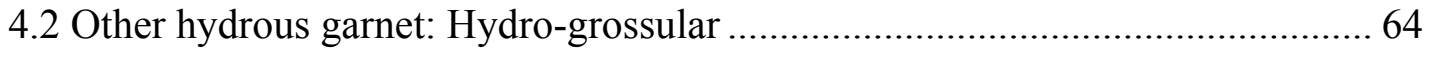

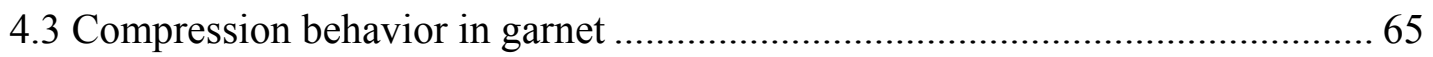

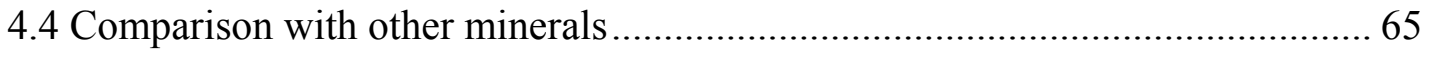

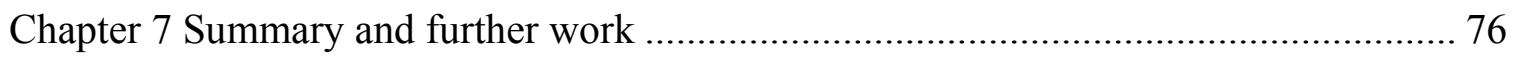

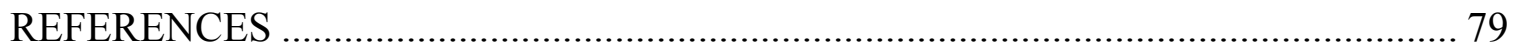

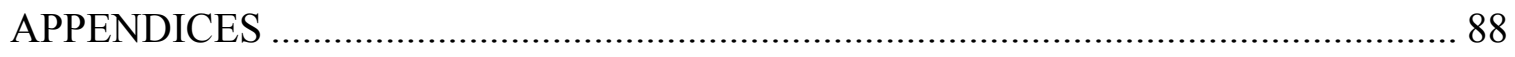

VITA …… 


\section{LIST OF TABLES}

TABLE

PAGE

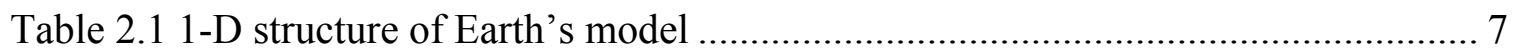

Table 2.2 Natural and synthetic garnet end members and formulas............................... 9

Table 2.3 Hydrous phases in the mantle ..................................................................... 13

Table 2.4 OH forms in minerals (Keppler \& Bolfan-Casanova, 2006) .......................... 15

Table 2.5 Water component and $\mathrm{OH}$ peak positions in natural garnets........................... 20

Table 4.1 Composition of pyrope-almandine garnets at room temperature ..................... 42

Table 4.2 Unit cell parameters of synthetic garnet of pyrope-almantine join ................. 43

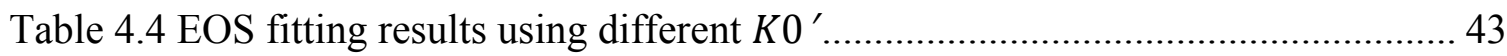

Table 4.3 Bulk modulus and pressure derivative of garnets .......................................... 44

Table 5.1 Synthesis conditions of single crystal pyrope and calculated water content .... 58

Table 6.1 Unit cell parameters of hydrous and dry pyrope............................................ 68

Table 6.2 EOS fitting results of hydrous and dry pyrope .............................................. 69 


\section{LIST OF FIGURES}

FIGURE

PAGE

Figure 2.1 The Preliminary Reference Earth Model ..................................................... 8

Figure 2.2 Mineral proportions in pyrolite as a function of depth in the mantle............... 8

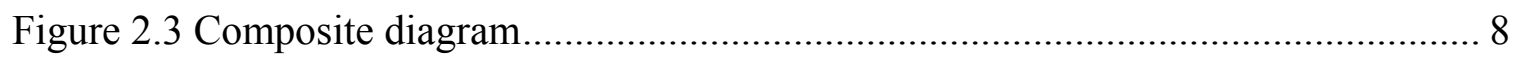

Figure 2.4 Structure of Garnet with local details .................................................... 10

Figure 2.5 Schematic models for global water circulation. ........................................ 13

Figure 2.6 IR spectra of garnet Mon-9 in the $\mathrm{OH}$ stretching region.............................. 19

Figure 2.7 Structure of silicate tetrahedron and $(\mathrm{OH})_{4}$ clusters................................ 21

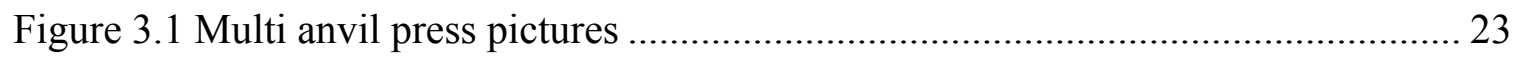

Figure 3.2 Illustration of the WC multi-anvil press .................................................. 24

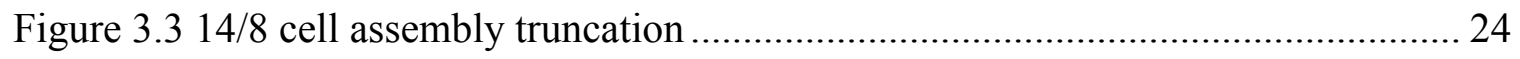

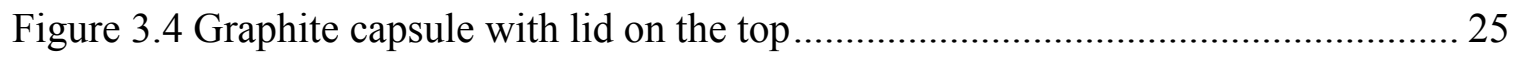

Figure 3.5 Capsule for hydrous pyrope synthesis ................................................. 25

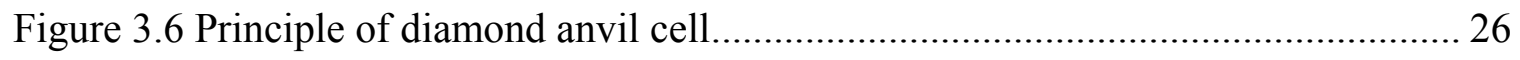

Figure 3.7 Geometry of different types of diamond anvils........................................ 27

Figure 3.8 Hutch layout of X17C for DAC experiment ........................................ 29

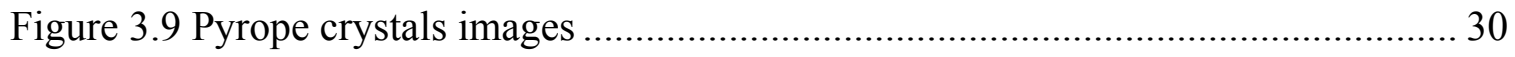

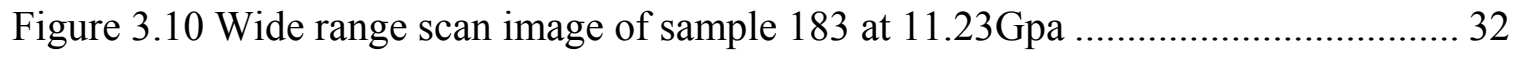

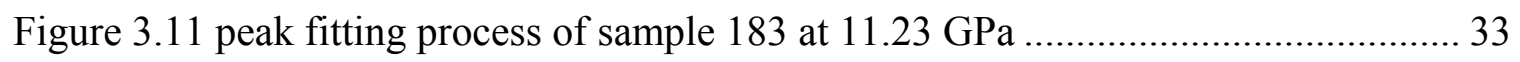

Figure 3.12 Index of peaks and calculation of orientation matrix by rsv software .......... 34

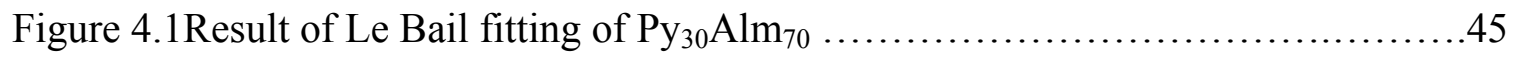


Figure 4.2 The unit cell volume as a function of pyrope content ............................... 46

Figure 4.3 Volume of Py-Alm garnets as a function of pressure measured ................... 46

Figure 4.4 Bulk modulus data of almandine-pyrope binary system. ........................... 47

Figure $5.1 \mathrm{XRD}$ of ground pyrope powder at ambient conditions..................55

Figure 5.2 A fitting example...............................................56

Figure 5.3 FTIR spectra of pyrope synthesized at pressures from 4GPa to $12 \mathrm{GPa}$........ 57

Figure 5.4 Water solubility in pyrope as a function of pressure ................................ 58

Figure 6.1 Two samples (181and 183) in the DAC sample chamber with ruby sphere... 67

Figure 6.2 Unit cell volume as a function of dry pyrope, error bar is too small............. 69

Figure 6.3 Comparison of EOS fitting between dry and hydrous samples.................... 71

Figure 6.4 Birch-normalized pressure (FE) as a function of Euler finite strain (fE) plots 72

Figure 6.5 Bulk modulus of hydrous pyrope as a function of water content.................. 73

Figure 6.6 Bulk modulus plotted as a function of pressure ..................................... 73

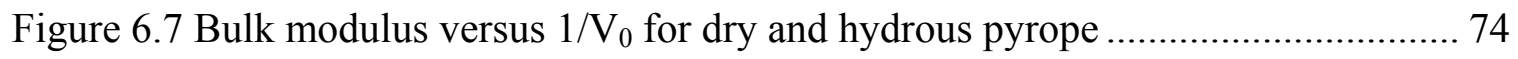

Figure 6.8 Unit cell volume as a function of water content in each sample.................. 74

Figure 6.9 Bulk modulus as a function of water content ....................................... 75 


\section{Chapter 1}

\section{Introduction}

\section{Overview}

Seismic waves travel through the Earth's interior and reach the Earth's surface. Interpretation of seismic velocity reveals the Earth's interior information: chemical composition, mineralogical anomalies, structure and so on. Variation of the velocity with depth depends on the elastic moduli and density of minerals. Elastic properties of minerals are, therefore, essential to examine seismic files and construct a composition model of the Earth.

High-pressure equipment, such as the multi anvil press and the diamond anvil cell, provides a way to generate high pressure similar to the Earth interior's environment. Xrays serve as a tool to probe the physical properties of minerals. Synchrotron radiation sources produce X-rays of high brilliance, which are many orders of magnitude brighter than the conventional X-rays and enable in situ measurement of various minerals of the mantle at high pressures and high temperatures.

Garnets are important minerals of the Earth's interior. According to pyrolite and piclogite mantle mineralogical models, garnets may comprise up to $\sim 15 \%$ or $\sim 22 \%$ of the total volume in the upper mantle, which corresponds to high pressures up to $13 \mathrm{GPa}$. Within the pressure range between 13 and $24 \mathrm{GPa}$ of the transition zone, garnets may even constitute $40 \%$ or more of the total volume (Ringwood, 1991). Garnets are stable in the Earth's interior from the crust to the top of the lower mantle. They have a cubic crystal structure with a space group of $\mathrm{Ia} 3 d$ and a general formula $\mathrm{X}_{3} \mathrm{Y}_{2} \mathrm{Si}_{4} \mathrm{O}_{12}$. The most 
abundant garnet in the mantle is magnesium aluminum silicate, with $\mathrm{Al}^{3+}$ taking $\mathrm{Y}$ sites. The $\mathrm{X}$ site is flexible in chemical compositions. $\mathrm{Fe}^{2+}-\mathrm{Mg}^{2+}$ substitution at $\mathrm{X}$ sites is quite common in nature and forms binary garnet solid solutions. Those anomalies of chemical composition result in a variation of seismic velocity at certain depths. Therefore, knowledge of elasticity of the garnet solid solution with different compositions becomes significant.

Although chemical composition alters physical properties of minerals, volatiles, such as water, also significantly influence the properties. Water is introduced into the Earth's mantle by subduction slabs. Traces of water can dramatically affect the properties of minerals, such as transport properties, diffusion and electrical conduction. Water incorporated into nominally anhydrous minerals, even at the ppm level, will influence their elastic properties. In mineral physics studies, investigations have been conducted on hydrous olivine, ringwoodite and wadsleyite. However, studies on hydrous pyrope are very few. This experimental study of hydrous pyrope can supply complementary data to other dominant mantle minerals. Besides, water in minerals is related to another issue-the water cycle and budget in the deep Earth. Water solubility study offers an upper limit of water in minerals that can be used for water budget calculation. In different depths of the Earth's mantle, water content varies. Thus, water solubility as a function of pressure is also needed.

\section{Specific Statement of Research Questions/Objectives}

The main goal of this study is to investigate the elastic property of garnet along the pyrope-almandine join and water influence on the equation of state of hydrous pyrope. 
In this study, we will synthesize pyrope-almandine solid solutions with different ratios $\left(\mathrm{Alm}_{100}, \mathrm{Alm}_{80} \mathrm{Py}_{20}, \mathrm{Alm}_{50} \mathrm{Py}_{50}, \mathrm{Alm}_{20} \mathrm{Py}_{80}, \mathrm{Py}_{100}\right)$. Pressure (P)-volume (V) data of these samples will be measured using in situ X-ray diffractions. After that, a relationship is defined in terms of compositional dependence of the bulk modulus $\left(\mathrm{K}_{0}\right)$ of garnet along the almandine-pyrope join.

In order to study water influence in pyrope, we will synthesize a series of single crystal pyrope crystals at different pressures $(4,6,7,9,12 \mathrm{GPa})$ and in a water-saturated environment. Water content in each sample is characterized by using Fourier transform infrared (FTIR). For this part, we want to study water solubility as a function of pressure and its substitution mechanism in pyrope structure.

As hydrous pyrope garnets are prepared, the last step is to study their elasticity at high pressures. Since the pyrope samples are single crystals, a more precise lattice parameter can be obtained, which is critical in the equation of state fitting. To recognize the difference in bulk modulus caused by tenths of a weight percentage water and minimize the experimental error in such comparisons, we will load two samples in the highpressure cell for the comparative study to quantify the water influence on the bulk modulus.

\section{Content of chapters}

The first chapter describes overview, research objectives and chapter contents of this dissertation. 
The second chapter introduces the geological background of this dissertation. It is a review of Earth's structure, composition, garnet in the mantle, a summary of water in the mantle and water solubility in nominally anhydrous minerals related to this research.

The third chapter gives a description of instruments and techniques used in this study. It includes high-pressure synthesis press, such as the multi anvil press, and the diamond anvil cell for bulk modulus measurement. Also included are synchrotron facilities where most of the measurements were conducted, FTIR and single crystal techniques for precise $\mathrm{P}-\mathrm{V}$ measurements of hydrous pyrope.

The fourth chapter presents the equation of state study on the garnet solid solution along the pyrope-almandine join. In this chapter, compositional dependence of the bulk modulus in this pyrope-almandine binary system will be discussed: how $\mathrm{Mg}^{2+} \mathrm{Fe}^{2+}$ substitution influences the elasticity of end member pyrope, and a relationship of composition and bulk moduli will be derived. This part has been published in the journal of Physics of the Earth and Planet Interiors.

The fifth chapter describes the systemic study of water solubility in synthetic pyrope at high pressures and a high temperature. Results of water solubility and characteristics of IR spectra at different pressures are presented. The water incorporation mechanism and the pyrope structure change are discussed as well.

The sixth chapter is about water influence on the equation of state of hydrous pyrope, in which water content had been investigated in the previous chapter. Equations of state of the three hydrous pyrope samples are derived and the relationship of bulk moduli as a function of water content is defined. 
The seventh chapter is a summary of experiment results: bulk modulus of garnet solid solution and also water influence on the equation of state and water solubility at different pressures. Further work includes the chemical composition characterization and refinement of the crystal structure of single crystal pyrope at $12 \mathrm{GPa}$. 
Chapter 2

\section{Literature review and background}

\section{Earth structure and composition}

Seismologists use elastic waves collected from global seismic stations to probe the inaccessible interior of the Earth and to build a seismological model (Table 2.1) about the structure of the Earth. One of the important models is the Preliminary Reference Earth Model (PREM) by (Dziewonski \& Anderson, 1981) (Figure 2.1). They defined different layers in the Earth by the variation and discontinuities of seismic wave velocities. Seismic waves are very sensitive to temperature, chemical and mineralogical anomalies. When seismic waves travel through various phases in the Earth, the travel time depends on elastic moduli and density of the medium where the waves propagate. Those properties of minerals are related to their crystal structure and compositions at high pressures and temperatures. Therefore, mineralogy information is quite essential to examine velocity files to achieve Earth's information in return.

The petrological models are assembled of different minerals with different percentages, which result in less anisotropy of velocities. The pyrolite model (Fig. 2.2-2.3) is one of the compositional Earth's models that show volume percentages of minerals at different depths. 
Table 2.1 1-D structure of Earth's model

\begin{tabular}{|l|l|}
\hline $0-80$ & Lithosphere \\
\hline $0-35$ & Crust \\
\hline $35-80$ & Uppermost part of mantle \\
\hline $35-2890$ & Mantle \\
\hline $80-220$ & Asthenosphere \\
\hline $410-660$ & Transition zone \\
\hline $35-660$ & Upper mantle \\
\hline $660-2890$ & Lower mantle \\
\hline $2740-2890$ & D"-layer \\
\hline $2890-5150$ & Outer core \\
\hline $5150-6360$ & Inner core \\
\hline
\end{tabular}

PREM reference model

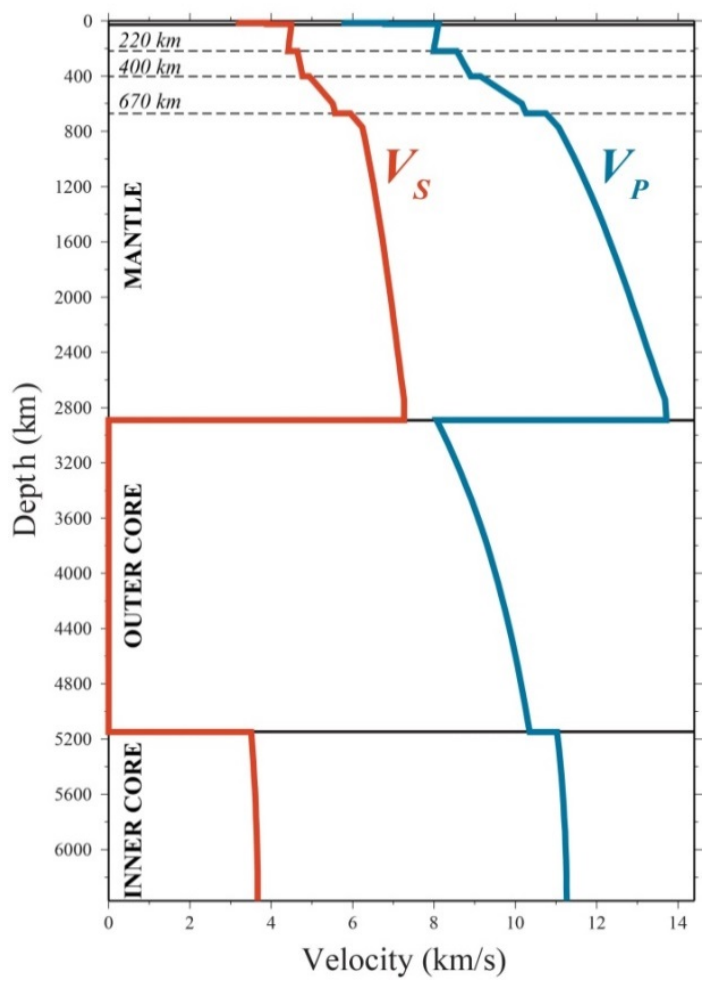


Figure 2.1 The Preliminary Reference Earth Model by Dziewonski and Anderson, 1981

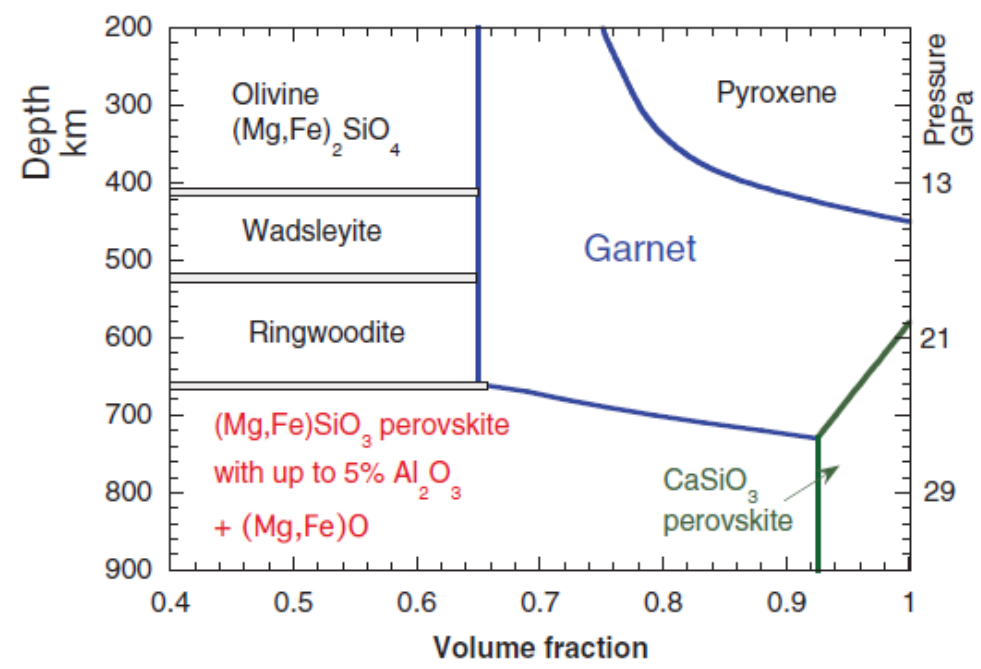

Figure 2.2 Mineral proportions in pyrolite as a function of depth in the mantle (Ringwood, 1991). Note the increasing modal amount of garnet with depth from 200 to $450 \mathrm{~km}$ due to the dissolution of pyroxene into garnet. Garnet becomes more majoritic in this depth interval ( cited from (Wood, Kiseeva, \& Matzen, 2013))

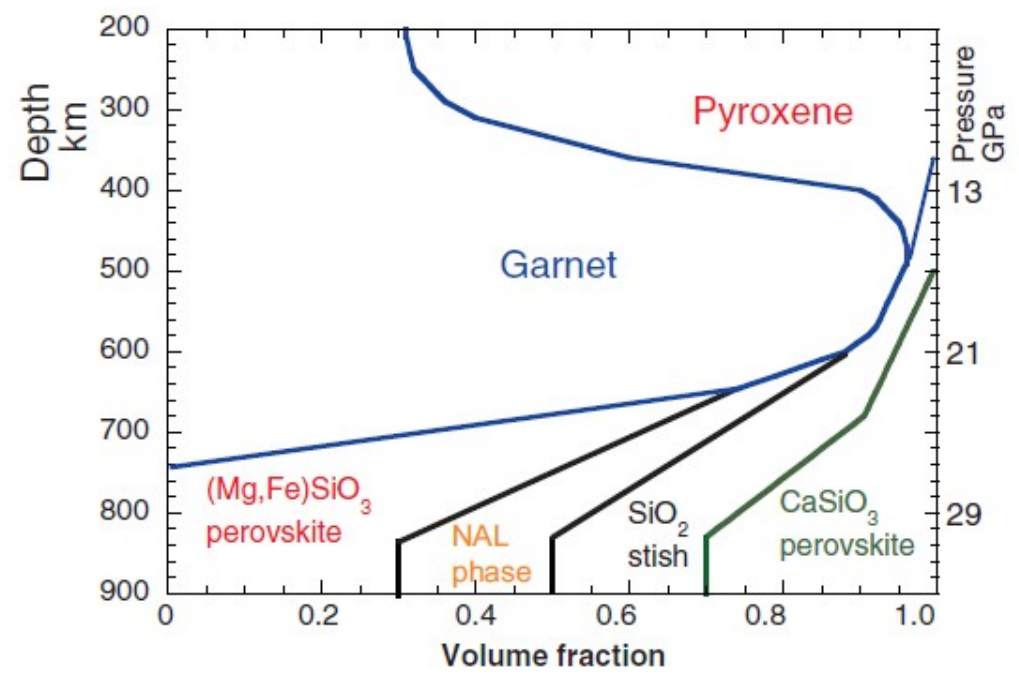

Figure 2.3 Composite diagram ((Irifune, Sekine, Ringwood, \& Hibberson, 1986; Ricolleau et al., 2010) showing phase transformations and proportions for an eclogite composition as a function of depth in the Earth. Note that eclogite becomes essentially a garnet in the deeper parts of the transition zone $(410-660 \mathrm{~km})$. Stish $=$ stishovite. NAL $=$ new aluminous phase, Na-rich (cited from(Wood et al., 2013)) 


\section{Garnet in the mantle}

Garnet exists in a wide pressure and temperature range, as shown in Fig. 2.2. It is stable up to $25 \mathrm{GPa}$ and $2000^{\circ} \mathrm{C}$. Its physical properties are closely related to mantle processes and are useful for modifying seismic wave velocities to layer the Earth's interior. Garnet takes the cubic structure with a space group Ia3d. Its general formula is $\mathrm{X}_{3} \mathrm{Y}_{2} \mathrm{Z}_{3} \mathrm{O}_{12}$, where $\mathrm{X}$ is in dodecahedral sites, $\mathrm{Y}$ is in octahedral sites, and $\mathrm{Z}$ is in tetrahedral sites. The garnet structure is shown in Figure 2.4 with local detail connections of polyhedrons. X, $\mathrm{Y}$ and $\mathrm{Z}$ are in a wide composition, where 53 elements are reported to form a garnet structure in the Inorganic Crystal structure Database (Allmann \& Hinek, 2007). The most common garnets' end members and their formulas are listed in table 2.2.

Table 2.2 Natural and synthetic garnet end members and formulas

\begin{tabular}{ll|ll}
\hline Almandine & $\mathrm{Fe}_{2} \mathrm{Al}_{2} \mathrm{Si}_{3} \mathrm{O}_{12}$ & Andradite & $\mathrm{Ca}_{3} \mathrm{Fe}_{2} \mathrm{Si}_{3} \mathrm{O}_{12}$ \\
\hline Grossular & $\mathrm{Ca}_{2} \mathrm{Al}_{2} \mathrm{Si}_{3} \mathrm{O}_{12}$ & Majorite & $\mathrm{Mg}_{3}\left(\mathrm{MgSi}_{3} \mathrm{Si}_{3} \mathrm{O}_{12}\right.$ \\
\hline Pyrope & $\mathrm{Mg}_{3} \mathrm{Al}_{2} \mathrm{Si}_{3} \mathrm{O}_{12}$ & Spessartine & $\mathrm{Mn}_{3} \mathrm{Al}_{2} \mathrm{Si}_{3} \mathrm{O}_{12}$ \\
\hline Uvarovite & $\mathrm{Ca}_{2} \mathrm{Cr}_{2} \mathrm{Si}_{3} \mathrm{O}_{12}$ & & \\
\hline $\begin{array}{l}\text { YAG (synthetic yttirum } \\
\text { aluminum garnet) }\end{array}$ & $\mathrm{Y}_{3} \mathrm{Al}_{2} \mathrm{Al}_{3} \mathrm{O}_{12}$ & $\begin{array}{l}\text { YIG (synthetic yttirum } \\
\text { iron garnet) }\end{array}$ & $\mathrm{Y}_{3} \mathrm{Fe}_{2} \mathrm{Fe}_{3} \mathrm{O}_{12}$ \\
\hline
\end{tabular}

Most of the natural garnets are solid solutions with two or more components. In the structure (Figure 2.2), $\mathrm{X}$ and $\mathrm{Y}$ sites can be exchanged by cations. Aluminosilicate garnets $\left(\mathrm{X}_{3} \mathrm{Al}_{2} \mathrm{Si}_{3} \mathrm{O}_{12}\right)$ with a single $\mathrm{X}$ site, offer a good system for thermodynamics behaviors studies in silicates. 

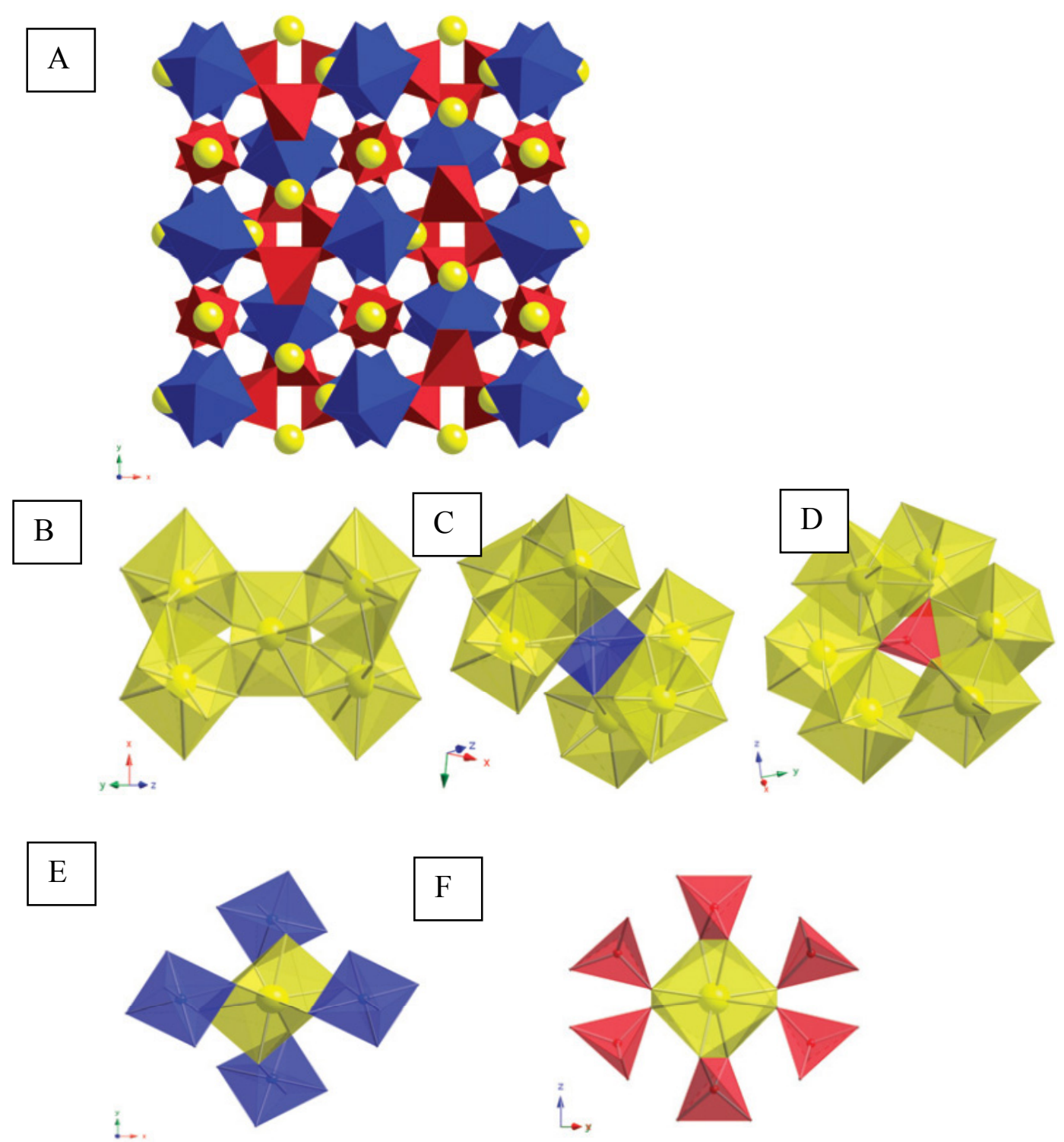

Figure 2.4 Structure of Garnet with local details

A: (A) Polyhedral model of garnet and unit cell directions. The tetrahedra and octahedra share corners, building a three-dimensional framework. The $\mathrm{X}$ cations (yellow spheres) are located in small cavities of triangular dodecahedral coordination. Various local coordination polyhedra relationships are shown in (B) to (F). (B) Edge-sharing relationship between neighboring dodecahedra (yellow). (C) A central octahedron (blue) and six edge-shared dodecahedra. (D) A central tetrahedron (red) and two edge-shared and four corner-shared dodecahedra. (E) A central dodecahedron and four edge-shared octahedra. (F) A central dodecahedron and two edge-shared and four corner-shared tetrahedra. (Cited from (C. A. Geiger, 2013)) 


\section{Equation of state (EOS)}

The equation of state is essential to describe minerals and dynamics of the Earth's interior. The best-known equation of state is $P V=R T$ for ideal gas. In mineral physics, we are concerned with the EOS for minerals at high pressures and high temperatures. The importance of the EOS in mineral physics is because it can provide an equation to extrapolate the bulk modulus at extreme pressures. The Birch-Murnaghan equation is one of the popular methods to obtain the bulk modulus of measured minerals and responding derivative. The third order Birch-Murnaghan equation of state is

$$
P=\left(\frac{3}{2}\right) K_{0}\left[\left(\frac{V_{0}}{V}\right)^{\frac{7}{3}}-\left(\frac{V_{0}}{V}\right)^{\frac{5}{3}}\right] \times\left\{1+\frac{3}{4}\left(K_{0}^{\prime}-4\right)\left[\left(\frac{V_{0}}{V}\right)^{\frac{2}{3}}-1\right]\right\}
$$

where $V_{0}, K_{0}$ and $K_{0}^{\prime}$ are zero pressure volume, isothermal bulk modulus and pressure derivative of the bulk modulus. The order of equation depends on pressure-volume data sets. In general, four is a common value during the fitting process, which is in the $2^{\text {nd }}$ order, and any value bigger than 4 is in the $3^{\text {rd }}$ order.

There are two types of bulk moduli: Isothermal and adiabatic moduli. The elastic moduli measured by ultrasonic methods and Brillouin scattering are adiabatic (constant entropy). The one derived from seismic wave velocity is adiabatic moduli, because the wave travels fast and doesn't have enough time for heat exchange. All the measurements in this dissertation are about isothermal bulk modulus using diamond anvil cells. 
Estimation of Bulk moduli of composite materials:

Rocks are aggregate of different minerals. The way to calculate their elastic moduli is to assume uniform stress or strain in the entire aggregate.

$$
M_{R}=\left(\sum_{i=1}^{n} v_{i} / M_{i}\right)^{-1} \leq \bar{M} \leq \sum_{i=1}^{n} v_{i} M_{i}=M_{v}
$$

Where $M_{i}$ is the elastic modulus ( $\mathrm{K}$ or $\mathrm{G}$ ) of the i phase, $\bar{M}$ is the actual modulus, $\mathrm{R}$ and V denote Reuss (uniform stress) and Voigt (uniform strain). If $M_{i}$ are not in wide range, then $M_{R}=M_{V}$. (Anderson, 1989)

\section{Water in the mantle}

\subsection{Water cycle}

Peacock and Simon (1990) estimated around $8.7 \times 10^{11} \mathrm{~kg} / \mathrm{year}$ of water is transported to the Earth's mantle by subduction slabs and about $2.0 \times 10^{11} \mathrm{~kg} / \mathrm{year}$ of water is out-gassed from the mantle to the surface. The imbalance of water is transported into the deep mantle by the Earth's interior water circulation (Figure 2.5). Water stays in the mantle as fluid, hydrous phases and hydroxyl defects in nominally anhydrous minerals. The selected hydrous phases are listed in Table 2.3. Most of these hydrous phases are not stable over a wide range of pressures and temperatures The water transported to the mantle is stored at nominally anhydrous minerals. That is one of the reasons to study water's influence on the bulk modulus of pyrope, which is one of the important end members in the garnet family. 


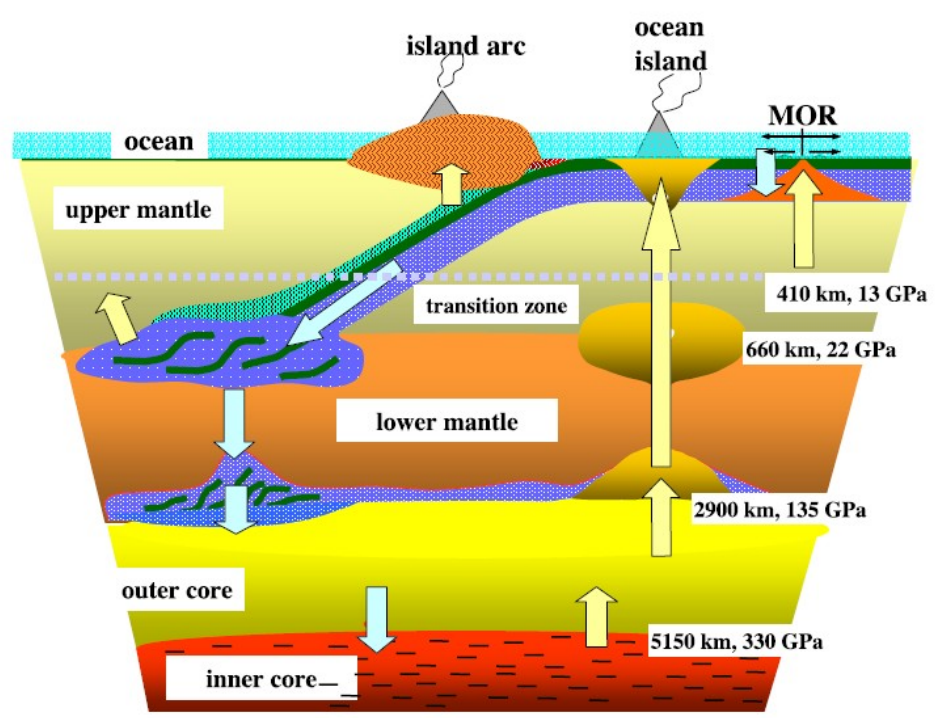

Figure 2.5 Schematic models of the global water circulations. The model by Williams and Hemley (2001) is modified in this figure, based on Maruyama et al. (2001) and Ohtani et al. (2004, 2005). Arrows indicate directions of water or hydrogen movement ( pic from (Ohtani, 2005))

Table 2.3 Hydrous phases in the mantle

\begin{tabular}{llc}
\hline Name & Formular & Water content(wt\%) \\
\hline serpentine & $\mathrm{Mg}_{3} \mathrm{Si}_{2} \mathrm{O}_{5}(\mathrm{OH})_{4}$ & 14 \\
chlorite & $\mathrm{Mg}_{5} \mathrm{Al}_{2} \mathrm{Si}_{3} \mathrm{O}_{10}(\mathrm{OH})_{8}$ & 13 \\
phase A & $\mathrm{Mg}_{7} \mathrm{Si}_{2} \mathrm{O}_{8}(\mathrm{OH})_{6}$ & 12 \\
phase E & $\mathrm{Mg}_{2.3} \mathrm{Si}_{1.25} \mathrm{H}_{2.4} \mathrm{O}_{6}$ & 11.4 \\
wadsleyite & $\mathrm{Mg}_{2} \mathrm{SiO}_{4}$ & 3 \\
topaz-OH & $\mathrm{Al}_{2} \mathrm{SiO}_{4}(\mathrm{OH})_{2}$ & 10 \\
diaspore & $\mathrm{AlOOH}$ & 15 \\
phase EGG & $\mathrm{AlSiO}_{3} \mathrm{OH}$ & 7.5 \\
\hline
\end{tabular}

Superphase $\mathrm{B}\left(\mathrm{Mg}_{10} \mathrm{Si}_{3} \mathrm{O}_{14}(\mathrm{OH})_{4}\right)$ is stable at the lower mantle at the pressure of $30 \mathrm{GPa}$. However, most of the other hydrous phases are not stable along the geotherm. The transported water from the Earth's surface is mostly stored in the nominally anhydrous 
minerals (NAM). That is the reason why it is important to study water in NAM, even with traces of water. Water plays an important role in most of the mantle's processes.

\section{2 water in nominally anhydrous minerals}

Overall, traces of water in minerals are from ppm to tenths of a percent by weight. Studies on water in the NAM are closely related to two issues. One is the water budget of the Earth. NAM can be the major water storage in the mantle (Bell \& Rossman, 1992). Ringwood and Green (1966) estimated that five times the weight of the surface water could be present in the mantle if only $\sim 0.2 \mathrm{wt} \%$ of water was distributed in the entire mantle. The other issue is that traces of water can significantly influence properties of minerals. Those properties include elasticity, diffusion rate, electrical conductivity, rheology and melting behaviors. For example, L. Wang, Zhang, and Essene (1996) observed that the diffusion of Fe-Mg in olivine in wet conditions is one magnitude higher than under anhydrous conditions. Mei and Kohlstedt (2000) found that water has hydrolytic weakening to mantle convection by lowering the viscosity of the mantle.

\subsection{Water solubility}

Examination of water content in specific mineral crystals cannot tell us that the hydration conditions of the original sources, because there could be water lost when minerals ascend to the surface. However, investigation of water solubility gives an upper limit of water that mineral can incorporate if provided in a water-saturated environment.

Keppler and Bolfan-Casanova (2006) reviewed thermodynamics of water solubility and defined the term water solubility as the equilibrium water content of a mineral coexisting with an aqueous fluid phase. "Water" exists in minerals as bonded OH groups, which 
controls water solubility. $\mathrm{OH}$ groups can be isolated $\mathrm{OH}$, pairs of $\mathrm{OH}$ groups or four of $\mathrm{OH}$ clusters in different minerals (Table 2.4).

Table 2.4 OH forms in minerals (Keppler \& Bolfan-Casanova, 2006)

\begin{tabular}{llll}
\hline OH form & Mineral & Substitution Mechanism & Reference \\
\hline Isolated protons & orthopyroxene & $\mathrm{H}^{+}+\mathrm{Al}^{3+}--2 \mathrm{Mg}^{2+}$ & Mierdel 2006 \\
& orthopyroxene & $\mathrm{H}^{+}+\mathrm{Al}^{3+}--\mathrm{Si}^{4+}$ & Rauch and Keppler 2002 \\
& olivine & $\mathrm{H}^{+}+\mathrm{B}^{3+}--\mathrm{Al}^{3+}$ & Sykes et al. 1994 \\
& pyrope & $\mathrm{H}^{+}+\mathrm{Li}^{+}--\mathrm{Mg}^{2+}$ & Lu and Keppler 1997 \\
\hline Proton pairs & olivine & $2 \mathrm{H}^{+}--\mathrm{Mg}^{2+}$ & Smyth, pers. Comm. \\
& enstatite & & Rauch and Keppler 2002 \\
& wadsleyite & & Smyth 1987 \\
& ringwoodite & & Smyth et al. 2003 \\
& perovskite(MgSiO & & Ross et al. 2003 \\
& ringwoodite & $2 \mathrm{H}^{+}+\mathrm{Mg}^{2+}--\mathrm{Si}^{4+}$ & Kudoh et al. 2000 \\
& feldspars & interstitial $\mathrm{H}_{2} \mathrm{O}$ & Johnson and Rossman 2004 \\
\hline four protons & garnet & & Ackerman et al. 1983 \\
& & & Lager et al 2005 \\
\hline
\end{tabular}

$\mathrm{OH}$ pairs is generated by reation:

$$
\mathrm{H}_{2} \mathrm{O}+\mathrm{O}=(\mathrm{OH})_{2}
$$

Then, equilibrium constant $\mathrm{K}_{2}$ of this reaction is :

$$
K_{2}=\frac{a_{(\mathrm{OH})_{2}}}{f_{\mathrm{H}_{2} \mathrm{O}} \cdot a_{o}}
$$

Reaction of hydro grossular that generate four protons is

$$
2 \mathrm{H}_{2} \mathrm{O}+2 \mathrm{O}=(\mathrm{OH})_{4}
$$

Equilibrium constant $\mathrm{K}_{4}$ is 


$$
K_{4}=\frac{a_{(\mathrm{OH})_{4}}}{f^{2}{ }_{\mathrm{H}_{2} \mathrm{O}} \cdot a_{o}{ }^{2}}
$$

Thus water solubility is proportional to the square of water fugacity in the case of four protons substitution: $c_{\text {water }} \sim f^{2} \mathrm{H}_{2} \mathrm{O}$, while pair of protons with water solubility is $c_{\text {water }} \sim f_{\mathrm{H}_{2} \mathrm{O}}$. The dependence of water solubility on water fugacity indicates what kind of substitution mechanism minerals employed.

If we involved Gibbs free energy into the constant $\mathrm{K}$ equation, then

$$
\begin{gathered}
-R \operatorname{TIn} K=\Delta G=\Delta H-T \Delta S+\Delta V \\
C_{\text {water }}=A f_{\mathrm{H}_{2} \mathrm{O}}^{n} \exp \left(-\frac{\Delta H+\Delta V \cdot P}{R \cdot T}\right)
\end{gathered}
$$

Where $\mathrm{A}$ is a constant, $\mathrm{n}$ is an exponent related to $\mathrm{OH}$ forms: $\mathrm{n}=1$ for $\mathrm{OH}$ pairs, $\mathrm{n}=0.5$ for isolated $\mathrm{OH}$ groups, $\mathrm{n}=2$ for four $\mathrm{OH}$ clusters. (Lu \& Keppler, 1997) measured water solubility of pyrope and obtained $\mathrm{A}=0.679 \mathrm{ppm} / \mathrm{bar}, \mathrm{n}=0.5$ for the best fitting of results, $\Delta V=5.71 \mathrm{~cm}^{3} / \mathrm{mol}$.

\section{Water in garnet}

\section{1 $\mathrm{OH}$ analysis method and calibration}

Rossman (2006) reviewed various analytical methods to measure water in minerals. For decades, there have been extensive studies on hydrous components in nominally anhydrous minerals, where hydrous components are usually in a few percentages or tenths of a percent by weight. Common analytical methods, such as X-ray and electron probe, become difficult to quantify the small amount of hydrous component. 
Infrared (IR) spectroscopy has become one of the most widely used methods to characterize $\mathrm{OH}$ in minerals. It is sensitive to $\mathrm{OH}$ vibration and can detect and complete a spectrum rapidly. In the IR spectrum, the vibrational mode of the $\mathrm{OH}$ dipole gives rise to absorption bands and the positions of these bands depend on the strength of the hydrogen bond, bond geometry and neighbors.

Although Infrared spectra are easy to obtain, they still need independent analysis to calibrate the spectroscopic work. A variety of absolute hydrogen extraction methods were used for this purpose of calibration.

To determine concentration of an oriented and absorbing species, we use Beer-Lambert law:

$$
\text { Absorbance }=\varepsilon \times c \times t
$$

Absorbance : the band height in the region of interest

$c$ : concentration of hydrous component

$t$ : the thickness of the path through, usually is the crystal thickness

$\mathcal{E}$ : calibration factor which is a mineral specific value

The first calibration designed for hydrous minerals studies was done by Paterson (1982). He presented a calibration line that $\mathrm{OH}$ intensity is proportional to wavenumber, which can be used for silicates, quartz and various substances. His method is about integration of the infrared spectra over the $\mathrm{OH}$ stretching range, which is around 3750 to $3000 \mathrm{~cm}^{-1}$ (equation 2). Then, the concentration equation becomes: 


$$
c=\frac{1}{I \gamma} \int_{v_{1}}^{v_{2}} K(v) d v
$$

In equation 2:

$c:$ the concentration of the absorbing species

$K(v)$ : the absorption coefficient

$\gamma$ : orientation factor

I: integral molar coefficient and is specific value for each specie

Paterson also demonstrated that intensity of the $\mathrm{OH}$ band increases at lower wavenumber positions because of hydrogen bonding. Subsequent work has followed his trend to estimate $\mathrm{OH}$ in various minerals and demonstrated that this trend is correct for estimation, but precise determination of $\mathrm{OH}$ content needs specific calibration for each kind of mineral.

Bell, Ihinger, and Rossman (1995) followed Paterson's method and measured OH content in pure pyrope, augite and enstatite by mannometry after heating the minerals and extracting $\mathrm{H}_{2}$ under a vacuum. They determined an integral molar absorption coefficient of $6700 \pm 670 \mathrm{~L} \cdot \mathrm{mol}^{-1} \cdot \mathrm{cm}^{-2}$ for pyrope. Spectra of garnet before and after heating are shown in figure 2.6 (Bell et al., 1995). The absorption coefficient is mostly referred to for $\mathrm{OH}$ calculations in further hydrous garnet studies. Another value $\left(3630 \pm 1580 \mathrm{~L} \cdot \mathrm{mol}^{-}\right.$ ${ }^{1} \cdot \mathrm{cm}^{-2}$ ) was proposed later by Maldenser et al., 2003. They analyzed garnet crystals with a broad variety of compositions. 


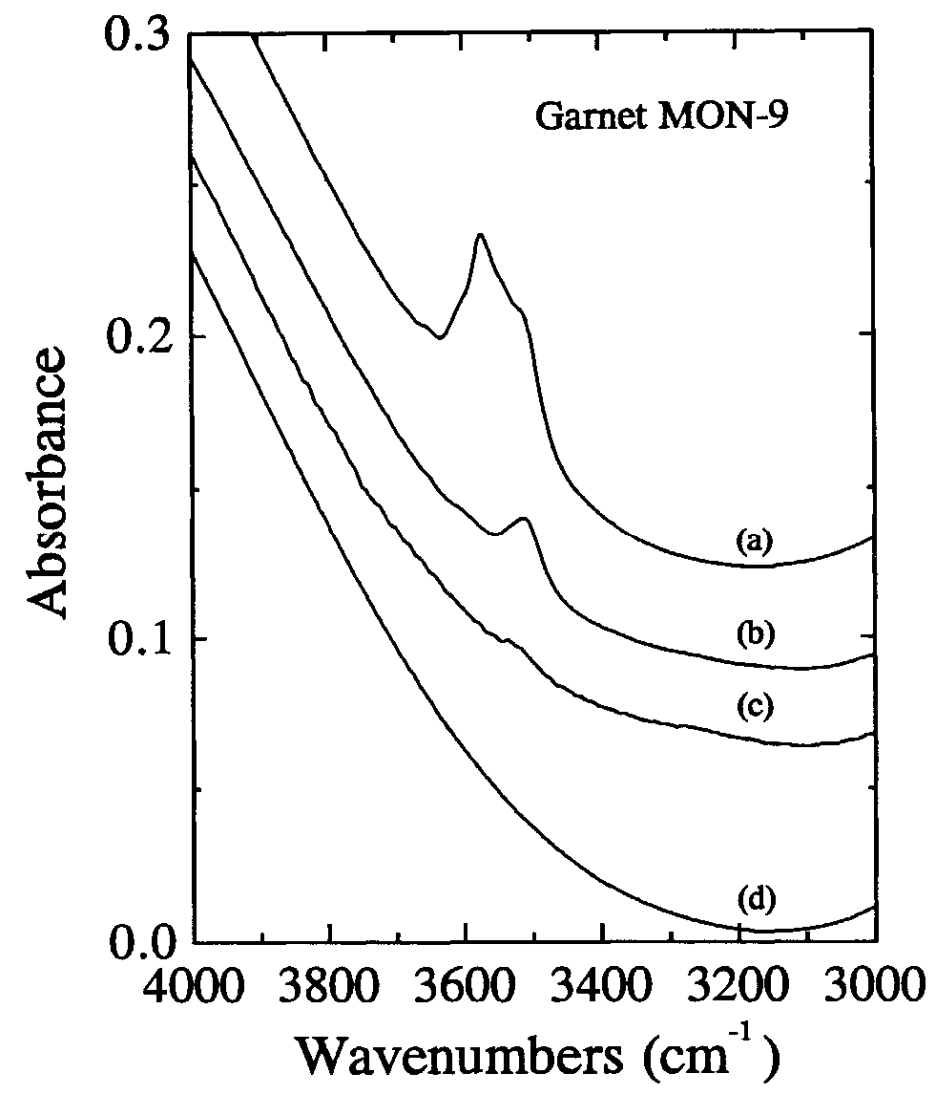

Figure 2.6 IR spectra of garnet Mon-9 in the $\mathrm{OH}$ stretching region between 3000$4000 \mathrm{~cm}^{-1}$. (a) Untreated sample before extraction. (b) Garnet after extraction at $900{ }^{\circ} \mathrm{C}$ for $10 \mathrm{hrs}$. (c) Garnet ater extraction at at $900{ }^{\circ} \mathrm{C}$ for $32 \mathrm{hrs}$. (d) Garnet with all detectable $\mathrm{OH}$ removed after hearting $24 \mathrm{hrs}$ at $1000{ }^{\circ} \mathrm{C}$. (from (Bell et al., 1995))

\subsection{IR spectra features of hydrous garnet}

The IR spectra of garnet are complicated. Natural garnets are found in different places. Their $\mathrm{OH}$ peak positions vary and water contents are in a wide range. Table 2.5 summarizes analysis of nature garnets from different places for water content and $\mathrm{OH}$ stretching peak positions. 
Table 2.5 Water component and $\mathrm{OH}$ peak positions in natural garnets

\begin{tabular}{|c|c|c|c|c|c|c|}
\hline \multirow{2}{*}{$\frac{\text { Sample }}{\text { Pyrope }}$} & \multicolumn{2}{|l|}{$\mathrm{OH}(\mathrm{ppm})$} & \multicolumn{3}{|c|}{$\mathrm{OH}$ positions $\left(\mathrm{cm}^{-1}\right)$} & \multirow{2}{*}{$\begin{array}{l}\text { Reference } \\
\text { Lu and Keppler } 1997\end{array}$} \\
\hline & 58 & 3601.9 & 3640.5 & 3650.8 & 3660.6 & \\
\hline Pyrope & $22-122(59)$ & $\mathrm{N} / \mathrm{a}$ & & & & Wang et al., 1996 \\
\hline Garnet & $1-135(29)$ & 3512 & 3570 & 3650 & & Bell and Rossman (1992) \\
\hline Garnet & $1-72(20)$ & 3590 & & 3650 & & Snyder et al., 1995 \\
\hline Garnet & $1-290(70)$ & \multicolumn{4}{|c|}{$3561-3583,3645-3662$} & Matsyuk et al., 1998 \\
\hline Garnet & $15-74(44)$ & 3512 & \multicolumn{3}{|c|}{3570} & Bell et al., 2004 \\
\hline Garnet & 130 & 3580 & \multicolumn{3}{|l|}{3630} & Katayama et al., 2006 \\
\hline \multicolumn{2}{|c|}{ Gro49Pyr26Alm20Uvar4 620} & & 3630 & & & Beran et al., 1993 \\
\hline
\end{tabular}

Gro: grossular; Pyr: pyrope; Alm:almandine, Uvar:uvarovite

\subsection{Substitution mechanism}

One of the confirmed substitution mechanisms is hydrogarnet substitution, shown in figure 2.7. $(\mathrm{OH})_{4}$ clusters replaced the $\mathrm{SiO}_{4}$ in the crystal structure, which is observed in hydrous grossular of a high water content $(>5 \mathrm{wt} \%)$. However, in the low water content, these hydrogarnet substitution characteristics are not observed. That indicates the hydrogarnet substitution is not the only way that garnet can incorporate $\mathrm{OH}$ into the structure.

Water content in other non-cubic garnet has been investigated by Andrut, Wildner, and Beran (2002). Andrut et al., (2002) measured three garnet crystals with compositions close to the uvarovite-grossular solid solutions and with water less than $0.5 \mathrm{wt} \%$. The IR spectra showed peaks between $3470 \mathrm{~cm}^{-1}$ and $3680 \mathrm{~cm}^{-1}$ and band doublets at $3559 / 3540$ $\mathrm{cm}^{-1}, 3572 / 3565 \mathrm{~cm}^{-1}$, and $3595 / 3588 \mathrm{~cm}^{-1}$. They proposed that $\mathrm{OH}$ defects $\left(\mathrm{SiO}_{3}(\mathrm{OH})\right.$ group) played an important role in garnets with a low water percentage. Another $\left[(\mathrm{OH})_{3} \mathrm{O}\right]$ substitution was reported by Khomenko, Langer, Beran, Koch-Müller, and Fehr (1994) in a Ti-bearing pyrope. 
C. A. Geiger, Langer, Bell, Rossman, and Winkler (1991) obtained different IR spectra of synthetic pyrope: pyrope synthesized from oxides showed a typical hydrogarnet absorption peak at $3629 \mathrm{~cm}^{-1}$, while sample synthesized from gel starting material showed several absorption bands. Single crystal pyrope doped with Ti has a similar spectrum as (Khomenko et al., 1994) and a $\mathrm{V}^{4+}$ bearing pyrope display the same number of bands. It suggests that high-charged cation can cause more $\mathrm{OH}$ substitutions and thus higher water content in garnet.
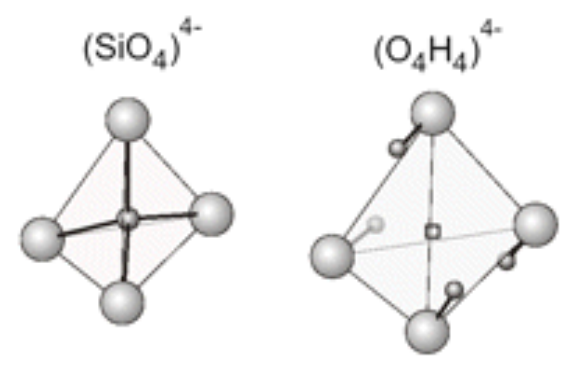

Figure 2.7 Structure of silicate tetrahedron and $(\mathrm{OH})_{4}$ clusters. $\left(\mathrm{O}_{4} \mathrm{H}_{4}\right)_{4}$ - has a larger size than silicate tetrahedron. Square is an empty $\mathrm{Si}^{4+}$ position and the $\mathrm{H}$ atoms are above tetrahedral surface. (structural data from (G. Lager, Armbruster, \& Faber, 1987), picture from (Libowitzky \& Beran, 2006)) 


\section{Chapter 3}

\section{Experimental Setup}

This chapter describes the high pressure devices (multi-anvil press and diamond anvil cell) used in the study. Synchrotron X-ray in situ measurements and FTIR water characterizations are presented as well.

\section{Multi-anvil Press}

The multi anvil press used in the synthesis of dry pyrope-almandine solid solutions and wet pyrope is a 500-ton multi-anvil apparatus equipped with a Walker module at the Center of Matter at Extreme Conditions (CeSMEC), showing in Figure. 3.1.

The basic compression diagram is shown in Figure 3.2. High pressure is generated with eight tungsten carbide (WC) anvils. Each anvil has a truncation with three pyrophyllite gaskets surrounded. The generated pressure depends on the length of the truncation and edge length of octahedron. The eight WC cubes are held together by six plastic boards with a cell assembly sitting in the center. The entire assembly is loaded in the module (Figure. 3.1 left panel).

There are three types of cell assemblies (14/8, 10/5 and 8/3) used for different pressure range. At pressures 0 - $10 \mathrm{GPa}$, the $14 / 8$ cell assembly is employed. The cross section of a 14/8 cell assembly is shown in Figure. 3.3, where 14 is the edge length of octahedron and 8 is the truncation length of WC anvil. In this type of cell, graphite tube serves as a furnace. The $\mathrm{MgO}$ sleeve inside is to ensure a quasi-hydrostatic condition. The thermocouple wires W5\%Re-W26\%Re are inserted into a 4-hole $\mathrm{Al}_{2} \mathrm{O}_{3}$ sleeve and the 
rest of wire outside of the $\mathrm{Al}_{2} \mathrm{O}_{3}$ sleeve is covered with a mullite tubing. The top of octahedron is covered with cement.

Different capsules are used according to different experiment requirements. For pyropealmandine garnet solid solution, we used the graphite capsule with a graphite lid (Figure. 3.4) and for hydrous pyrope synthesis, we used platinum tubes (Figure. 3.5). The two half Pt tubes are of closed ends at the bottom. One is $1.8 \mathrm{~mm}$ in diameter and the other is $0.2 \mathrm{~mm}$ larger in diameter. They are assembled together to create a closed chamber for starting oxides and the water source. As the sample is in pressure, capsule is pressed and water is not possible to escape so that a water saturated environment is ensured.

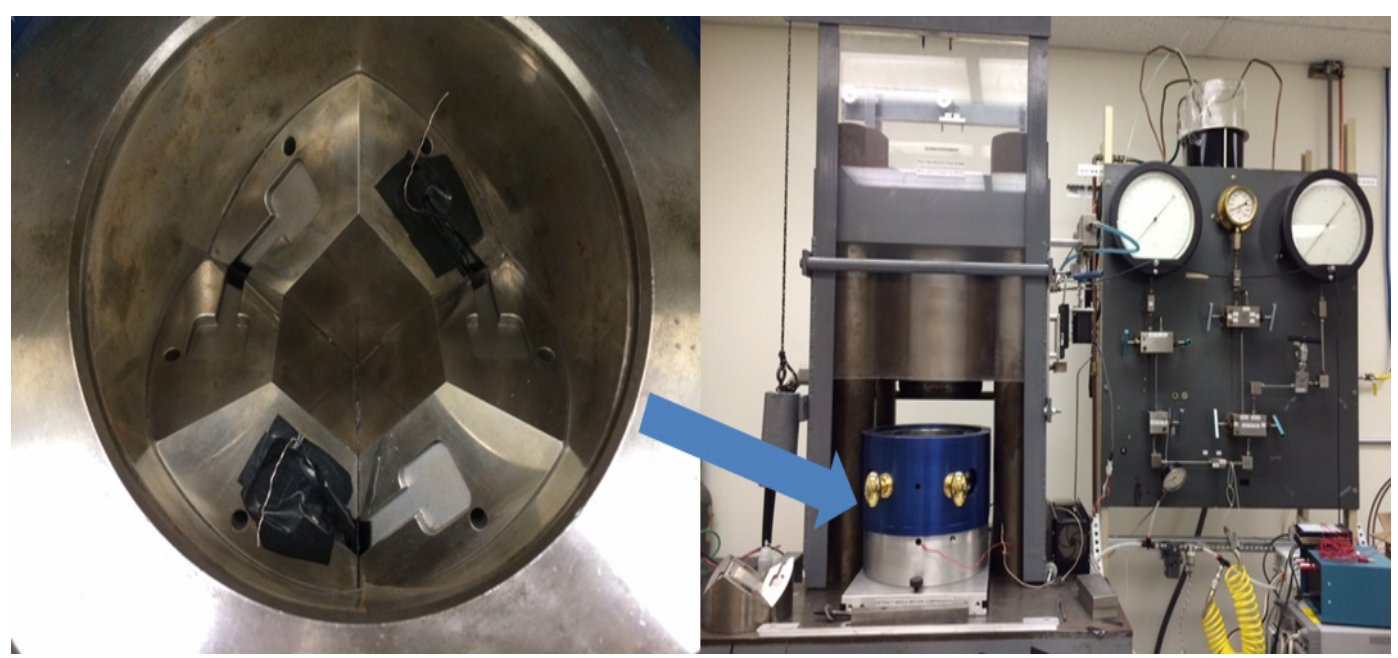

Figure 3.1 Picture (right) is multi-anvil press and control panel, picture ( left) is the top view of inner structure of module. 

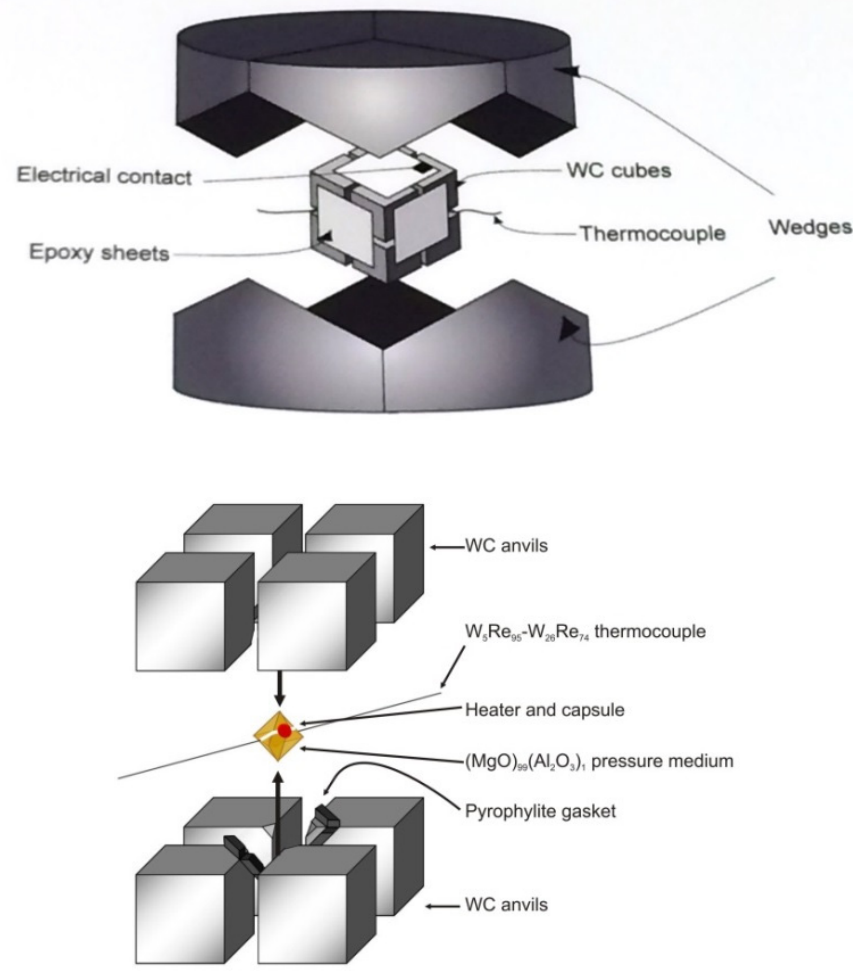

Figure 3.2 Illustration of the WC multi-anvil press used to generate pressure in experiment

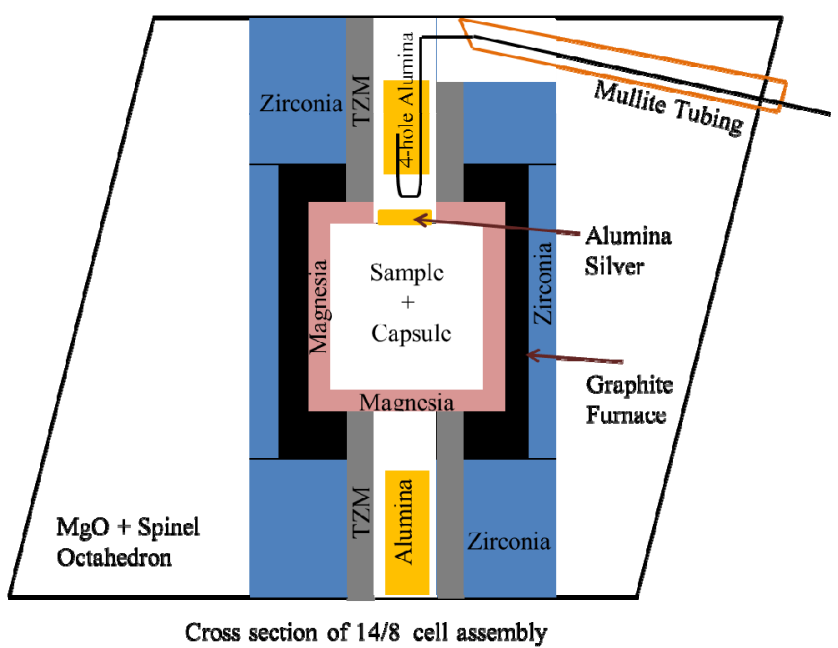

Figure $3.314 / 8$ cell assembly truncation: graphite serves furnace to heat up the sample and thermal couple is W5\%Re-W26\%Re 


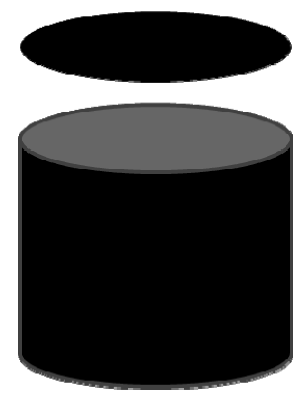

Figure 3.4 Graphite capsule with lid on the top

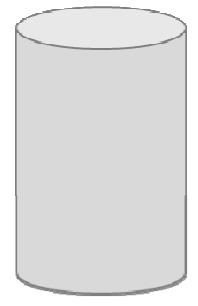

1

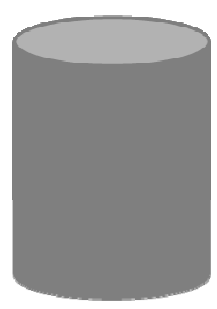

2

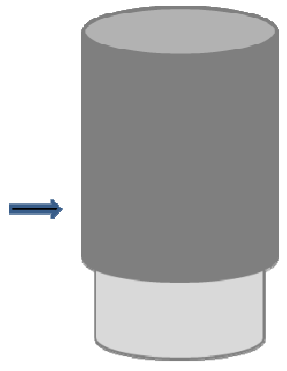

assembly

Figure 3.5 Capsule for hydrous pyrope synthesis, 1 and 2 are both platinum caps with one end closed. 2 is $0.2 \mathrm{~mm}$ larger in diameter, assemble the two to ensure a closed chamber to seal water in under pressure

\section{Diamond anvil cell}

The principle of diamond is generating pressure by two diamonds (Fig. 3.6). The gasket is usually made of steel and pre-indented to $40-70 \mu \mathrm{m}$ in thickness, in which depends on the target pressure. A hole in the pre-indented area is drilled as a sample chamber. Ruby fluoresce is used to measure pressure inside the cell. To maintain a hydrostatic 
environment, a pressure medium is loaded, such as silicon oil and neon gas. X-rays go through the diamonds, hit the sample and are reflected back crystal information which is collected by the detector.

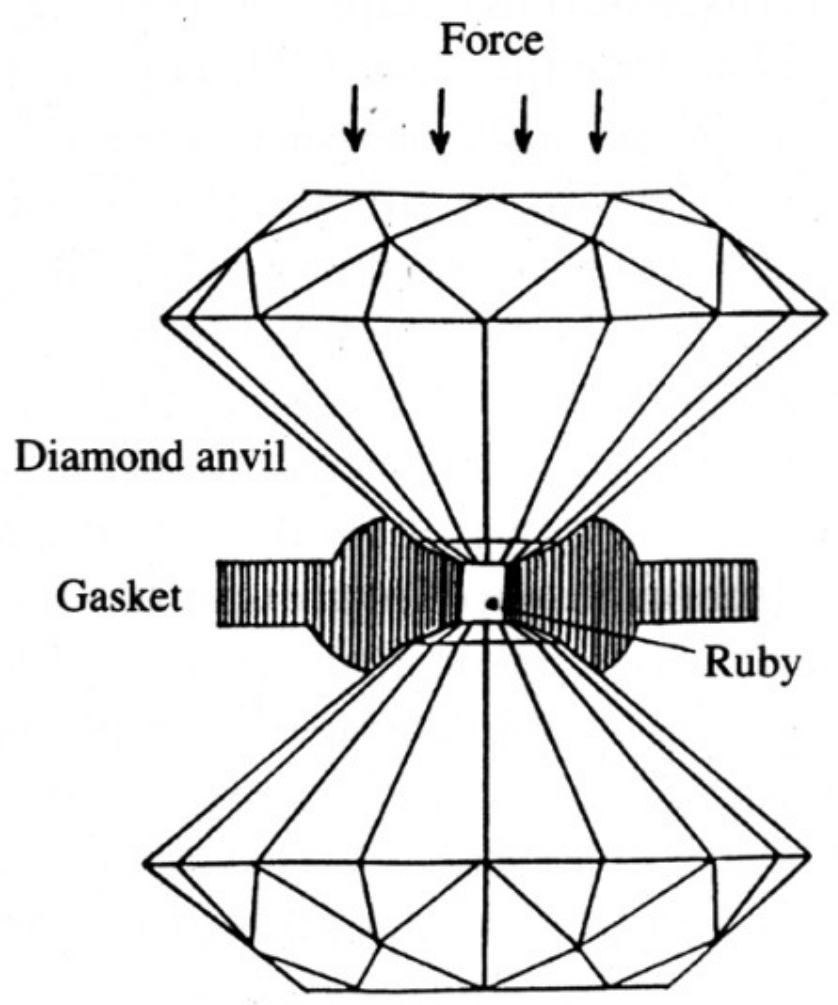

Figure 3.6 Principle of diamond anvil cell

The cells used in the experiment are symmetrical cells for P-V measurement of pyropealmandine solid solution. Its typical opening is $\sim 35^{\circ}$, as shown in Fig. 3.7 (top picture). In the powder diffraction, there is no strict requirement for the opening of the cell. However, in single crystal X-ray diffractions, the opening is critical for collecting enough diffraction spots. In this experiment, we used a new designed diamond anvil cell, BX90 (Fig.7 bottom). Thus diffractions were not blocked by the supporting plate. 

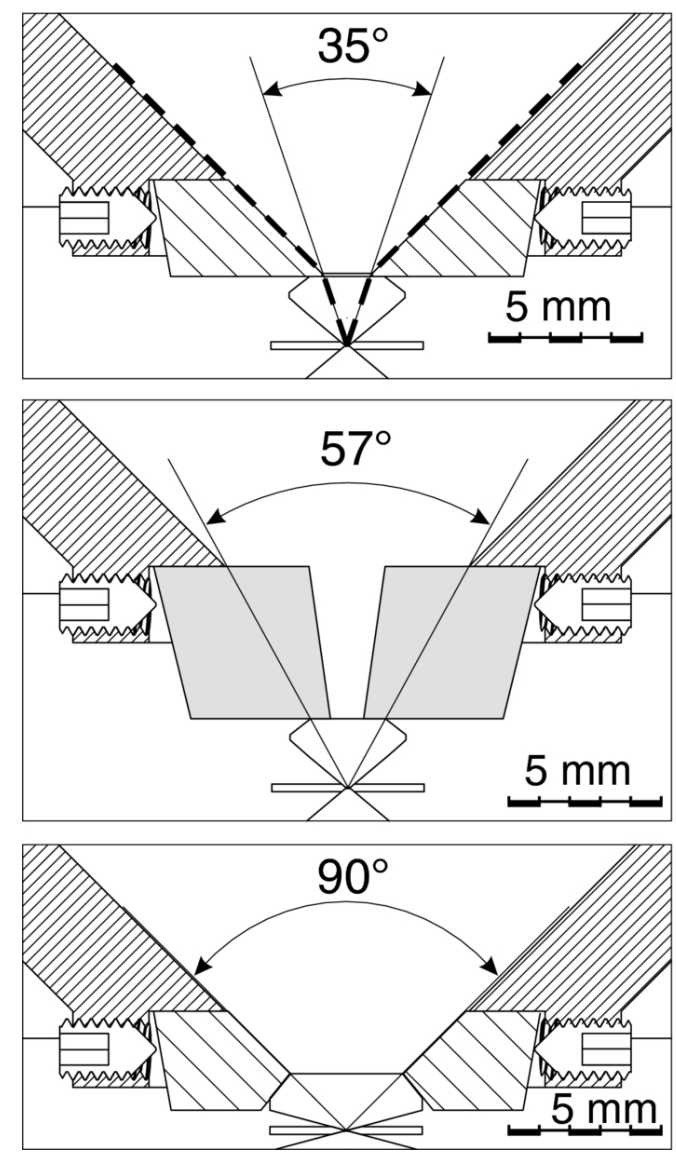

Figure 3.7 Geometry of different types of diamond anvils and supporting seats and corresponding X-ray and optical openings in the BX90 cell.

Top: a typical setup for optical measurements: standard diamond anvils of $\sim 2.1 \mathrm{~mm}$ thick and a tungsten carbide supporting plate of $3.2 \mathrm{~mm}$ thick. Due to the high refraction index of diamond, a full $90^{\circ}$ optical opening is achieved (bold dashed line), while the X-ray opening is only $35^{\circ}$.

Center: a typical setup for powder X-ray diffraction studies. A standard diamond anvil of $2.1 \mathrm{~mm}$ and a $5 \mathrm{~mm}$ thick cubic boron nitride supporting plate provide a $57^{\circ} \mathrm{X}$-ray opening.

Bottom: a highest possible X-ray opening can be achieved using specially designed anvils and supporting plate (cited from Kantor et al., 2012) 
Most of the in-situ X-ray diffraction experiments were conducted using beamline X17C synchrotron X-rays of the National Synchrotron Light Source (NSLS), BNL. Beamline $\mathrm{X} 17 \mathrm{C}$ (Fig. 3.8) is a delicate diamond anvil cell (DAC) high pressure beamline with a focused monochromatic beam $(\sim 30 \mathrm{keV})$. It can provide the capabilities of diffractions at extreme conditions of pressure and temperature for studies of equation of State, compressibility of materials at extreme conditions.

The instrument setup is as follows: a diamond anvil cell coupled with X-ray beam (wavelength is $\sim 0.407$ Angstrom) is used for bulk modulus measurements through in-situ X-ray diffractions. A sample is loaded between two diamonds of a $400 \mu \mathrm{m}$ anvil culet, which can create high pressures beyond 20GPa. Synchrotron X-rays penetrating through the diamonds reach the sample and diffracted X-rays are collected by Ge-detector. Diffraction patterns are recorded from 0(ambient pressure) to 20GPa by the step of $1 \mathrm{GPa}$. Those patterns can be used for volume of crystal unit cell calculation. Thus series of Pressure-Volume data sets are collected. 

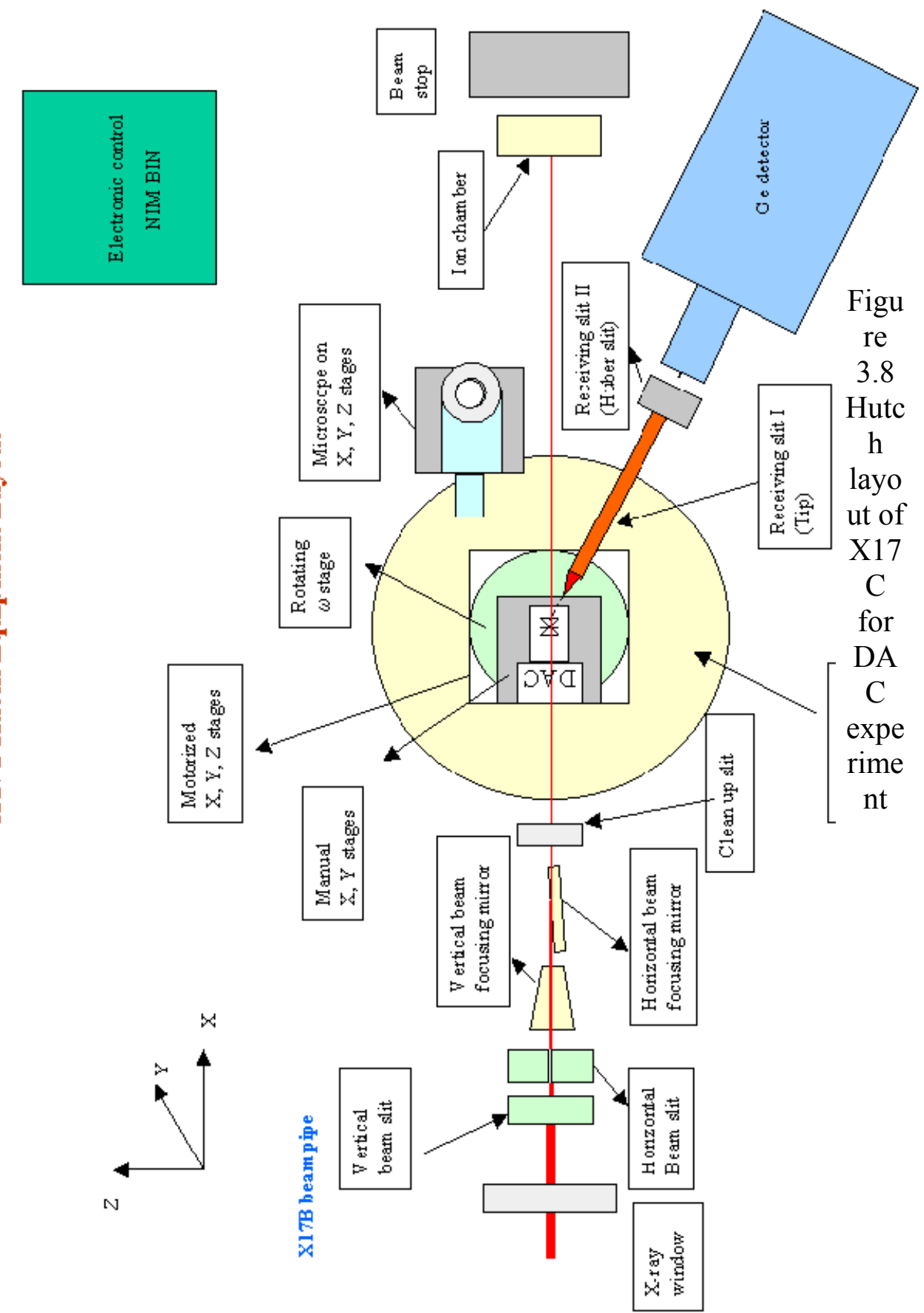

\section{Fourier transform infrared spectroscopy-FTIR}

Pyrope was synthesized according to this reaction:

$$
3 \mathrm{MgO}+\mathrm{Al}_{2} \mathrm{O}_{3}+3 \mathrm{SiO}_{2}-----\mathrm{Mg}_{3} \mathrm{Al}_{2} \mathrm{Si}_{3} \mathrm{O}_{12}
$$

with $10 \mathrm{wt} \%$ of $\mathrm{SiO}_{2}$ in excess and $15 \mathrm{wt} \%$ of distilled water as water source. 
Water content was characterized at Beamline $\mathrm{U}_{2}$, which provided the infrared spectroscopy to study $\mathrm{OH}$ in materials. Crystals were prepared for $\mathrm{OH}$ characterizations. Crystals were mounted in the epoxy first and both sides were polished to get a pair of parallel surfaces. In the measurements, we were trying to avoid any cracks and inclusions. Background spectra are always collected before each single measurement and software will subtract the background from sample spectra to avoid moisture from atmosphere. The instrument is Bruker IRscopeII with a resolution of $1 \mathrm{~cm}^{-1}$. The detector is MCT-A $\mathrm{SiB} / \mathrm{Si}$. IR image is showing in Fig. 3.9, the grid is the aperture size and can be adjusted according to sample's dimension and quality.
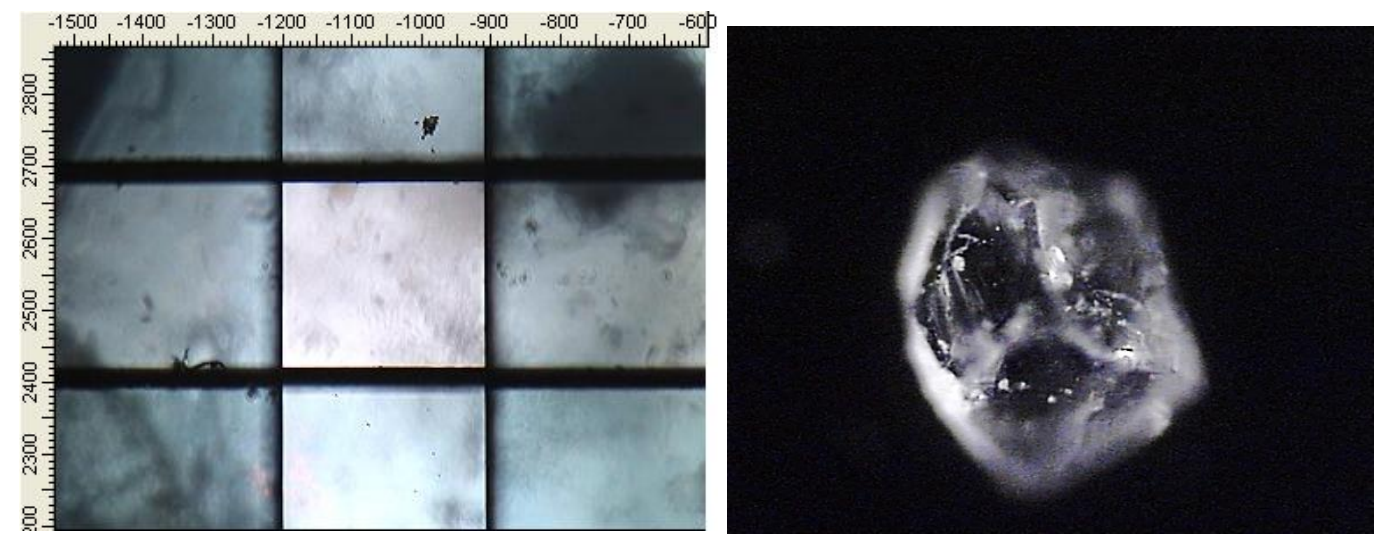

Figure 3.9 Left: image under FTIR, grid in the center is where beam is located. Clear area is selected for examination. Right: single crystal of pyrope under microscopy.

\section{Analysis of single crystal X-ray diffraction data}

The bulk modulus of single crystal X-ray diffraction measurements were conducted at GSECARS, section 13-BM-D, APS. This experiment was similar to P-V measurement of pyrope-almandine solid solution. The difference was that single crystal experiment used a special designed diamond anvil cell (BX90), which has a larger opening than the regular 
symmetrical cell, so that more diffraction spots were collected by the detector, not been blocked by the supporting seat.

The data analysis procedure is also different from that of powder X-ray diffractions. For powder X-ray diffraction, since all the crystals are oriented randomly, we get diffraction patterns of rings from crystals and the integration of the patterns gives the lattice parameters. However, the analysis of single crystal data is much more complicated. Single crystal has continuous crystal lattice. Its diffraction pattern is random spots at specific regions which depend on how the crystal is oriented. Fig. 3.10 is a typical wide range scan image of pyrope 183 at the pressure $11.23 \mathrm{GPa}$. 


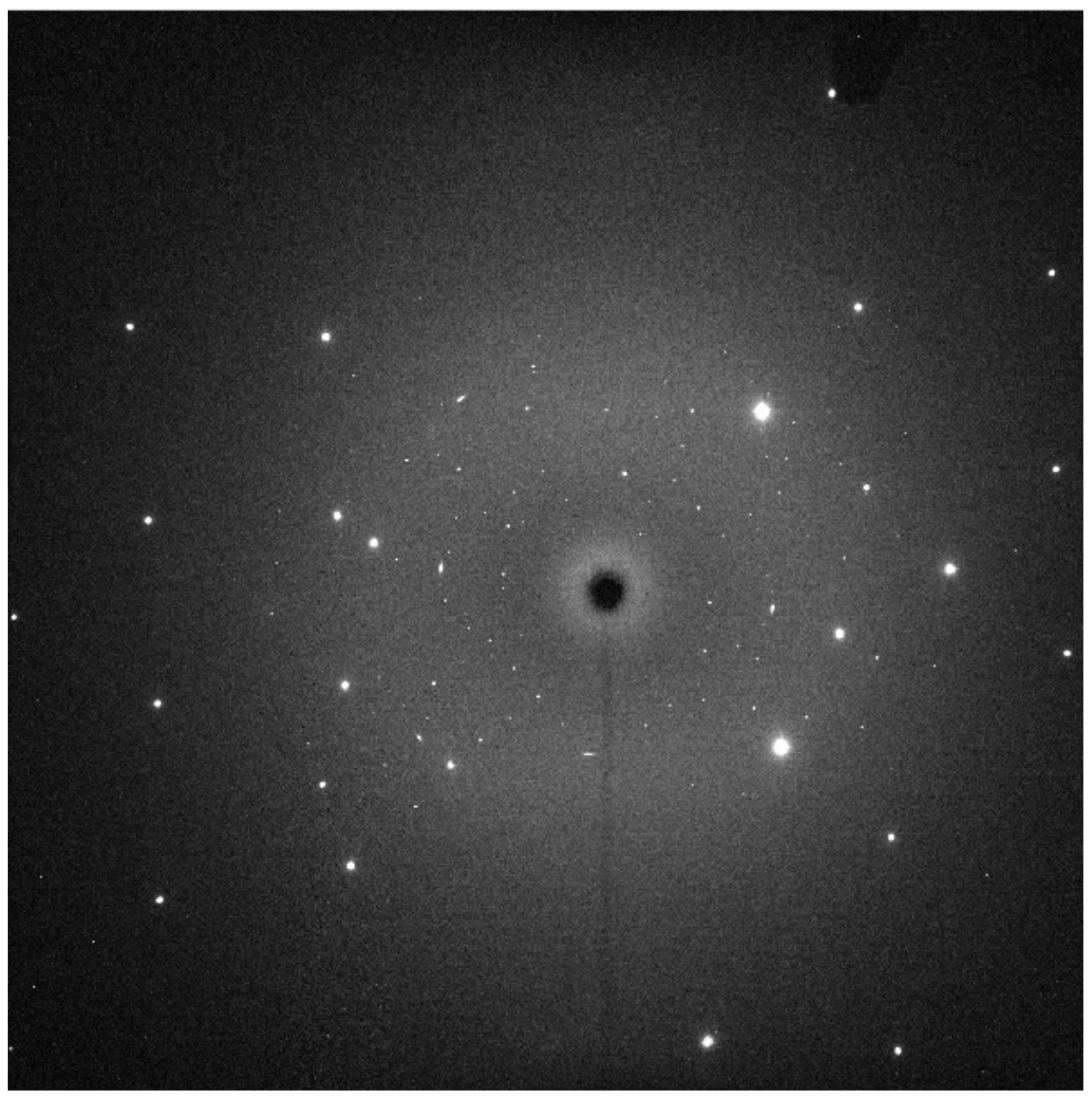

Figure 3.10 Wide range scan image of sample 183 at $11.23 \mathrm{Gpa}$

In Fig. 3.10, it is a close examination of single crystal diffraction pattern. The strong shiny spots are from diamond diffractions. The tiny spots surrounded the center are from the sample. This image is merged by the software ADA. Since diamond spots are just noise to the data analysis, we will use ADA do the peak search and remove those spots, such as diamond diffraction spots, sample diffractions on the rings and dust diffractions, As shown in Fig 3.11, it is a typical peaking fitting process for single crystal data sets. The white dot in the green square is selected for fitting. The three small windows show the fitting process: the left on the top is the enlarged image of spot, and box size can be 
changed to zoom in if the peak is weak; the right on the top is how this peak is fitted, a calculated file; the right on the bottom is the residue, the difference between the observed peak and the calculated one.

The peaks of irregular shapes and failed in fitting process were deleted from the image. After the fitting process is finished, a peak list will be displayed in the window for the sample analysis and each peak will have an assigned omega.

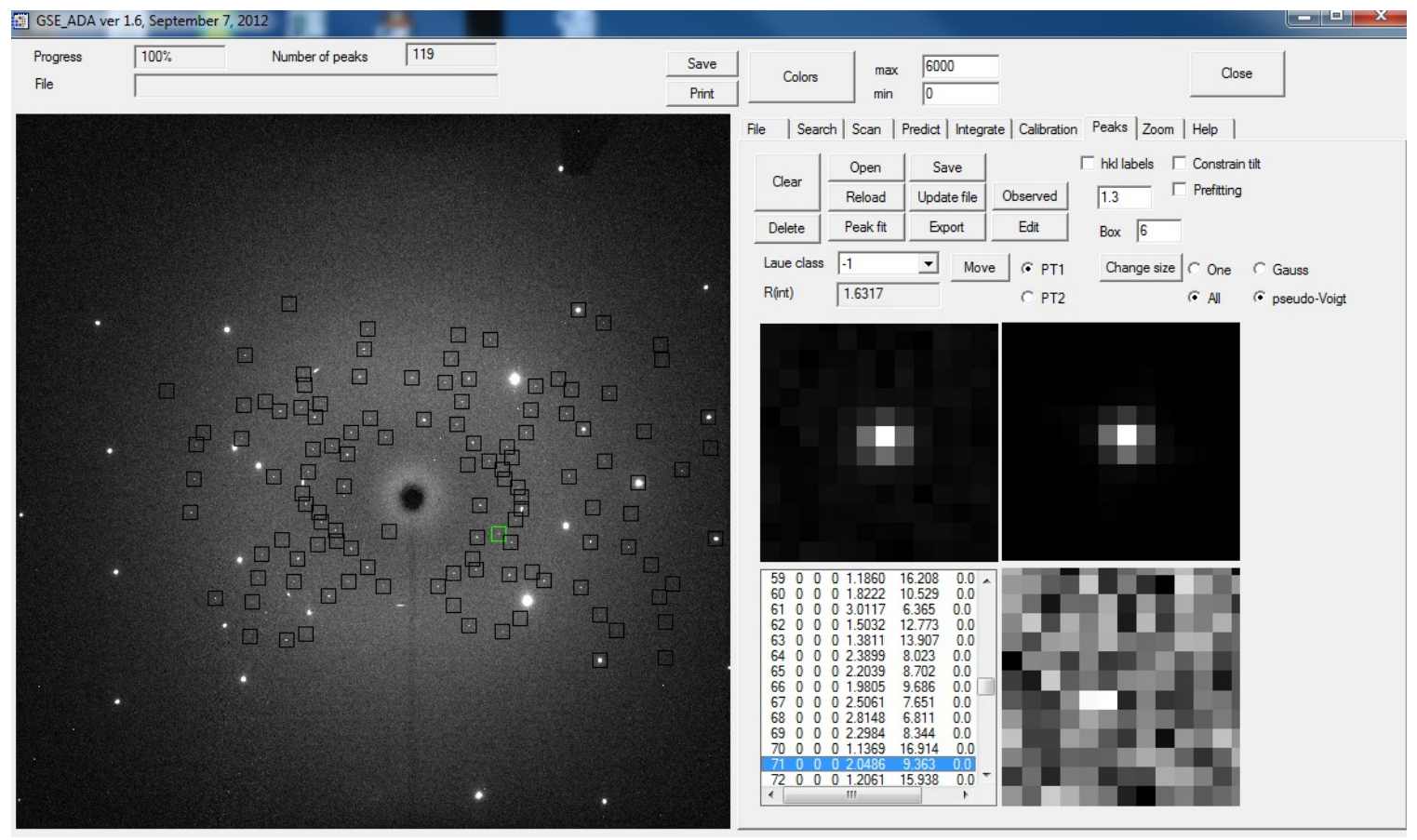

Figure 3.11 peak fitting process of sample 183 at $11.23 \mathrm{GPa}$

In Figure 3.12, it is a peak indexing process by software RSV. When the peaks file is loaded into the software, it shows in the left window. If the quality of data is good, well aligned rows will be displayed in the window. This software features a 3-D rotation, any axis ( $\mathrm{X}, \mathrm{Y}$ and $\mathrm{Z}$ direction) can be chosen to rotate the pattern. Then, peaks will be 
indexed and the orientation matrix will be determined. The lattice parameter will be calculated and refined. This is a basic data analysis procedure for each diffraction pattern at certain pressures.

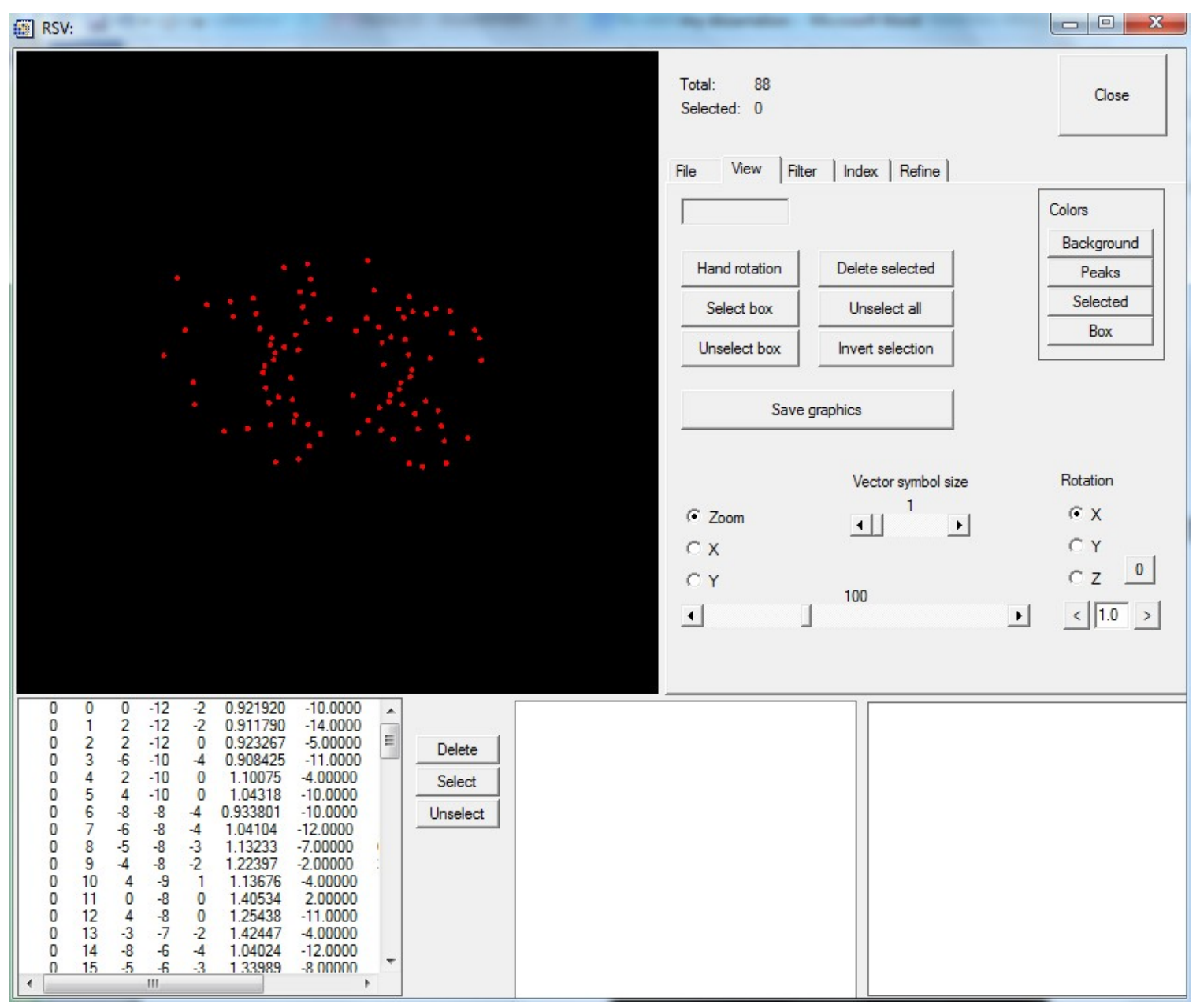

Figure 3.12 Index of peaks and calculation of orientation matrix by rsv software 
Chapter 4

\section{Chemical composition influence on the bulk modulus of pyrope}

This chapter is about the chemical composition (iron substitution) influence on the bulk moduli of garnet solid solutions in the pyrope-almandine binary system. Three garnet solid solutions along this py-alm join were synthesized using multi-anvil press. Bulk modulus measurements at room temperature were conducted at Brookhaven National Lab. This chapter, titled Equation of state of pyrope-almandine solid solution measured using a diamond anvil cell and in situ synchrotron X-ray diffraction by Huang and Chen has been published in Journal of Physics of the Earth and Planetary Interiors.

\section{Abstract:}

The Pressure-Volume relations of three synthetic garnet samples along pyrope-almandine (Py-Alm) join were measured at ambient temperature and high pressures up to $7 \mathrm{GPa}$, 21GPa and 19GPa for $\mathrm{Py}_{83} \mathrm{Alm}_{17}, \mathrm{Py}_{54} \mathrm{Alm}_{46}$ and $\mathrm{Py}_{30} \mathrm{Alm}_{70}$, respectively. The obtained $\mathrm{P}-\mathrm{V}$ data were fitted to the third order Birch-Murnaghan equation of state (EOS). The ambient cell volumes $V_{0}$ of the three samples were measured to be $1511(1) \AA^{3}, 1515$ (2) $\AA^{3}$, and 1526(1) $\AA^{3}$ respectively. With fixed pressure derivative of the isothermal bulk modulus $K^{\prime}$ at 4.3 , isothermal bulk moduli $\mathrm{K}_{0}$ of the three samples were determined to be 172(4), 174(2), and 183(2) GPa respectively. These results confirm that almandine content (iron substitution) increase the bulk modulus of the garnet join following a nearly ideal mixing model. The relation between bulk modulus and almandine mole fraction $(n)$ 
in this garnet join is derived to be $K_{0}=170+15 n$. These data can be used to contribute to construction of compositional model of Earth mantle.

\section{Introduction:}

Garnets are important minerals of Earth's interior existing in the upper mantle and transition zone. Pyrope garnet, $\mathrm{Mg}_{3} \mathrm{Al}_{2}\left(\mathrm{SiO}_{4}\right)_{3}$, is a primary aluminum carrier in the upper mantle (Ita \& Stixrude, 1992). Along the geotherm, both phase fraction and composition of garnets changes as a function of depth. Knowledge about elastic properties of different composition variations is essential for construction of the upper mantle and transition zone composition models. Elastic properties of garnets along pyrope-majorite(Py-Mj) join have been extensively studied using ultrasonic techniques (G. Chen, Cooke, Gwanmesia, \& Liebermann, 1999; Gwanmesia et al., 2000; Gwanmesia, Wang, Triplett, \& Liebermann, 2009; Rigden, Gwanmesia, \& Liebermann, 1994; Z. Wang \& Ji, 2001), Brillouin scattering(Conrad, Zha, Mao, \& Hemley, 1999; Sinogeikin \& Bass, 2000, 2002), and X-ray diffraction(Hazen, Downs, Conrad, Finger, \& Gasparik, 1994; Y. Wang, Weidner, Zhang, Gwanrnesia, \& Liebermann, 1998; Yagi, Akaogi, Shimomura, Tamai, \& Akimoto, 1987; Yagi, Uchiyama, Akaogi, \& Ito, 1992). However, study on garnet along pyrope-almandine join is very limited although some natural samples containing pyrope, almandine and some other phase, e.g. spessartine (Fan et al., 2009), uvarovite and andradite (Suzuki \& Anderson, 1983) or unidentified phases(Takahashi \& Liu, 1970) have been investigated. Equations of state of the end members, pyrope and almandine $\left(\mathrm{Fe}_{3} \mathrm{Al}_{2}\left(\mathrm{SiO}_{4}\right)_{3}\right)$, have been also studied (O'Neill, Bass, Rossman, Geiger, \& Langer, 1991; Y. Wang et al., 1998; Zhang, Ahsbahs, \& Kutoglu, 1998; Zhang, Ahsbahs, Kutoglu, \& 
Geiger, 1999). Compositional effect on bulk moduli of natural garnet in grossularalmandine-pyrope system have been examined (Jiang, Speziale, \& Duffy, 2004; O'Neill, Bass, Smyth, \& Vaughan, 1989). To our knowledge, no experimental bulk modulus data is available on synthetic binary Py-Alm solid solution.

Here we report some new data on bulk moduli measurements of three garnet samples $\left(\mathrm{Py}_{83} \mathrm{Alm}_{17}, \mathrm{Py}_{54} \mathrm{Alm}_{46}\right.$ and $\left.\mathrm{Py}_{30} \mathrm{Alm}_{70}\right)$ along pyrope-almandine join, which were conducted using diamond anvil cell combined with in situ X-ray diffraction at X17C beamline, BNL.

\section{Experiment:}

The sample synthesis followed the procedure described by Geiger et al., (1987). Glasses with compositions of two end members, pyrope and almandine, respectively were first prepared by pulse arc. Garnet samples were synthesized using a multi-anvil press at 2.8 $\mathrm{GPa}$ and $1250^{\circ} \mathrm{C}$ for 20 hours. The starting materials were mixtures of end member glasses with 1:4, 1:1 and 4:1 pyrope to almandine ratios. The synthesized garnet phases were confirmed by X-ray diffraction and their composition were analyzed using JEOL 8900R superprobe with wavelength dispersive spectrometers (WDS). The beam size of the microprobe is of 1-2 $\mu \mathrm{m}$. The samples were mounted in epoxy, and carbon coated after polishing for the composition analysis. 5-6 spots were probed for each sample, and the final results are average values over these spots. Since the starting oxides (MgO, $\mathrm{Al}_{2} \mathrm{O}_{3}, \mathrm{SiO}_{2}$ ) are pre-fired at $800{ }^{\circ} \mathrm{C}$ and mixed powder are kept in an oven at temperature above $100{ }^{\circ} \mathrm{C}$ to avoid moisture from atmosphere, the synthesized samples are assumed 
to be dry although we did not conduct measurements to quantify the water content in the samples in this study.

A diamond anvil cell (DAC) with $400 \mu \mathrm{m}$ culets was used for equation of state measurement through in situ X-ray diffraction at the $\mathrm{X} 17 \mathrm{C}$ beamline of National Synchrotron Light Source (NSLS) at Brookhaven National Laboratory (BNL). The synthetic garnet crystals were ground into fine powder and then pressed into pellets. A stainless steel sheet was used as a gasket for the DAC. The gasket was pre-indented to $\sim 50 \mu \mathrm{m}$ thickness, and a hole of $140 \mu \mathrm{m}$ in diameter was drilled to use as a sample chamber. Silicone oil (Aldrich, $5 \mathrm{cSt}$ viscosity) was used as pressure transmitting medium to ensure a hydrostatic environment. According to Shen et al., (2004), silicone oil behaves as a good pressure medium at pressures up to $20 \mathrm{GPa}$. Ruby chips were loaded with the sample in each run as a pressure calibrant; the pressure was calculated using the pressure dependence of ruby fluorescence $(\mathrm{H} . \mathrm{Mao}, \mathrm{Xu}, \&$ Bell, 1986) programmed at the beamline. A newer ruby pressure scale was also used for pressure calculation (Dewaele, Loubeyre, \& Mezouar, 2004) with improved parameters A=1904GPa, B=9.5 (where $\mathrm{B}=7.665$ by Mao et al., 1986) in the formulas of

$$
P=\frac{A}{B}\left\{\left[1+\frac{\Delta \lambda}{\lambda_{0}}\right]^{B}-1\right\}
$$

Pressure difference calculated using the two ruby pressure scales is small (within 1\%) in pressure range of our experiments. For example, the highest pressure $21.4 \mathrm{GPa}$ measured in this study is re-calculated to be $21.6 \mathrm{GPa}$. Width of the ruby fluorescence peak $\mathrm{R}_{1}$ in the pressure range of our experiment is similar to that under ambient conditions. The X-ray beam was $20 \mu \mathrm{m} \times 20 \mu \mathrm{m}$ in cross-section and $0.4075( \pm 0.0001) \AA$ in wavelength. The 
absolute X-ray energy was calibrated using an iterative algorithm in which X-ray diffractions of different common standards are taken at a series of sample to detector distance for the energy calibration (Hong, Chen, \& Duffy, 2012). During the experiment, sample pressure was increased stepwise at room temperature. At each step, ruby fluorescence was collected first, and then X-ray diffraction was collected. After X-ray diffraction, ruby fluorescence was collected again to confirm the pressure. Occasionally, the pressure before and after the X-ray diffraction were slightly different (within $0.5 \mathrm{GPa}$ ). In this case an average value was used for the sample pressure.

\section{Results and discussion:}

The microprobe results indicate compositions of the three garnet samples were $\mathrm{Py}_{30} \mathrm{Alm}_{70}$, $\mathrm{Py}_{54} \mathrm{Alm}_{46}$ and $\mathrm{Py}_{83} \mathrm{Alm}_{17}$, respectively, as shown in Table 4.1. All the X-ray diffraction patterns collected at different pressures were analyzed through full spectrum fitting (Le Bail fit) using program Rietica (Hunter, 1997). Figure 4.1 (b) shows a typical fitting of the full X-ray pattern at $19 \mathrm{GPa}$ after integration of powder diffraction pattern Figure (a). The calculated unit cell parameter (a) and volume (V) are listed in Table 2.

Unit cell volumes of samples $\mathrm{Py}_{83} \mathrm{Alm}_{17}, \mathrm{Py}_{54} \mathrm{Alm}_{46}$ and $\mathrm{Py}_{30} \mathrm{Alm}_{70}$ are determined to be 1511(1) $\AA^{3}, 1515$ (2) $\AA^{3}$, and 1526(1) $\AA^{3}$ at ambient conditions. Geiger et al. (1997) measured a series of garnet samples along this Py-Alm join and derived a volumecomposition relationship in this system (figure. 4.2). The two $V_{0}$ of $\mathrm{Py}_{83} \mathrm{Alm}_{17}$ and $\mathrm{Py}_{30} \mathrm{Alm}_{70}$ from our experiments agree well with Geiger's data, while $V_{0}$ of $\mathrm{Py}_{54} \mathrm{Alm}_{46}$ is slightly smaller (ca. $0.3 \%$ ). 


\subsection{P-V equation of state}

A survey of bulk moduli of the end members and Py-Alm solid solutions is summarized in Table 4.3. $K_{0}$ is in the range of $169 \mathrm{GPa}$ to $185 \mathrm{GPa}$ and $K^{\prime}$ is varied from 3.8 to 6.2 because different techniques are employed and sample quality.

Our volume-pressure data were fitted into the third order Birch-Murnaghan equation of state:

$$
P=\left(\frac{3}{2}\right) K_{0}\left[\left(\frac{V_{0}}{V}\right)^{\frac{7}{3}}-\left(\frac{V_{0}}{V}\right)^{\frac{5}{3}}\right] \times\left\{1+\frac{3}{4}\left(K_{0}^{\prime}-4\right)\left[\left(\frac{V_{0}}{V}\right)^{\frac{2}{3}}-1\right]\right\}
$$

where $V_{0}, K_{0}$ and $K_{0}^{\prime}$ are zero pressure volume, isothermal bulk modulus and pressure derivative of the bulk modulus. With fixed $K_{0}^{\prime}=4.3$, and fixed $V_{0}$, the bulk moduli of $\mathrm{Py}_{30} \mathrm{Alm}_{70}, \mathrm{Py}_{54} \mathrm{Alm}_{46}$ and $\mathrm{Py}_{83} \mathrm{Alm}_{17}$ samples are derived to be 183(2) GPa, 174(2) GPa and 172(4) GPa respectively using EOSfit (Angel, 2000). Figure 4.3 shows the unit cell volumes of the three samples as a function of pressure and the derived equation of state. The reason to fix $K_{0}^{\prime}=4.3$ is for the study compositional influence on bulk modulus since value of $K_{0}$ relies on $K_{0}^{\prime}$ and Zhang et al., 1999 proposed $K_{0}^{\prime}=4.2(3)$ for almandine and $K_{0}^{\prime}=4.4(2)$ for pyrope. Therefore a value between 4.2-4.4 is chosen for solid solution in Py-Alm binary system.

There have been extensive discussions about $K_{0}^{\prime}$ of garnet. Different techniques employed and sample quality may have influence on value of $K_{0}^{\prime}$. Takahashi and Liu (1970) estimated two natural garnet samples, $\mathrm{Py}_{60} \mathrm{Alm}_{31}$ and $\mathrm{Py}_{22} \mathrm{Alm}_{72}$ and obtained $K_{0}^{\prime}=5.45$. This slightly bigger pressure derivative may due to partial unidentified phases in natural samples and technique limitations at that time. Zhang et al. (1999) suggested that $K_{0}^{\prime}$ of 
garnets with different compositions are slightly different, such as $K^{\prime}(P y)>K^{\prime}(A l m)$. They obtained an experimental value of 4.2(3) for almandine and 4.4(2) for pyrope. Recently, Li, Weidner, Brodholt, Alfè, and Price (2011) calculated $K_{0}^{\prime}$ of pyrope to be 4.3 using $\mathrm{Ab}$ initio molecular dynamic simulation. Zou et al., (2012) estimated $K_{0}^{\prime}=4.6(3)$ for synthetic pyrope at high pressure up to 19GPa. Therefore, based current experimental data and theoretical calculation, $K_{0}^{\prime}$ is in the range of 4-4.6. We tried to fit the data using fixed $K_{0}^{\prime}=4.4$ for pyrope rich garnet $\left(\mathrm{Py}_{83} \mathrm{Alm}_{17}\right.$ and $\left.\mathrm{Py}_{54} \mathrm{Alm}_{46}\right)$ and $K_{0}^{\prime}=4.2$ for sample $\mathrm{Py}_{30} \mathrm{Alm}_{70}$, the results are list in table 4.4. There is not much change in bulk moduli for the three samples from those when $K_{0}^{\prime}$ is fixed at 4.3.

4.2 $\mathrm{Mg}^{2+}-\mathrm{Fe}^{2+}$ substitution effect on bulk modulus

Pyrope has been intensively studied because it is an important garnet end member in the mantle. However, minerals in the mantle do not exist as pure phases and they form solid solutions through element partitioning, such as Py-Alm join and pyrope-majorite (Py-Mj) join. As shown in Table 4.3, experimental studies have indicated that $K_{0}$ values of almandine and pyrope are about $185 \mathrm{GPa}$ and $170 \mathrm{GPa}$ respectively. Therefore $K_{0}$ of garnet in Py-Alm join is expected to be between these values. Our results show that bulk moduli of the three samples, 172(4) GPa, 174(2) GPa and 183(2) GPa for $\mathrm{Py}_{83} \mathrm{Alm}_{17}$, $\mathrm{Py}_{54} \mathrm{Alm}_{46}$ and $\mathrm{Py}_{30} \mathrm{Alm}_{70}$ respectively, are within this range when $K_{0}^{\prime}$ fixed at 4.3. Similar to the compositional effect on the bulk modulus of $(\mathrm{Mg}, \mathrm{Fe})_{2} \mathrm{SiO}_{4}$ olivine solid solution, iron partitioning increases the incompressibility of the Py-Alm garnet joint. From $\mathrm{Py}_{83} \mathrm{Alm}_{17}$ to $\mathrm{Py}_{30} \mathrm{Alm}_{70}, 53 \%$ more of almandine results in $6.3 \%$ increase in bulk modulus. In Py-Mj join, $K_{0}$ decreases with increasing Majorite content (Gwanmesia et al., 
2000; Nishihara, Aoki, Takahashi, Matsukage, \& Funakoshi, 2005). The results of this study on garnets along Py-Alm join, as well as data on the other garnet solid solution, provide useful for mineralogical modeling of the Earth mantle.

Figure 4.4 plots bulk moduli of Py-Alm solid solution in this system. Solid symbols are synthetic samples and open symbols are natural samples. The bulk moduli of two natural samples, $\mathrm{Py}_{60} \mathrm{Alm}_{31}$ and $\mathrm{Py}_{22} \mathrm{Alm}_{72}$, were measured by Takahashi and Liu (1970). $\mathrm{Py}_{60} \mathrm{Alm}_{31}$ contains $60 \%$ of pyrope and has a higher $K_{0}$ than that of $\mathrm{Py}_{22} \mathrm{Alm}_{72}$, which is opposite to the general trend that iron substation increases $K_{0}$. This may be attributed to unidentified phases in natural samples. Geiger et al., (1997) reported the volume mixing along Py-Alm join is ideal. Therefore a simple ideal mixing model $\left(K=n_{1} K_{1}+n_{2} K_{2} ; \mathrm{n}_{1}\right.$, $\mathrm{n}_{2}$ : mole fraction of pyrope and almandine) is used to fit our bulk modulus data. If we consider the experimental data from the samples that have the exact compositions along the Py-Alm binary system (i.e. synthetic samples), we obtain $K_{0}=170+15 n$ ( $n$ is mole fraction of almandine). From these data, we conclude that bulk moduli of garnet along Py-Alm join basically follow ideal mixing model.

Table 4.1 Composition of pyrope-almandine garnets at room temperature

\begin{tabular}{ccc}
\hline $\begin{array}{l}\text { Measured } \\
\text { composition }\end{array}$ & $\begin{array}{c}\mathrm{Fe} /(\mathrm{Mg}+\mathrm{Fe}) \\
\text { in mole ratio }\end{array}$ & $\begin{array}{c}\text { Standard } \\
\text { deviation }\end{array}$ \\
\hline $\mathrm{Py}_{30} \mathrm{Alm}_{70}$ & 0.700 & 0.003 \\
$\mathrm{Py}_{54} \mathrm{Alm}_{46}$ & 0.46 & 0.03 \\
$\mathrm{Py}_{83} \mathrm{Alm}_{17}$ & 0.17 & 0.03 \\
\hline
\end{tabular}


Table 4.2 Unit cell parameters of synthetic garnet of pyrope-almantine join at high pressures and room temperature

\begin{tabular}{|c|c|c|c|c|c|c|c|c|}
\hline \multicolumn{3}{|c|}{$\mathrm{Py}_{30} \mathrm{Alm}_{70}$} & \multicolumn{3}{|c|}{$\mathrm{Py}_{54} \mathrm{Alm}_{46}$} & \multicolumn{3}{|c|}{$\mathrm{Py}_{83} \mathrm{Alm}_{17}$} \\
\hline $\mathrm{P}(\mathrm{GPa})$ & $\mathrm{a}(\AA)$ & $\mathrm{V}\left(\AA^{3}\right)$ & $\mathrm{P}(\mathrm{GPa})$ & $\mathrm{a}(\AA)$ & $\mathrm{V}\left(\AA^{3}\right)$ & $\mathrm{P}(\mathrm{GPa})$ & $\mathrm{a}(\AA)$ & $\mathrm{V}\left(\AA^{3}\right)$ \\
\hline 0 & $11.5121(3)$ & $1526(1)$ & 0 & $11.4859(1)$ & $1515(2)$ & 0 & $11.4650(3)$ & $1511(1)$ \\
\hline 0.4 & $11.5068(3)$ & $1524(1)$ & 3.4 & $11.4262(6)$ & 1492(3) & 0.9 & $11.4604(5)$ & $1505(2)$ \\
\hline 3.8 & $11.4312(7)$ & 1493(2) & 7.9 & $11.3392(4)$ & $1458(2)$ & 1.6 & $11.4348(4)$ & $1495(2)$ \\
\hline 4.1 & $11.4253(6)$ & 1491(2) & 9.8 & $11.3011(2)$ & $1443(1)$ & 2.1 & $11.4252(6)$ & 1491(3) \\
\hline 6.1 & $11.4074(2)$ & $1484(6)$ & 11.1 & $11.2824(8)$ & $1436(3)$ & 2.7 & $11.4163(5)$ & $1487(2)$ \\
\hline 10.1 & $11.3334(2)$ & $1456(1)$ & 15.1 & $11.1963(7)$ & 1403(3) & 3.7 & $11.3961(8)$ & $1480(4)$ \\
\hline 11.5 & $11.2958(3)$ & 1441(1) & 18.9 & $11.1423(4)$ & $1383(2)$ & 5.3 & $11.3700(9)$ & $1470(4)$ \\
\hline 14.7 & $11.2578(1)$ & $1426.8(5)$ & 20.3 & $11.1281(7)$ & $1378(3)$ & 7.0 & $11.3377(4)$ & $1457(2)$ \\
\hline 17.1 & $11.2133(4)$ & 1410(1) & 21.4 & $11.1169(1)$ & $1374(1)$ & & & \\
\hline 19.0 & $11.1794(4)$ & $1397(2)$ & & & & & & \\
\hline
\end{tabular}

Note: pressure uncertainty is estimated to be $0.5 \mathrm{GPa}$

Table 4.3 EOS fitting results using different $K_{0}^{\prime}$

\begin{tabular}{lccc}
\hline Sample & $V_{0}\left(\AA^{3}\right)$ & $\begin{array}{c}K_{0} \\
(\mathrm{GPa})\end{array}$ & $K_{0}^{\prime}$ \\
\hline $\mathrm{Py}_{30} \mathrm{Alm}_{70}$ & $1526(1)$ & $183(2)$ & 4.3 (fixed) \\
& $1526(1)$ & $181(4)$ & 4.2 (fixed) \\
$\mathrm{Py}_{54} \mathrm{Alm}_{46}$ & $1515(2)$ & $174(2)$ & 4.3 (fixed) \\
& $1515(2)$ & $174(2)$ & $4.4($ fixed) \\
Py $_{83} \mathrm{Alm}_{17}$ & $1511(1)$ & $172(4)$ & 4.3 (fixed) \\
& $1511(1)$ & $171(4)$ & 4.4 (fixed) \\
\hline
\end{tabular}


Table 4.4 Bulk modulus and pressure derivative of garnets

\begin{tabular}{|c|c|c|c|c|c|}
\hline Sample & $\mathrm{V}_{0}\left(\AA^{3}\right)$ & $\mathrm{K}_{0}(\mathrm{GPa})$ & $\mathrm{K}_{0}{ }^{\prime}$ & Method & Reference \\
\hline Almandine(synthetic) & 1528.62 & $185(3)$ & 4.2 & Xrd & $\begin{array}{l}\text { Zhang et al. } \\
1999\end{array}$ \\
\hline Almandine(natural) & --- & $175(1)$ & $6.2(5)$ & Us & $\begin{array}{l}\text { Wang and } \mathrm{Ji} \\
2001\end{array}$ \\
\hline Pyrope(synthetic) & $1502.9(3)$ & $171(2)$ & $4.4(2)$ & Xrd & $\begin{array}{l}\text { Zhang et al. } \\
1998\end{array}$ \\
\hline Pyrope(synthetic) & $1500(1)$ & $167(2)$ & $4.6(3)$ & Xrd & Zou et al. 2012 \\
\hline Pyrope(synthetic) & $1503.4(5)$ & $175(1)$ & $4.5(5)$ & Xrd & $\begin{array}{l}\text { Levien et al. } \\
1979\end{array}$ \\
\hline Pyrope(synthetic) & 1503.87 & 172.8 & $3.8(1)$ & Xrd & $\begin{array}{l}\text { Leger } e t \\
\text { al. } 1990\end{array}$ \\
\hline Pyrope(natural) & --- & 171.32 & 3.22 & Bs & $\begin{array}{l}\text { Conrad et al. } \\
1999\end{array}$ \\
\hline Pyrope(natural) & 1509.59 & $174(3)$ & 4 & Xrd & $\begin{array}{l}\text { Hazen et al. } \\
1994\end{array}$ \\
\hline $\mathrm{Py}_{60} \mathrm{Alm}_{31}$ & 1529.22 & 177 & 5.45 (fixed) & Xrd & $\begin{array}{l}\text { Takahashi and } \\
\text { Liu } 1970\end{array}$ \\
\hline $\mathrm{Py}_{22} \mathrm{Alm}_{72}$ & 1530.02 & 173 & 5.45 (fixed) & Xrd & $\begin{array}{l}\text { Takahashi and } \\
\text { Liu } 1970\end{array}$ \\
\hline $\mathrm{Alm}_{72} \mathrm{Pyp}_{20} \mathrm{Sp}_{3} \mathrm{Grs}_{3} \mathrm{And}_{2}$ & 1535.2 & $173.6(16)$ & _- & Bs & $\begin{array}{l}\text { Jiang et al. } \\
2004\end{array}$ \\
\hline $\mathrm{Alm}_{86} \mathrm{Py}_{7} \mathrm{Spe}_{7}$ & $1539.2(2)$ & $177(2)$ & 4(fixed) & Xrd & Fan et al. 2009 \\
\hline $\mathrm{Py}_{83} \mathrm{Alm}_{17}$ & 1511(1) & $172(4)$ & 4.3(fixed) & Xrd & This work \\
\hline $\mathrm{Py}_{54} \mathrm{Alm}_{46}$ & $1515(2)$ & $174(2)$ & 4.3 (fixed) & Xrd & This work \\
\hline $\mathrm{Py}_{30} \mathrm{Alm}_{70}$ & $1527(2)$ & $183(2)$ & 4.3(fixed) & Xrd & This work \\
\hline
\end{tabular}

Us: Ultrasonic technique;Bs: Brillouin scattering; Uv: uvarovite; Sp: spessartine And:andradite;Grs:grossular 
(a)

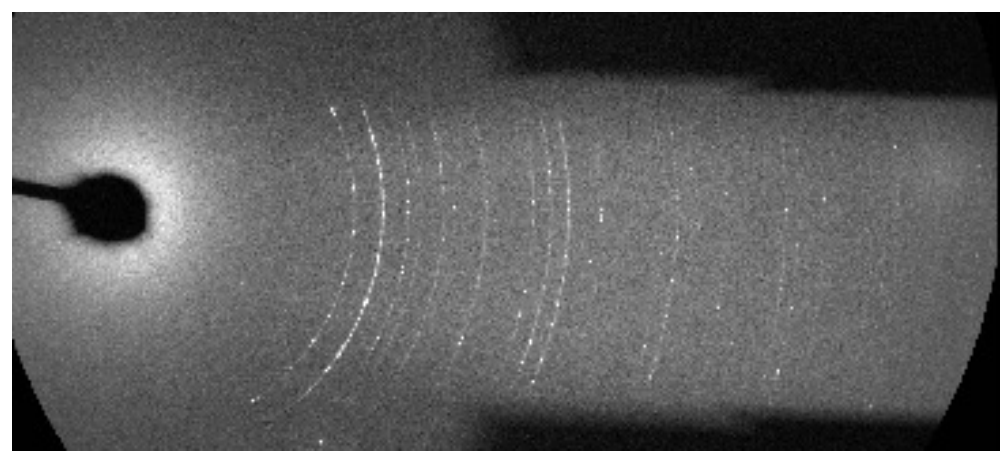

(b)

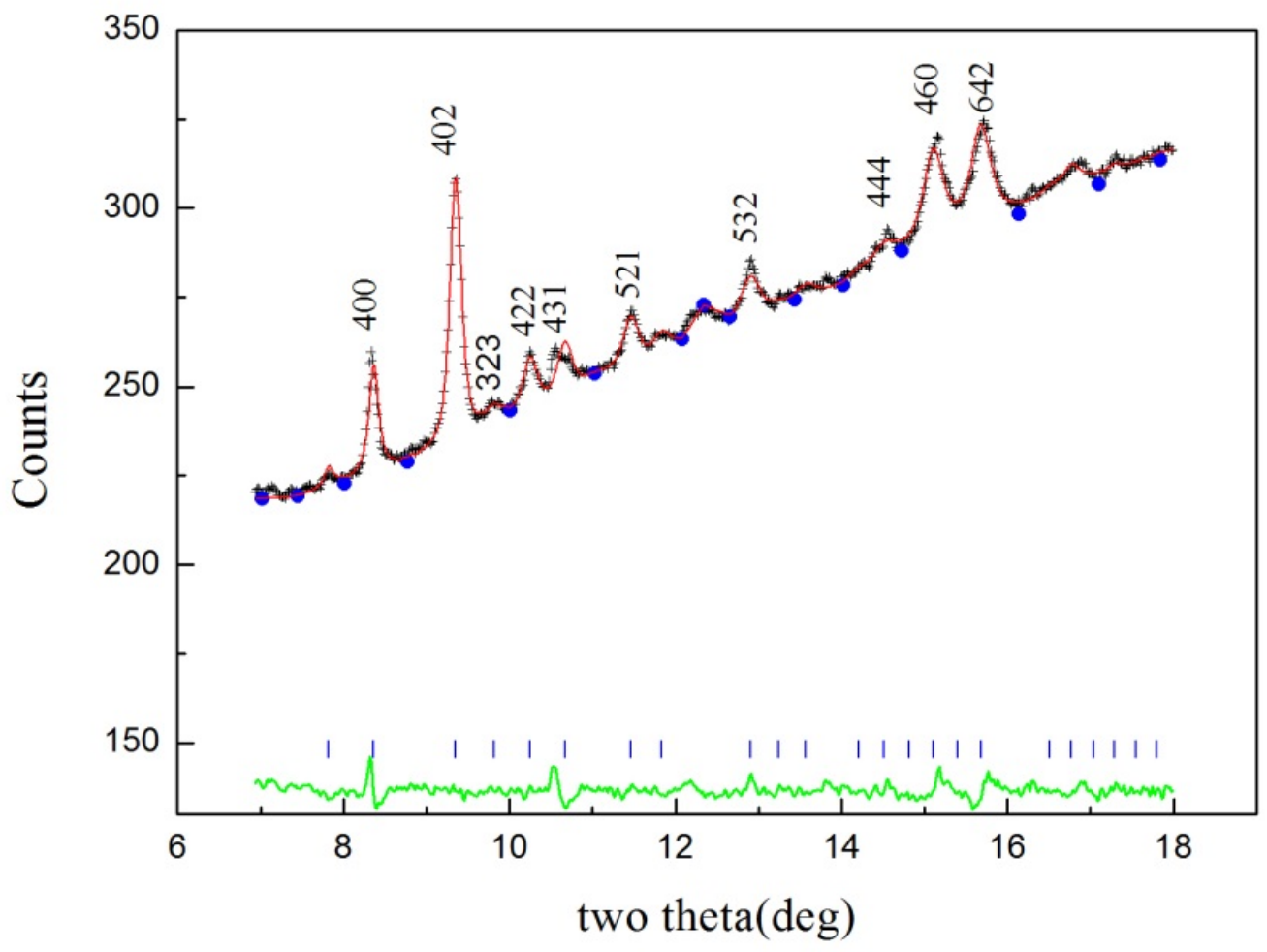

Figure 4.1 (a) Powder diffraction image collected by CCD detector. (b)Result of Le Bail fitting of $\mathrm{Py}_{30} \mathrm{Alm}_{70}$ at $19 \mathrm{GPa}$ and room temperature. Black crosses are experimental data; red line is calculated spectrum; blue dots represent background; blue bars at the bottom are expected positions of diffraction peaks; green line at the bottom is difference between the experimental data and the calculated spectrum. The Miller indices of major peaks are indicated by $h k l$ next to the peaks 


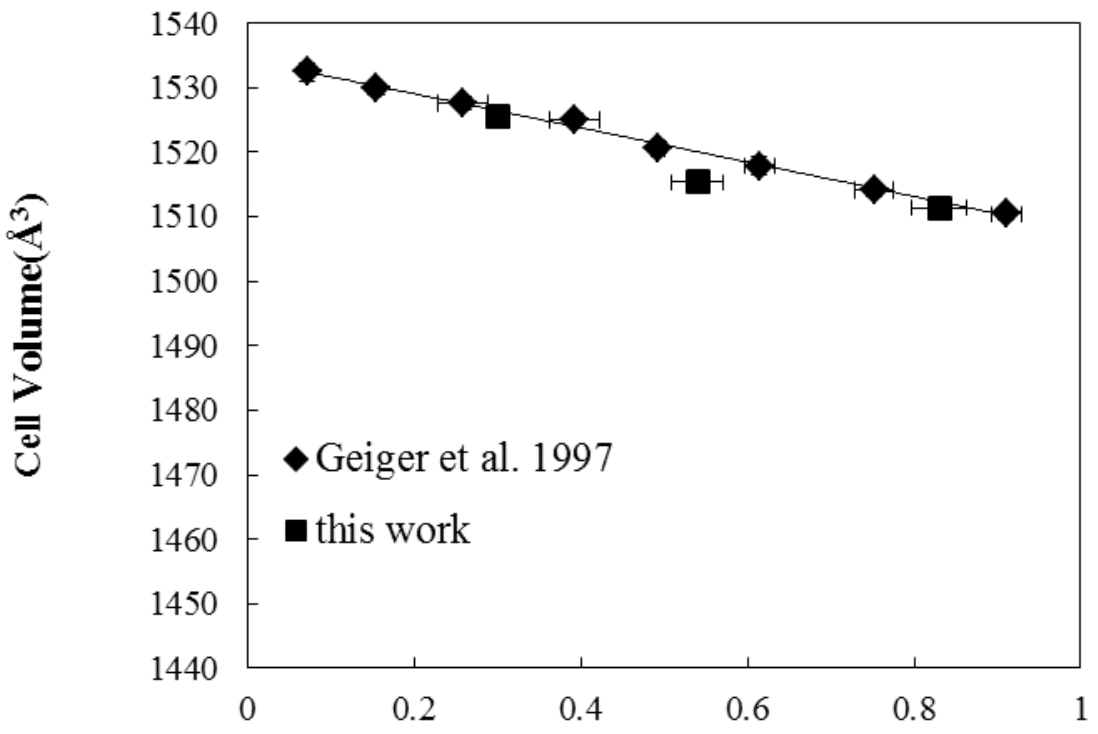

Pyrope mole fraction in Py-Alm join

Figure 4.2 The unit cell volume as a function of pyrope content in the Py-Alm binary system. Bars attached to the symbols represent the experimental uncertainties.

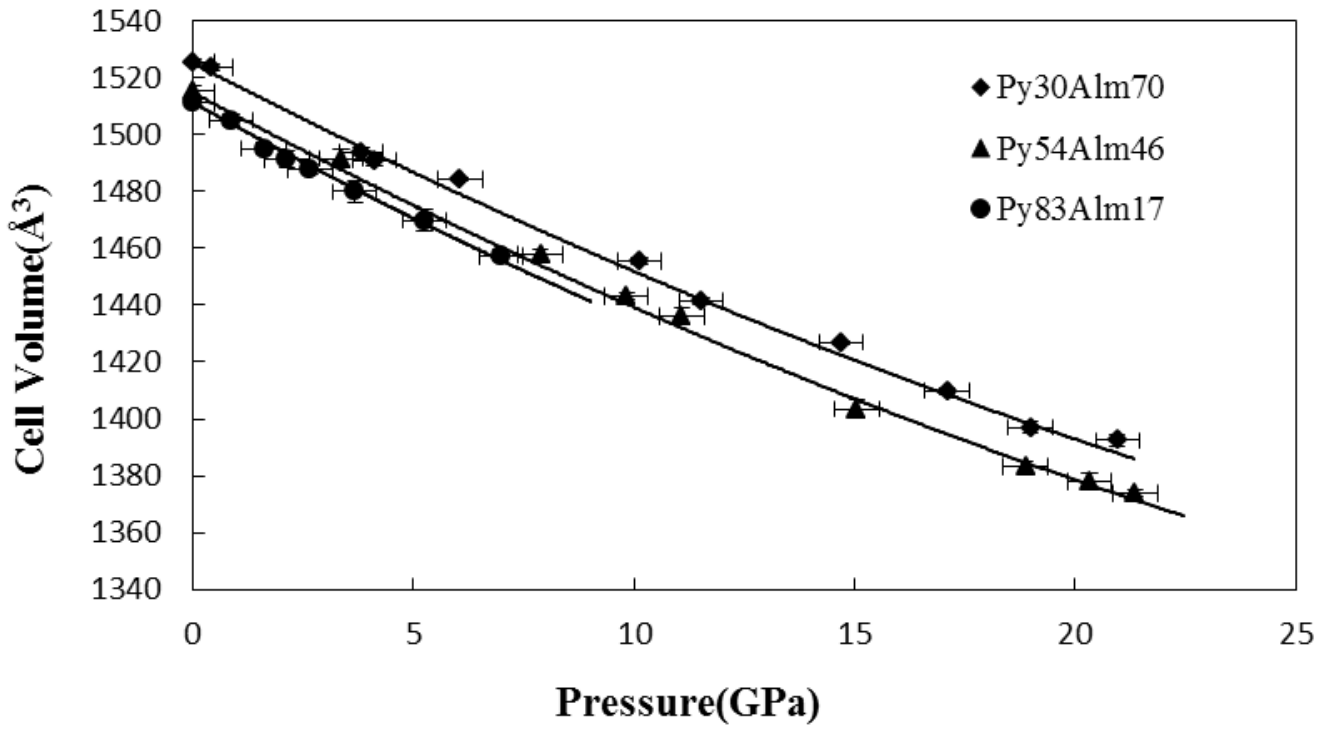

Figure 4.3 Volume of Py-Alm garnets as a function of pressure measured using in situ Xray diffraction at room temperature. Uncertainties of volume data are smaller than symbols. Solid lines represent the third order Birch-Murnagahan EOS fitting. 


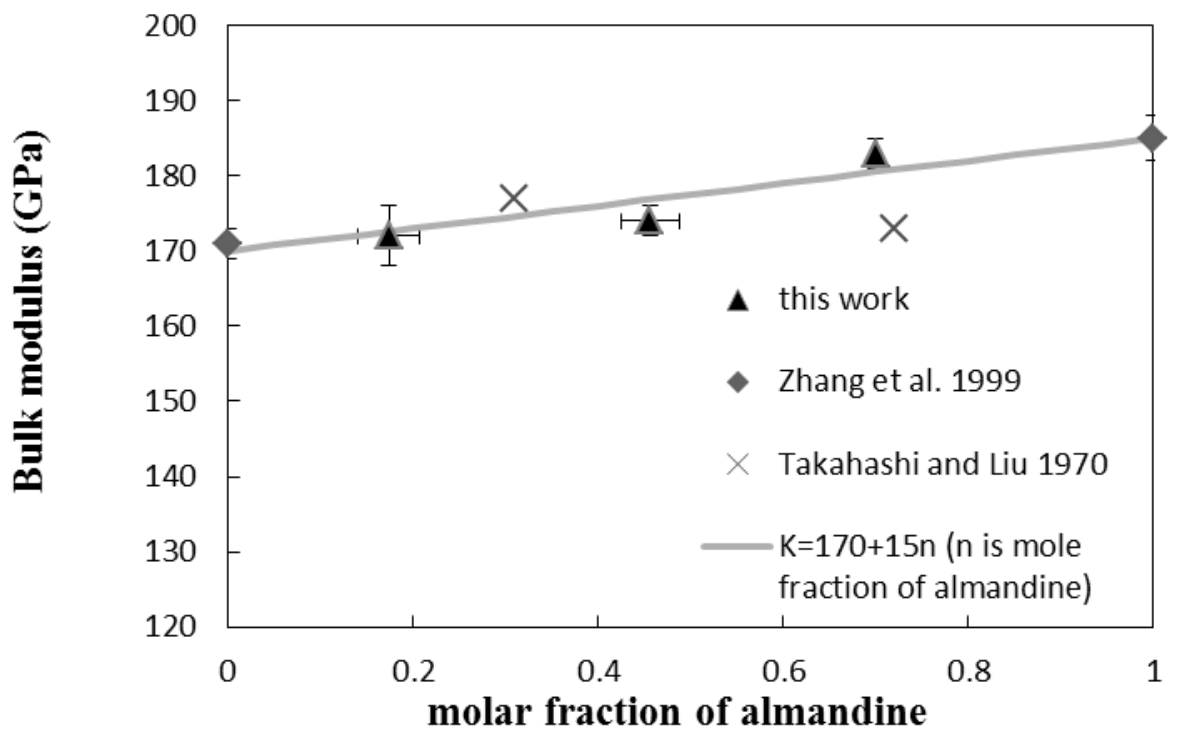

Figure 4.4 Bulk modulus data of almandine-pyrope binary system. Solid symbols are the data from synthetic sample; open symbols from natural sample. X-axis error bar for $\mathrm{Py}_{30} \mathrm{Alm}_{70}$ sample is smaller than the symbol. The line presents a linear fitting of the data from synthetic samples (solid symbols), based on the ideal mixing model. 


\section{Chapter 5}

\section{Water solubility in synthetic pyrope at high temperature and high pressure}

This chapter investigated water solubility in pyrope as a function of pressure. In order to study water influence on the bulk modulus of pyrope, hydrous pyrope samples were synthesized at high temperature and high pressure under water saturated environment. Therefore, water content in each sample needed to be quantified, which was water solubility in pyrope at different pressure. This chapter, titled Water solubility in pyrope at high pressure and high temperature by Huang and Chen will be submitted to Geophysical Research Letters.

\section{Abstract:}

A series of single crystal pyrope crystals were synthesized at $1000{ }^{\circ} \mathrm{C}$ and high pressure up to 9GPa. Water content of each sample was characterized by FTIR. Water content increased with pressure till $7 \mathrm{GPa}$ and dropped after $7 \mathrm{GPa}$. The water content in synthetic pyrope reached $1903 \mathrm{ppm}$ at $7 \mathrm{GPa}$, while previous reported water solubility in pyrope is around $0.1 \%$ wt. (Withers, Wood, \& Carroll, 1998). The OH stretching peak we observed at 4-7 GPa is an asymmetric peak located at $3630 \mathrm{~cm}^{-1}$. Peak at $3630 \mathrm{~cm}^{-1}$ represents the incorporation of hydroxyl into pyrope structure by means of $\mathrm{SiO}_{4}=(\mathrm{OH})_{4}$. Spectra at 9 GPa and $12 \mathrm{GPa}$, it shows two major peaks located at $3572 \mathrm{~cm}^{-1}$ and $3504 \mathrm{~cm}^{-1}$ and indicates that $\mathrm{OH}$ may enter pyrope structure via different substitution mechanisms when $\mathrm{OH}$ content is low. Besides, structure symmetry information of sample 184 obtained by single crystal X-ray diffraction reveals a tetragonal structure of pyrope at $12 \mathrm{GPa}$. A 
possible cubic to tetragonal phase transition may occur to incorporate more $\mathrm{OH}$ into the structure. At $12 \mathrm{GPa}$, water content increased to $0.3 \mathrm{wt} \%$.

\section{Introduction:}

Water can be incorporated into normally anhydrous minerals as $\mathrm{OH}^{-}$defects and transported into the mantle. Its existence in the mantle may affect property of minerals, such as elasticity, electrical conductivity and rheological properties. Water solubility measurement can provide an upper limit of water that possibly stores in the mantle at specific temperatures and pressures. Analysis of natural samples may only provide a lower limit of water solubility since minerals may lose water when transported to the Earth's surface (Keppler \& Bolfan-Casanova, 2006). As the secondary mineral in the mantle and pyrope is an important end member, water solubility in pyrope has not been extensively studied and there are discrepancies among the existing experiments on the water solubility at high temperature and high pressure. C. A. Geiger et al. (1991) investigated water content in synthetic pyrope and concluded $0.02 \mathrm{wt} \%$ to $0.07 \mathrm{wt} \% \mathrm{OH}$ substitution. Lu and Keppler (1997) found out 198ppm water in the Dora Miara pyrope at $100 \mathrm{Kbar}$ and $1000^{\circ} \mathrm{C}$. Withers et al. (1998) obtained that water solubility in pyrope reached $1000 \mathrm{ppm}$ at $5 \mathrm{GPa}$ and then decreased as pressure increasing; above $7 \mathrm{GPa}$, no water was detected. Mookherjee and Karato (2010) also explored pyrope-rich garnet, which contains water up to $0.1 \%$ wt at $5-9 \mathrm{GPa}$ and temperatures $1373 \mathrm{~K}-1473 \mathrm{~K}$. Here we report a new study of water solubility in synthetic pyrope along pressures range from 4 to $12 \mathrm{GPa}$ and constant temperature $1000^{\circ} \mathrm{C}$. Single crystals of pyrope were synthesized 
using multi-anvil press and water contents in these samples were measured by FTIR at beamline U2a, Brookhaven national lab.

\section{Experimental:}

\section{1 pyrope synthesis}

Single crystals of pyrope were synthesized at $1000^{\circ} \mathrm{C}$ and high pressure from $4 \mathrm{GPa}$ to 12 GPa using a 500 ton multi-anvil apparatus equipped with a walker module. The largest cell assemblies (14/8) were used in the experiments (octahedral edge length $14 \mathrm{~mm}$, the truncated edge length of WC anvil $8.0 \mathrm{~mm}$ ). Cylindrical graphite was employed as heater and temperature was measured with a W6\%Re-W25\%Re thermocouple. The starting materials are oxides $\left(\mathrm{MgO}, \mathrm{SiO}_{2}\right.$, and $\left.\mathrm{Al}_{2} \mathrm{O}_{3}\right)$ from alfa aesar, mixed at a composition of pyrope $\left(\mathrm{Mg}_{3} \mathrm{Al}_{2} \mathrm{Si}_{4} \mathrm{O}_{12}\right)$ with $10 \mathrm{wt} \%$ of $\mathrm{SiO}_{2}$ in excess. $15 \mathrm{wt} \%$ of distilled water was added to the oxides mixture as water source. A platinum capsule was used to seal the water in the sample during the synthesizing process. The synthesizing conditions are shown in Table. 1. The sample was characterized in powder X-ray diffraction (Fig. 5.1).

\subsection{Infrared spectroscopy}

Water measurements were performed at the U2A beamline at the National Synchrotron Light Source (NSLS), Brookhaven National Laboratory. Infrared spectra were collected using Bruker 66/S vacuum Fourier transform interferometer (FTIR) equipped with a Bruker IRscope-II microscope. Liquid $\mathrm{N}_{2}$ was purged in the microscope to avoid water absorption peaks from the air moistures. The resolution is $1 \mathrm{~cm}^{-1}$ and frequency range is $200-10000 \mathrm{~cm}^{-1}$. Spot size is $100 \times 100 \mu \mathrm{m}$ for large samples and can be adjusted to 
smaller size to avoid the visible inclusions. Crystals synthesized at different pressure are selected and mounted in epoxy resin. During selection, big crystal and with less inclusion are preferred. The crystals are polished both sides to make it approximately parallel. The thickness is measured by electro micrometer. Uncertainty of $10 \%$ is estimated in the water content calculation. Water content is calculated using absorption coefficient $6700 \pm 670 \mathrm{~mol}^{-1} \mathrm{~cm}^{-2}$ by Bell et al. (1995). The broad background is subtracted by Fityk using functions spline and polyline for peak integration (Fig. 5.2). The $\mathrm{OH}$ peak is fitted by software FITYK to calculate its area value. Water content is calculated using the following equation:

$$
C=\frac{1}{I} \int_{v_{1}}^{v_{2}} K(v) d v, K=\log \left(I_{0} / I_{t}\right) / d
$$

Where $\mathrm{c}$ is the concentration of water per mole, $\mathrm{v}$ is wavenumber and $\mathrm{I}$ is the integral molar absorption coefficient $\left(6700 \pm 670 \mathrm{~mol}^{-1} \mathrm{~cm}^{-2}\right.$, Bell et al. (1995)); $\mathrm{d}$ is thickness of sample; $I_{0}$ is the incident intensity of the infrared beam, $I_{t}$ is the transmitted intensity.

\section{Results and Discussion:}

\subsection{OH stretching spectra at high pressure}

The FTIR spectra of samples from 4 to $12 \mathrm{GPa}$ are shown in Fig. 5.3. An asymmetric $\mathrm{OH}^{-}$ stretching peak located at $3630 \mathrm{~cm}^{-1}$ is observed in each sample synthesized at pressure from 4-7GPa. This peak is already been confirmed by other references (C. A. Geiger et al., 1991; Mookherjee \& Karato, 2010; Withers et al., 1998), which indicates the $\mathrm{OH}$ vibration tetrahedral cluster $\mathrm{SiO}_{4}=(\mathrm{OH})_{4}$ substitution mechanism. At the low temperature 78K, this peak changed to two narrow peaks (C. A. Geiger et al., 1991). 


\subsection{Peak fitting analysis}

At $4 \mathrm{GPa}$, the $\mathrm{OH}$ peak is dominant at $3630 \mathrm{~cm}^{-1}$. After subtracting the broad background, this asymmetric peak can be fitted into two peaks, one dominate at $3630 \mathrm{~cm}^{-1}$, the other at around $3570 \mathrm{~cm}^{-1}$. Same fitting processes are performed for spectra at 6 and $7 \mathrm{GPa}$. As pressure goes up, this asymmetric peak split into two sharp peaks, one at $3520 \mathrm{~cm}^{-1}$ the other at $3570 \mathrm{~cm}^{-1}$. A close examination of the 184 spectrum shows a peak splitting process is starting.

\subsection{IR complexity}

We have observed complicated spectra at $9 \mathrm{GPa}$ and $12 \mathrm{GPa}$, at which pyrope showed new peaks at around $3572 \mathrm{~cm}^{-1}$ and $3504 \mathrm{~cm}^{-1}$ and the peak intensity at $3630 \mathrm{~cm}^{-1}$ was reduced. We also characterized the sample which is synthesized at 9GPa by X-ray diffraction, which showed a single pure phase. Such spectra diversity is also observed by Geiger et al. (1991). They observed four band spectra at $3665,3651,3641$ and $3618 \mathrm{~cm}^{-1}$ of synthetic pyrope, which was grown from a gel starting material and at a temperature lower than $1000^{\circ} \mathrm{C}$. That also indicates other incorporation mechanism may be dominant other than hydrogarnet substitution mechanism. In the natural pyrope, IR spectra are more complicated. Lu and Keppler (1997) investigated on the pure pyrope from Dora Maira and found $\mathrm{OH}$ region including a single peak at $3601.9 \mathrm{~cm}-1$, a band series of $3640.5 \mathrm{~cm}^{-1}, 3650.8 \mathrm{~cm}^{-1}$ and $3660.6 \mathrm{~cm}^{-1}$.

\subsection{Water solubility in pyrope under high pressure}

Previous water solubility studies and this work are shown in Fig. 5.4. Water percentage is plotted as a function of pressure. Withers et al. (1998) determined water solubility to be 
$0.1 \mathrm{wt} \%$ at $6 \mathrm{GPa}$ and no water was detected after 7GPa. Mookherjee and Karato (2010) examined pyrope-rich garnet at 5-9GPa and found its water solubility around $0.1 \% \mathrm{wt}$ at 5-9GPa. In our study, we obtained the highest water content at 7GPa (1903ppm in average). From $4 \mathrm{GPa}$ to $7 \mathrm{GPa}$, water solubility in pyrope was increased with pressure, which is consistent with the trend of Wither's results below 7GPa. We also observed water content dropped after 7GPa. At 9GPa, water in the sample decreased to $700 \mathrm{ppm}$, and $\mathrm{OH}$ peak positions changed as well. According to the theory of water equilibrium, water solubility should increase with water fugacity and we assume constant silica activity since excess $\mathrm{SiO}_{2}$ was added to each experiment.

4.5 Water in grossular garnet and incorporation mechanism

Grossular is a promising water carrier mineral in garnet family (Rossman, 1996). Rossman and Aines (1991) investigated natural grossular samples from 33 locations using IR. Their water content varied from $12.8 \%$ to $0.0005 \%$. (Withers et al., 1998) also synthesized hydrous grossular and found the $\mathrm{OH}$ peak was located at $3622 \mathrm{~cm}^{-1}$. This peak persisted to $8 \mathrm{GPa}$ at $1000{ }^{\circ} \mathrm{C}$, which represented $0.1 \mathrm{wt} \%$ of water. Under same conditions, pyrope became anhydrous.

Garnet shows the greatest complexity in the OH region. Rossman and Aines(1991) identified seven types of hydrous grossular spectra. The IR spectra collected from samples of high water content, which were consistent with that of hydrous grossular substitution, showing peaks at 3598 and $3662 \mathrm{~cm}^{-1}$. However, the spectra of samples with low $\mathrm{OH}$ concentrations were significantly different from that of synthetic grossular. $\mathrm{He}$ 
concluded that hydrogarnet substitution $\mathrm{SiO}_{4}=\left(\mathrm{O}_{4} \mathrm{H}_{4}\right)$ was not the only mechanism of incorporating $\mathrm{OH}$ into garnet structure.

$\mathrm{OH}$ ions can enter anhydrous minerals as an isolated proton, which is related to defects and the vacancy movement. Some is incorporated in a two-proton cluster, eg. olivine, or in a four-proton cluster, which is mostly considered as hydrogarnet substitution. However, evidence has shown that the hydrogarnet substitution is not an accurate description of the water incorporation. Cho and Rossman (1993) performed a solid state proton NMR study on natural single crystal grossular garnets from different locations; they reached an conclusion that some grossular was substituted in a manner of two-proton clusters and some were in the form of four-proton clusters or a mixture of two-proton and four-proton clusters. In our study, we observed IR complexity at $9 \mathrm{GPa}$ and $12 \mathrm{GPa}$, other than peak at $3630 \mathrm{~cm}^{-1}$. Thus, it is suggested that in the hydrous pyrope, $\mathrm{OH}$ may exist in different environments; in the low concentration, other dominant incorporation mechanism may apply.

\subsection{Tetragonal polymorph of pyrope at $12 \mathrm{GPa}$}

Single crystal X-ray measurement gave a tetragonal crystal structure with $\mathrm{a}=\mathrm{b}=8.098 \AA$ and $c=5.72$ Å. Harris, Hutchison, Hursthouse, Light, and Harte (1997) found a new tetragonal almandine-pyrope phase(TAPP) in the inclusions of diamonds. It had a garnet composition similar to pyrope-almandine and a tetragonal structure with a space group $I \overline{4} 2 \mathrm{~d}$. The other two tetragonal garnet phases are henritemierte $\left(\mathrm{Ca}\left(\mathrm{Mn}^{3+}\right)_{2}\left(\mathrm{SiO}_{4}\right)_{2}(\mathrm{OH})_{4}\right)$ and holtstamite $\left(\mathrm{Ca}_{3} \mathrm{Al}_{2}\left(\mathrm{SiO}_{4}\right)_{2}(\mathrm{OH})_{4}\right)$, which have a space group $I 4_{1} /$ acd (Grew et al., 2013). It is assumed that the tetragonal type of pyrope does exist and this phase transition 
occurred at $12 \mathrm{GPa}$ and $1000{ }^{\circ} \mathrm{C}$. Then, it indicates that water fluid may promote phase transitions and through this way pyrope can incorporate more $\mathrm{OH}$ than we expected. According to water calculation of this sample, it contains $3258 \mathrm{ppm}$ in the structure.

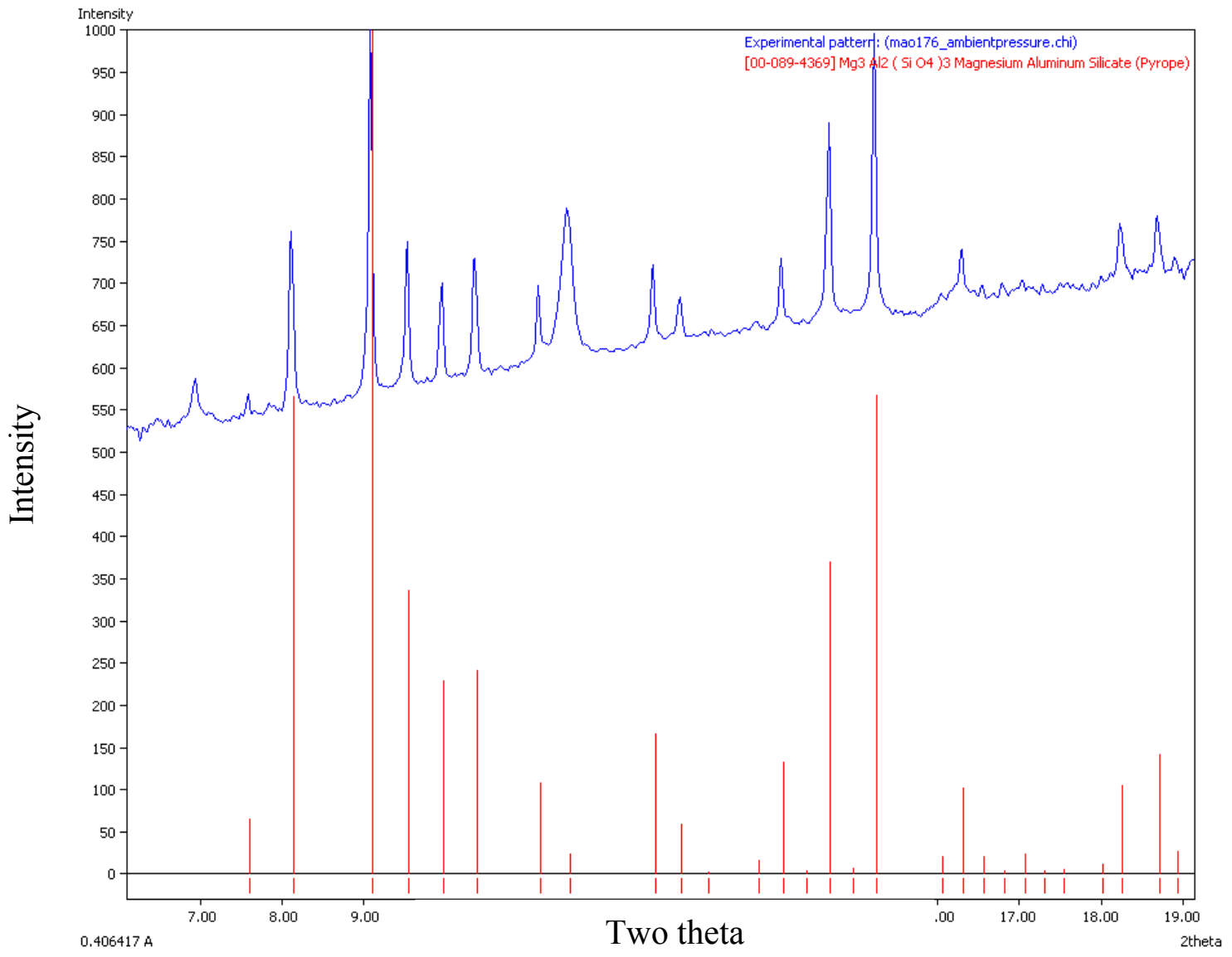

Figure 5.1 XRD of ground pyrope powder at ambient conditions 
(a)

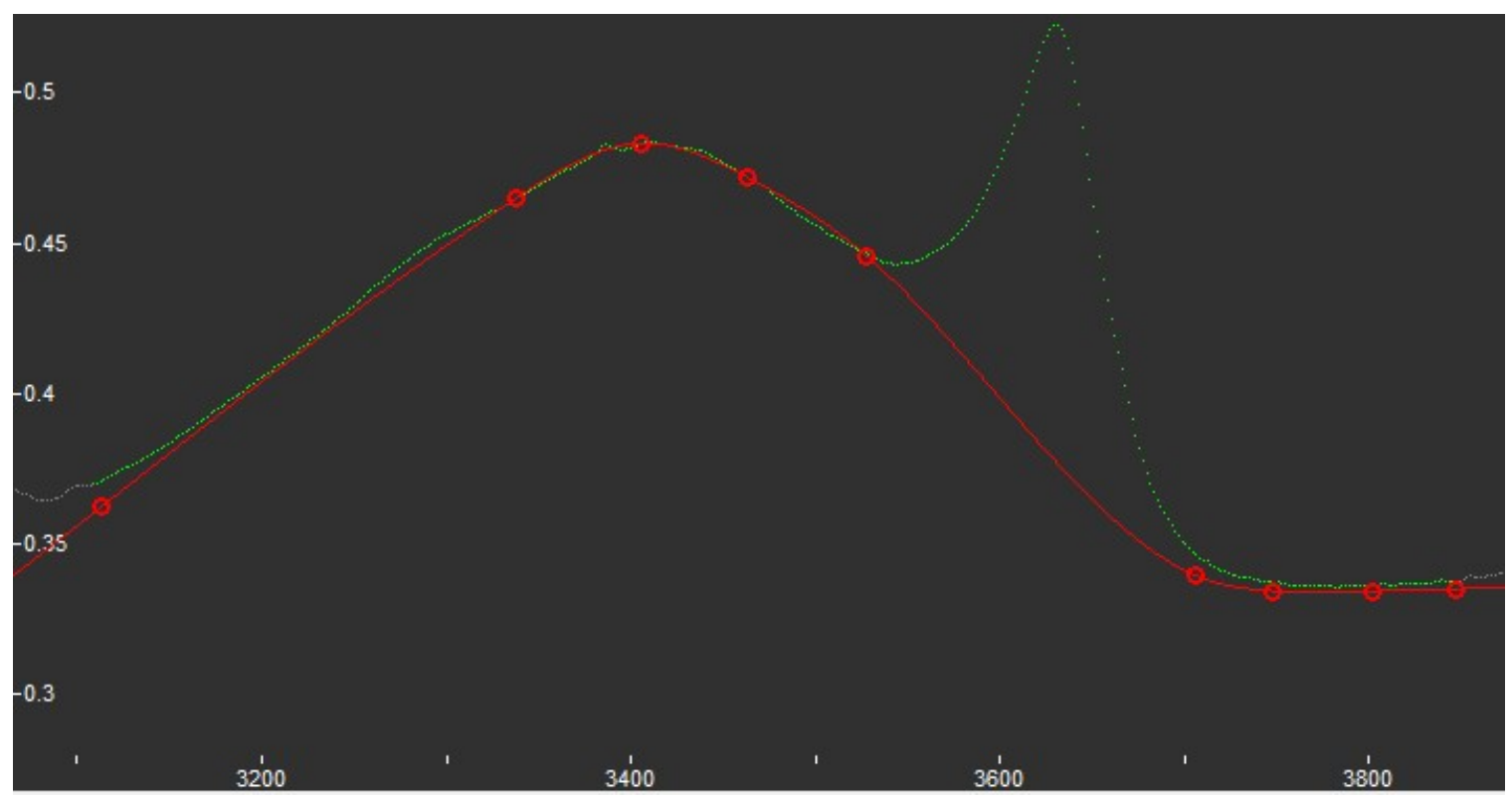

(b)

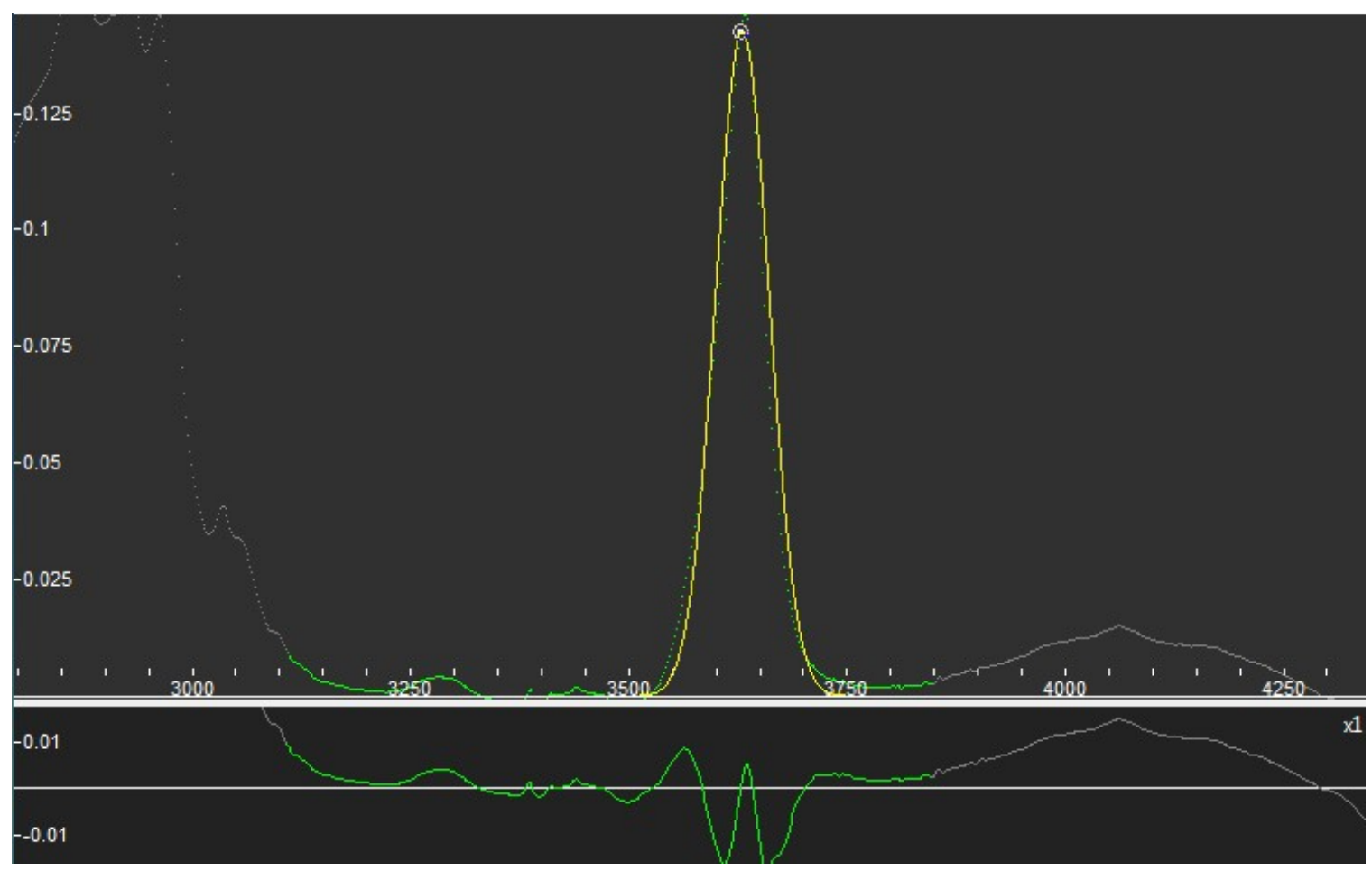

Figure 5.2 A fitting example. (a)Base line subtracted using function spline.(b) Peak located at $3630 \mathrm{~cm}^{-1}$ is fitted using Gaussian function and peak area is calculated. 


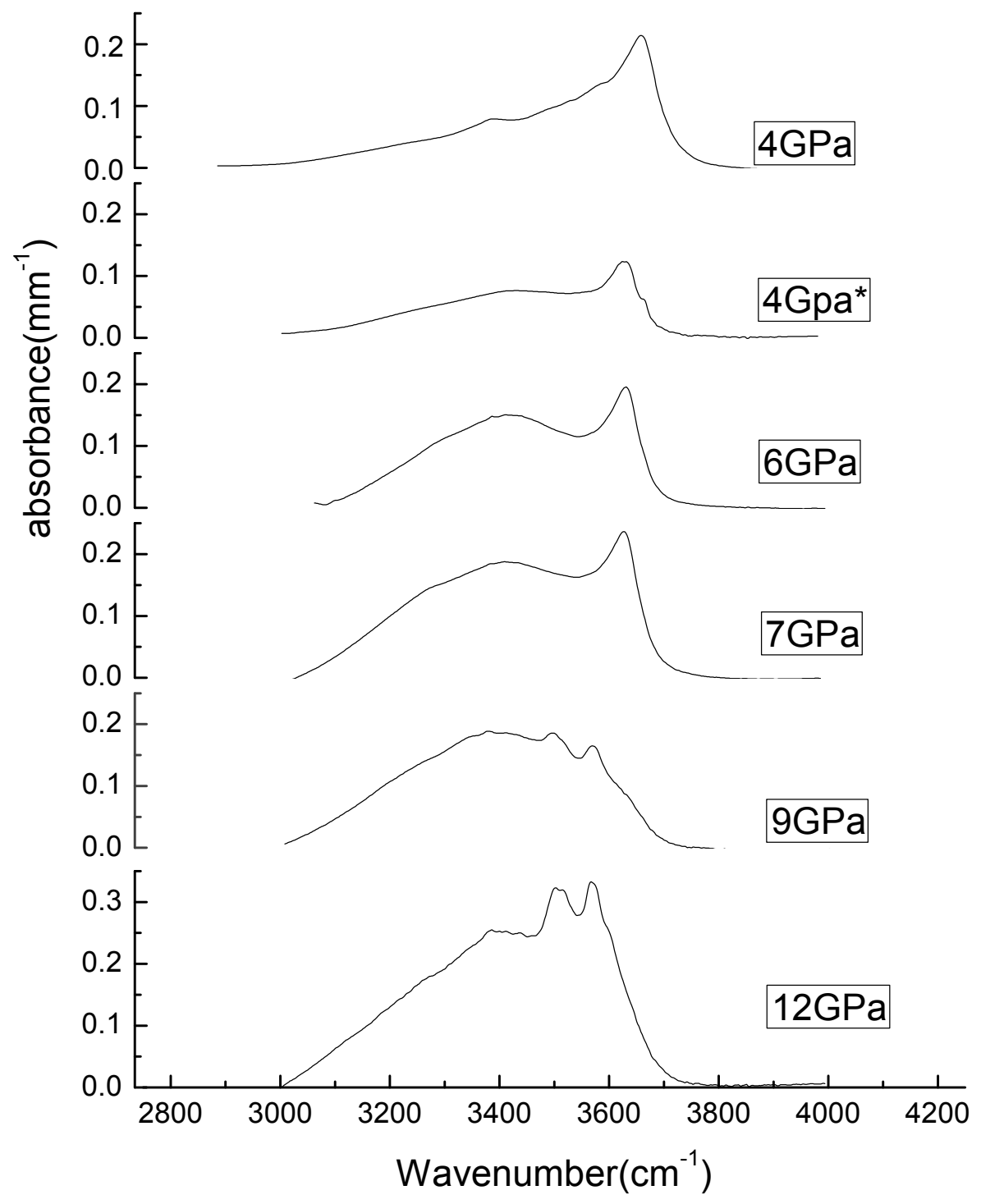

Figure 5.3 FTIR spectra of pyrope synthesized at pressures from $4 \mathrm{GPa}$ to $12 \mathrm{GPa}$; $*$ is synthesized from glass 


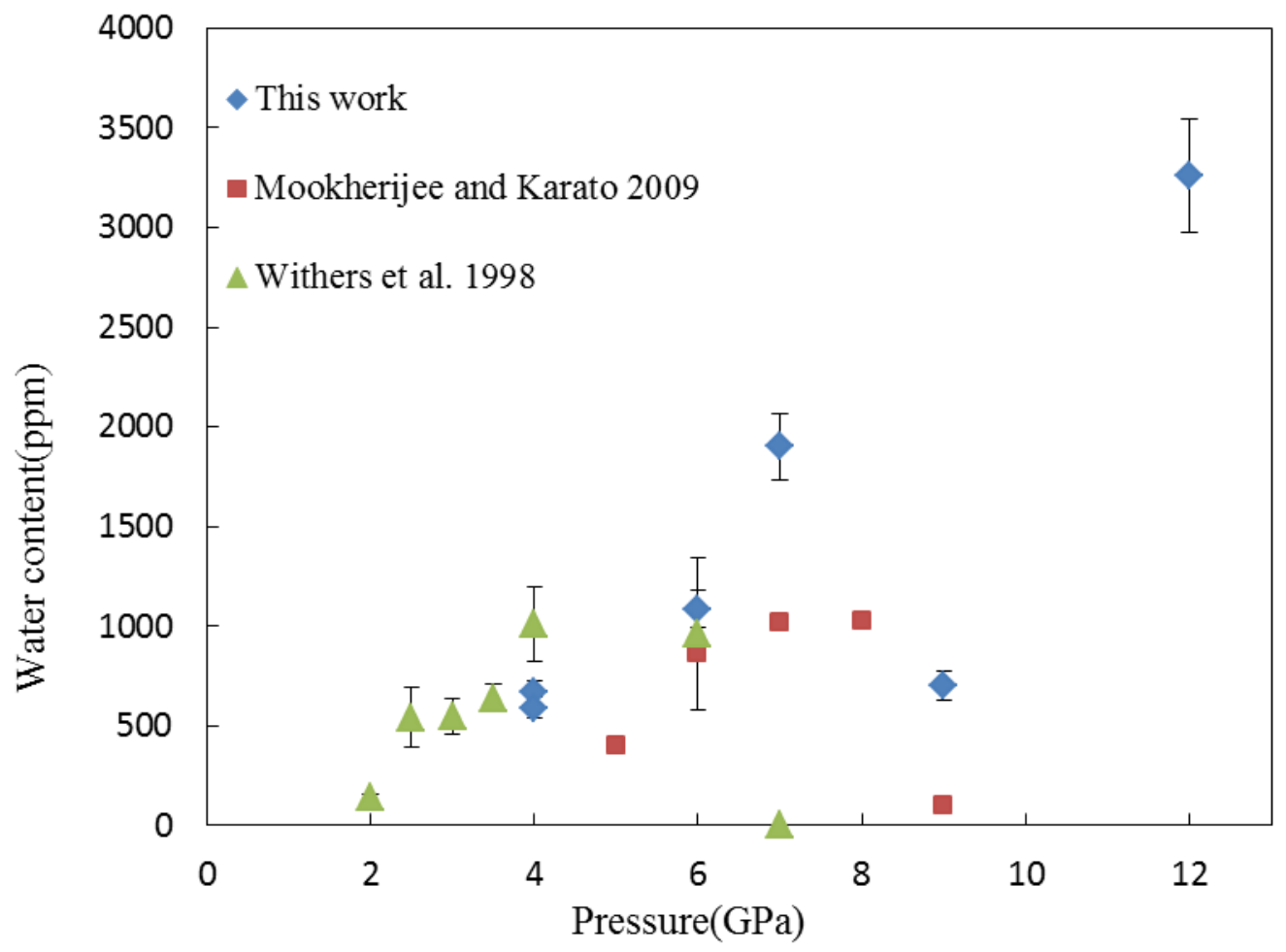

Figure 5.4 Water solubility in pyrope as a function of pressure, average water content in each sample is plotted in this study

Table 5.1 synthesis conditions of single crystal pyrope and calculated water content

\begin{tabular}{cccccccccc}
\hline Run\# & $\begin{array}{c}\text { Pressure } \\
\text { (GPa) }\end{array}$ & $\mathbf{T}\left({ }^{\circ} \mathbf{C}\right)$ & \multicolumn{2}{c}{ Time(hrs) Crystals \# } & \multicolumn{2}{c}{ water content(ppm) } & \multicolumn{2}{c}{$\mathbf{C}($ average) Uncertainty } \\
\hline $\mathbf{1 7 6}$ & 4 & 1000 & 15 & 3 & 539 & 609 & 865 & 671 & 59 \\
$\mathbf{1 7 8}$ & 4 & 1000 & 17 & 3 & 515 & 609 & 647 & 590 & 51 \\
$\mathbf{1 8 0}$ & 6 & 1000 & 13 & 3 & 1029 & 1078 & 1147 & 1085 & 94 \\
$\mathbf{1 8 1}$ & 7 & 1000 & 19 & 3 & 1802 & 1676 & 2232 & 1903 & 166 \\
$\mathbf{1 8 3}$ & 9 & 1000 & 14 & 2 & 749 & 652 & & 701 & 74 \\
$\mathbf{1 8 4}$ & 12 & 1000 & 8 & 3 & 2700 & 3828 & 3245 & 3258 & 284 \\
\hline
\end{tabular}




\section{Chapter 6}

\section{Water influence on Equation of state of hydrous Pyrope}

We have conducted high-pressure experiments to study single crystal pyrope grown under water saturated environment at different pressures. It showed pressure influences on water solubility. In this chapter, we studied equations of state of hydrous pyrope crystals.

\section{Abstract:}

We have synthesized dry pyrope at $4 \mathrm{GPa}$ and a suite of pure hydrous single crystal pyrope at $6,7,9$ and $12 \mathrm{GPa}$, which contain $0.1 \mathrm{wt} \%, 0.2 \mathrm{wt} \%$ and $0.07 \mathrm{wt} \%$ of water respectively. Several compressibility experiments were conducted up to 30GPa by single crystal in situ X-ray diffractions. The bulk moduli of the hydrous samples (180, 181 and 183) were determined to be 173(2)GPa, 161(1)GPa and 166(1)GPa at a fixed derivative

of bulk modulus, $K_{0}^{\prime}=4.4$. The bulk modulus of dry sample was $172(1) \mathrm{GPa}$. Water weakening effect has been observed on hydrous pyrope. A reduction rate of bulk modulus is obtained; $1 \mathrm{wt} \%$ of water reduces $12 \mathrm{GPa}$ of bulk modulus at water content range 0 $0.2 \mathrm{wt} \%$. Besides, the measured unit cell volume decreased with water content.

\section{Introduction:}

Water effect on properties of minerals in the mantle has been extensively studied. For example, elasticity of Wadsleyite (Holl, Smyth, Jacobsen, \& Frost, 2008; Z. Mao et al., 2008) and ringwoodite (Manghnani et al., 2005; Sinogeikin, Bass, \& Katsura, 2003; J. Wang, Sinogeikin, Inoue, \& Bass, 2003) and olivine (J. Chen, Liu, \& Girard, 2011; 
Jacobsen et al., 2008). Jacobsen (2006) reviewed effect of water on the equations of state of nominally anhydrous minerals and the availability of current experimental data. However, to date, very few studies have been conducted on qualifying water effect on elasticity of pyrope. Studies of hydrous garnet are mostly on grossular and its hydrous phase Katoite (C. A. Geiger, Dachs, \& Benisek, 2012; G. A. Lager, Downs, Origlieri, \& Garoutte, 2002; G. A. Lager, Marshall, Liu, \& Downs, 2005; O'Neill, Bass, \& Rossman, 1993; Olijnyk, Paris, Geiger, \& Lager, 1991). Those investigations showed that water effect on elasticity of grossular via hydrogarnet substitution is significant. Garnet is an important mineral and takes a substantial fraction from upper mantle to transition zone; it may act as a potential water bearing phase and its properties may be influenced by water as well. Pyrope is a major end member in the garnet family. Previous studies on hydrous pyrope were carried out on water influence on electrical conductivity of pyrope rich garnet (Dai \& Karato, 2009) and recent experiments on rheological properties of natural pyrope under water saturated conditions (Xu et al., 2013). Here, we report an experimental study conducted on hydrous pyrope by in situ single crystal X-ray diffractions and investigate water influence on equations of state of hydrous pyrope.

\section{Experimental:}

The hydrous single crystal samples were synthesized using a 500-ton multi anvil press at Center (CeSMEC). The synthesis conditions of the samples were at $1000^{\circ} \mathrm{C}$ and 6,7 and 9 GPa (See chapter 5 for details). High pressure single crystal XRD measurements were conducted at GSECARS beamline 13 BM-D, Advanced Photon Source (APS), Argonne National Laboratory. High pressure single crystals diffractions were collected using a BX90 cell (Kantor et al., 2012), which provided a broad opening for collecting more data 
of single crystal diffractions. The BA type diamond anvils were of $400 \mu \mathrm{m}$ culets. The gasket was made from steel plate and pre-indented to $30-40 \mu \mathrm{m}$ in thickness. Neon was loaded as a pressure-transmitting medium by COMPRES/GSECARS gas loading system. The initial pressure point in the cell was measured after the gas loading. The zero pressure volume was measured outside the cell in the ambient conditions. Pressure was calculated from fluorescence shift of ruby sphere (H. Mao et al., 1986). The beam size is $15 \mu \mathrm{m} \times 5 \mu \mathrm{m}$ with a $0.3344 \AA$ wavelength. Clear crystals of $30 \mu \mathrm{m}$ in diameter and 10 $\mu \mathrm{m}$ in thickness were selected for measurements. Four hydrous samples, dry and three other hydrous pyrope samples $(0.07 \mathrm{wt} \%, 1 \mathrm{wt} \%$ and $0.2 \mathrm{wt} \%$ of water $)$ have been measured. One of the sample chamber pictures with two samples is shown in Fig. 6.1.

During single crystal diffraction collections, omega range was from $-14^{\circ}$ to $14^{\circ}$. After $1^{\circ}$ of rotation, one image was taken. In total, 28 tiff images were collected for diffractions of single crystal sample at one pressure point. Those step-scan images were then merged and analyzed by software GSE-ADA/rsv (Dera et al., 2013). The orientation matrix was determined by the omega assignment and the index of each peak in the merged images. Once orientation matrix was determined, it provided an approximation to index peaks in the next pressure for the same sample, if no phase change was observed and no obvious movement of sample was shown. Unit cell parameter was calculated and refined when orientation matrix was determined. In each diffraction pattern, $\sim 60$ to 70 peaks were indexed for crystal structure determinations and lattice parameter calculations. The lattice parameter of each sample is listed in table 6.1. 


\section{Results and discussion:}

\subsection{Equation of state and bulk modulus}

The compression data sets were fitted to the Birch-Murnaghan equation of state using EOSFIT 5.2 (Angel, 2000) with non-weighting schemes.

$$
P=\left(\frac{3}{2}\right) K_{0}\left[\left(\frac{V_{0}}{V}\right)^{\frac{7}{3}}-\left(\frac{V_{0}}{V}\right)^{\frac{5}{3}}\right] \times\left\{1+\frac{3}{4}\left(K_{0}^{\prime}-4\right)\left[\left(\frac{V_{0}}{V}\right)^{\frac{2}{3}}-1\right]\right\}
$$

where $V_{0}, K_{0}$ and $K_{0}^{\prime}$ are zero pressure volume, isothermal bulk modulus and pressure derivative of the bulk modulus. The fitting results are summarized in Table 6.2. We fitted all the data in two fitting strategies: One with a fixed $K_{0}^{\prime}=4.4$, the other with a refined $K_{0}^{\prime}$. The reason to show results of $K_{0}^{\prime}=4.4$ is for the bulk moduli comparison between dry and hydrous samples. The second fitting procedure was as follows: all the parameters had been refined and $\mathrm{V}_{0}$ refinement started with an experimental value measured outside of DAC. With the 2nd order $\left(K_{0}^{\prime}=4\right)$ EOS fitting of dry pyrope, it gave a $K_{0}=172.7(3) \mathrm{GPa}$, which is close to previous bulk modulus's measurement of single crystal pyrope (Sinogeikin \& Bass, 2000; Zhang et al., 1998; Zou et al., 2012). The EOS fitting curve is shown in Fig. 6.2. For the hydrous samples, the EOS fittings yield decreased bulk moduli compared to that of dry pyrope $\left(K_{0}=172 \mathrm{GPa}\right)$. The fitting curves are illustrated in Fig. 6.3 with a comparison among dry pyrope and hydrous samples.

To give a visual evaluation of $K_{0}^{\prime}$, Birch normalized pressure (F), vs Euler finite strain (f), is plotted in Fig. 6.4, where $f=\left[\left(V / V_{0}\right)^{-2 / 3}-1\right] / 2, F=P /\left[3 f(1+2 f)^{2.5}\right\rfloor$. The slope represents the $K_{0}^{\prime}$. It reveals that $K_{0}^{\prime}=4$ represents well for the $\mathrm{P}-\mathrm{V}$ data of pyrope and sample 181. Positive slopes are for samples 180 and 183. 
The trend of bulk modulus as a function of water content is plotted in Fig. 6.5. It is the fitting results at a fixed pressure derivative (4.4). An approximate linear relationship is obtained for the bulk moduli of sample $180(0.1 \mathrm{wt} \%), 181(0.2 \mathrm{wt} \%), 183(0.07 \mathrm{wt} \%)$ and dry pyrope. In Fig. 6.6, we plotted the bulk modulus results by the other fitting method with all the parameters refined. It also shows a linear relationship. The sample 183 (0.07 wt $\%)$ has the lowest bulk modulus $\left(K_{0}=157(2) \mathrm{GPa}\right)$ among the three hydrous samples. This sample was synthesized at $1000{ }^{\circ} \mathrm{C}$ and 9 GPa. Its IR spectrum shows that $\mathrm{OH}$ stretching peaks are located at $3572 \mathrm{~cm}^{-1}, 3504 \mathrm{~cm}^{-1}$ and peak at $3630 \mathrm{~cm}^{-1}$ becomes very weak. OH may enter different sites of the structure other than substituting the $\mathrm{SiO}_{4}$ clusters' positions. However, for hydrous pyrope, it may employ different incorporation mechanisms at pressures of 9GPa and above. Since this hydrous sample was synthesized at a significant higher pressure ( $9 \mathrm{GPa}$ ), which is another variable in this study, one would think that pressure may play an role in elasticity as well. In the upper mantle and the transition zone, those crystals were generated under high pressures and high temperatures. While water reduces bulk moduli, the high pressure in the Earth may also intensify this effect.

According to bulk modulus-molar volume law (Anderson, 1970), isostructural crystals follow that bulk modulus $\times$ volume $=$ constant. $K_{0}$ versus $1 / V_{0}$ is plotted in Fig. 6.7 ; it appears that this law still holds for dry and hydrous pyrope of different water contents. Unit cell volume of each sample is plotted as a function of water content in Fig. 6.8.

Derivative of bulk modulus

Elevated derivatives of $K_{0}$ (5.3 and 5.4) have been observed for samples 180 and 183 . The f-F plots (Fig. 6.4) of the two samples show positive slopes. It seems that the value 
of $K_{0}^{\prime}$ depends on the water content of each individual sample. Holl et al. (2008) studied a series of hydrous wadsleyite with different water contents and obtained $K_{0}^{\prime}=4.1$ for 0.005 wt $\% \mathrm{H}_{2} \mathrm{O}, K_{0}^{\prime}=5.4(11)$ for $0.38 \mathrm{wt} \% \mathrm{H}_{2} \mathrm{O} ; K_{0}^{\prime}=4.2(9)$ for $1.18 \mathrm{wt} \% \mathrm{H}_{2} \mathrm{O}$; and $K_{0}^{\prime}=$ 4.9(11) for $1.66 \mathrm{wt} \% \mathrm{H}_{2} \mathrm{O}$. Z. Mao et al. (2008), (2010) investigated hydrous wadsleyite and hydrous forsterite by Brillouin scattering and found that hydrous wadsleyite had an identical $K_{0}^{\prime}$ to dry sample, while hydrous forsterite had an elevated $K_{0}^{\prime}(7 \%$ more). In the theoretical calculation, Li, Brodholt, and Alfè (2009) predicted $K_{0}^{\prime}$ (3.91 and 4.21) by first principal calculation for hydrous ringwoodite with $1.65 \mathrm{wt} \%$ and $3.3 \mathrm{wt} \%$ water percentage individually. All the observations and calculations above suggest that experimental elevated $K_{0}^{\prime}$ depends on individual sample and techniques employed.

4.2 Other hydrous garnet: Hydro-grossular

In the garnet family, hydrous grossular is mostly studied because of its availability, and its hydrous phase Katotite $\left(\mathrm{Ca}_{3} \mathrm{Al}_{2}\left(\mathrm{O}_{4} \mathrm{H}_{4}\right)_{3}\right.$ is well determined. The structure difference between grossular and Katotite is that $\mathrm{SiO}_{4}$ is completely replaced by $(\mathrm{OH})_{4}$ in the tetrahedron site, which is defined as hydrogarnet substitution. The $K_{0}$ of Katotite reflects the lower bound of the $K_{0}$ of hydrous grossular, showing a hydration weakening effect on the elasticity of minerals. G. A. Lager et al. (2002) (2005) examined the structure of Katotite by X-ray diffractions and neutron powder diffractions. They found a phase transition from $I a 3 d$ to $I 43 d$ in the neutron spectrum at $7.5 \mathrm{GPa}$ and proposed that compression of $\mathrm{H}-\mathrm{H}$ distance between $\mathrm{O}_{4} \mathrm{H}_{4}$ groups destabilized the structure. However, C. A. Geiger et al. (2012) calculated entropy and Gibbs-free energy of Katoite and pointed out that no phase transition evidence was found. O'Neill 1993 studied another 
hydrous grossular phase, hibschite $\left(\mathrm{Ca}_{3} \mathrm{Al}_{2}\left(\mathrm{SiO}_{4}\right)_{1.72}\left(\mathrm{H}_{4} \mathrm{O}_{2}\right)\right.$ using Brillouin spectroscopy. Both adiabatic bulk modulus and shear moduli were $40 \%$ lower than anhydrous grossular.

\subsection{Compression behavior in garnet}

Hazen et al. (1994) suggested that the octahedron-tetrahedron framework was the important factor that controls compressibility of garnet. For example, Pyrope is more compressible than the other garnets, such as andradite and grossular, which may be

resulted from less support from a smaller dodecahedra cation $\left(\mathrm{Mg}^{2+}\right)$ for the octahedraltetrahedral framework. In addition, Zhang et al. (1999) pointed out that in similar frameworks presented in almandine, pyrope, grossular and spessartine, and their bulk moduli discrepancies may be due to the different electronic configurations of the dodecahedral cation. However, the dodecahedral site is not the primary factor, which is documented by the bulk modulus of Na-majorite. It incorporates $\mathrm{Na}$ in the dodecahedral site, however, does not have the lowest bulk modulus in the garnets. The valence of the octahedral cation determined the compressibility of garnet. Thus, if pressure is above 9GPa, hydrous pyrope employs another substitution mechanism. OH enters other sites, instead of substituting $\mathrm{SiO}_{4}$ as clusters, and weakens the tetrahedron-octahedron framework. Then, it will not follow the trend of $K_{0}$ as a function of water percentage, where water is calculated based on the $3630 \mathrm{~cm}^{-1} \mathrm{OH}$ stretching peak, which is hydrogarnet substitution $(\mathrm{OH})_{4}=\mathrm{SiO}_{4}$.

\subsection{Comparison with other minerals}

Figure 6.9 shows the bulk modulus plotted as a function of water content in various dry and hydrous minerals, including olivine, ringwoodite, wadsleyite, grossular and pyrope. 
The slopes of the lines indicate the hydration effect on bulk moduli: $2.5 \mathrm{wt} \%$ of water lowers by $10 \%$ of bulk modulus of wadsleyite; $1 \mathrm{wt} \%$ of water reduces the bulk modulus of olivine by $6 \% ; 2.2 \mathrm{wt} \%$ of water in ringwoodite decreases $16 \%$ of bulk modulus. Water content in pyrope is not high, compared with water incorporation levels, such as wadsleylite, $2-3 \mathrm{wt} \%$. The highest water content we obtained is $0.3 \mathrm{wt} \%$ at $12 \mathrm{GPa}$. The slope of pyrope, obtained in this study, however, shows a much stiffer reduction rate, $12 \mathrm{GPa}$ decrease of bulk modulus per $\mathrm{wt} \%$ of water at the water range from $0-0.2 \mathrm{wt} \%$. One possible explanation can be the new substitution mechanism at high pressure in pyrope, which weakens its framework. The evidence that support this statement was the cubic to tetragonal structure change at $12 \mathrm{GPa}$. We also observed new peaks in IR of pyrope synthesized at 9 and $12 \mathrm{GPa}$, which may represent new $\mathrm{OH}$ stretching mode. To verify if the new substitution mechanism employed at the high pressure in pyrope, we need do a micro probe study to confirm the chemical composition of pyrope. If certain atoms are less than the composition ratios, then most likely it is replaced by the $\mathrm{OH}$ hydroxyl. Besides, structure refinement is also needed for the pyrope sample at 12GPa. 


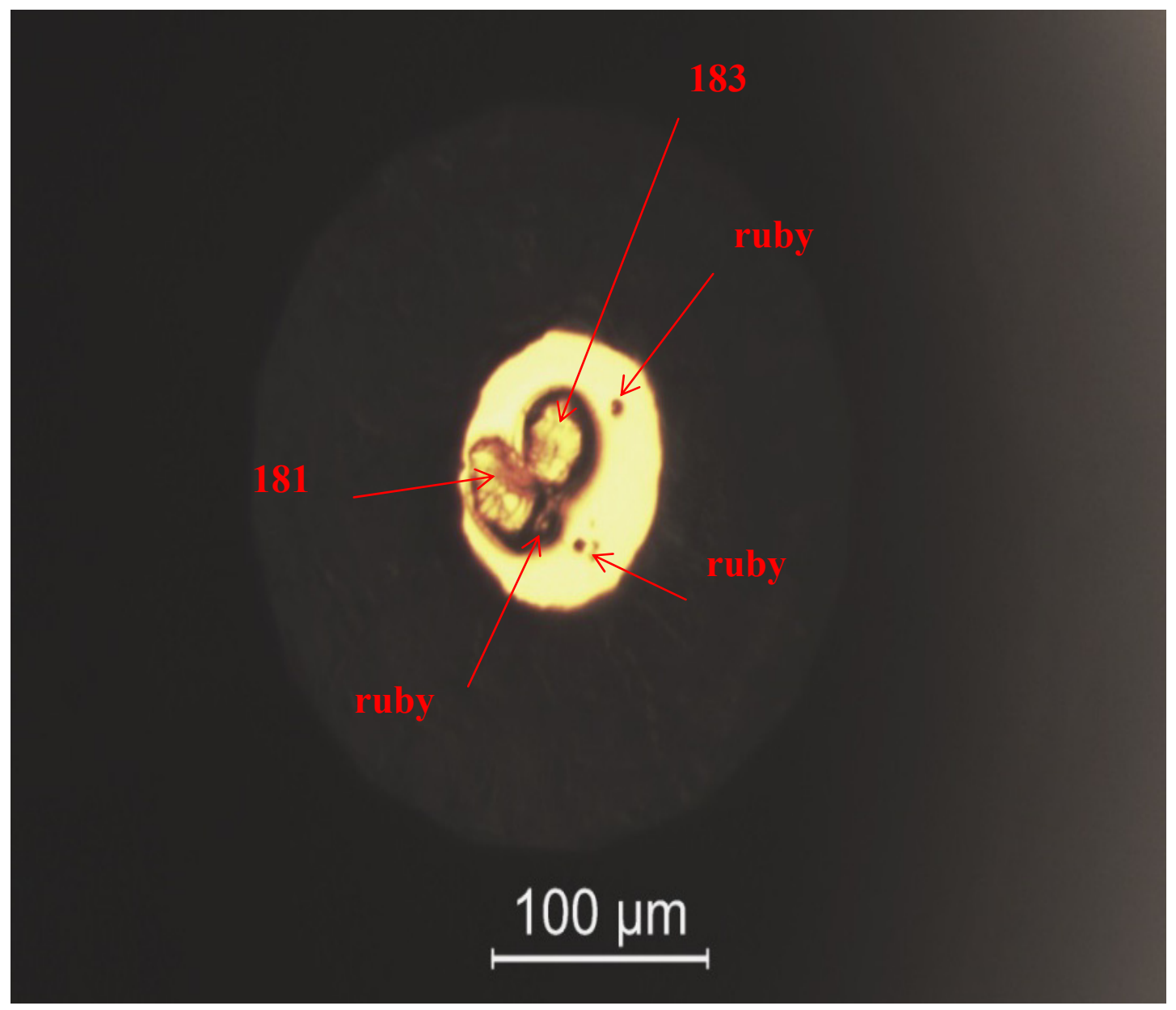

Figure 6.1 Two samples (181and 183) in the DAC sample chamber with ruby sphere 
Table 6.1

Unit cell

parameters

of hydrous

and dry

pyrope

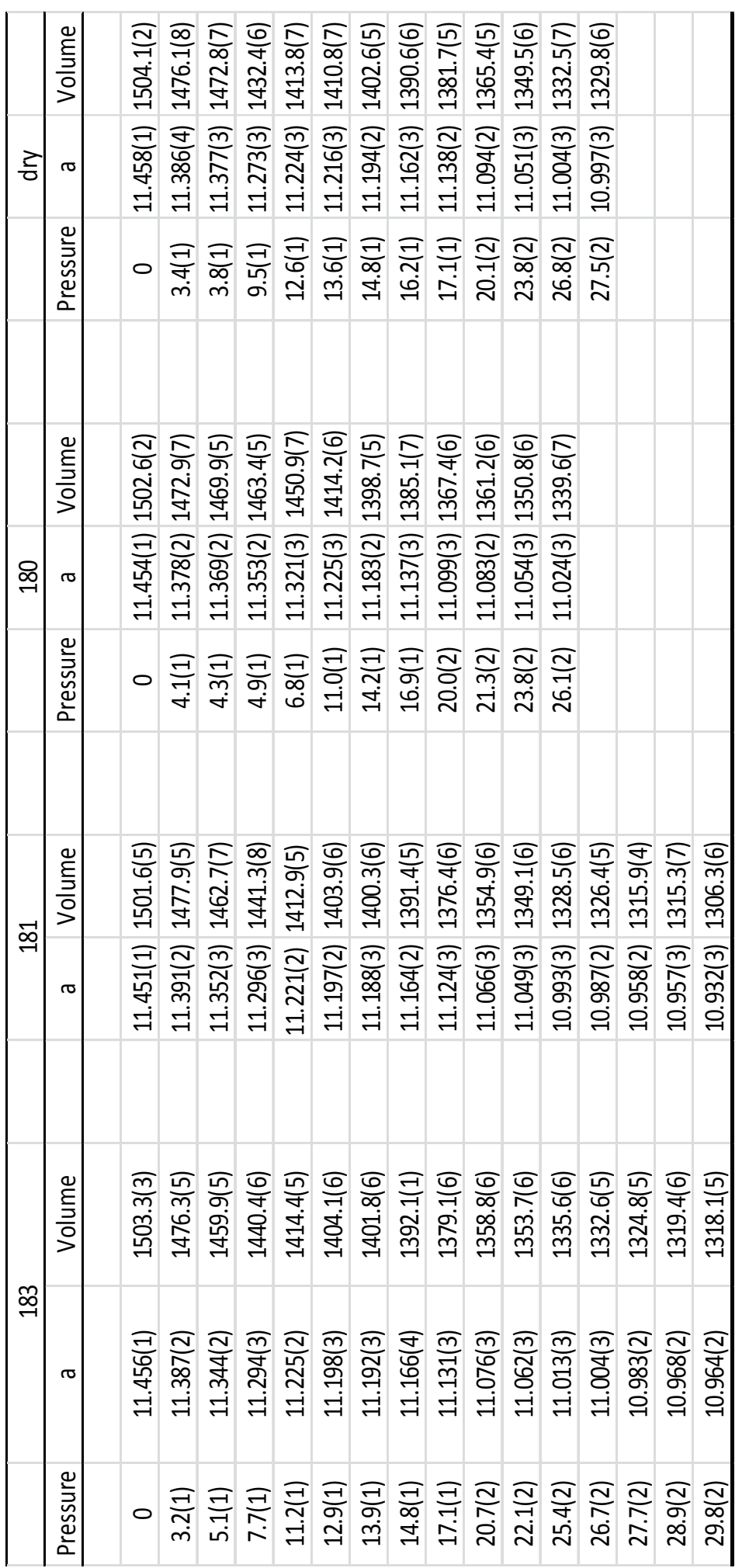


Table 6.2 EOS fitting results of hydrous and dry pyrope (a) all the parameters refined (b) $\mathrm{K}^{\prime}$ fixed at 4.4 and $\mathrm{V}_{0}$ fixed at the measured value.

(a)

\begin{tabular}{cccccc}
\hline Sample \# & Water wt $\%$ & Pressure $(\mathrm{GPa})$ & $\mathrm{V}_{0}\left(\AA^{3}\right)$ & $\mathrm{K}_{0}(\mathrm{GPa})$ & $\mathrm{K}^{\prime}$ \\
\hline dry & 0 & 4 & $1506(2)$ & $172.7(3)$ & 4 \\
180 & 0.1 & 6 & $1502.5(7)$ & $166(6)$ & $5.4(8)$ \\
181 & 0.2 & 7 & $1505(1)$ & $160(2)$ & 4 \\
183 & 0.07 & 9 & $1504(2)$ & $157(6)$ & $5.3(5)$ \\
\hline
\end{tabular}

(b)

\begin{tabular}{cccccc}
\hline Sample \# & Water wt $\%$ & Pressure $(\mathrm{GPa})$ & $\mathrm{V}_{0}\left(\AA^{3}\right)$ & $\mathrm{K}_{0}(\mathrm{GPa})$ & $\mathrm{K}^{\prime}$ \\
\hline dry & 0 & 4 & $1504.1(2)$ & $172(1)$ & 4.4 \\
183 & 0.07 & 9 & $1503.3(3)$ & $166(1)$ & 4.4 \\
180 & 0.1 & 6 & $1502.6(2)$ & $173(2)$ & 4.4 \\
181 & 0.2 & 7 & $1501.6(5)$ & $161(1)$ & 4.4 \\
\hline
\end{tabular}

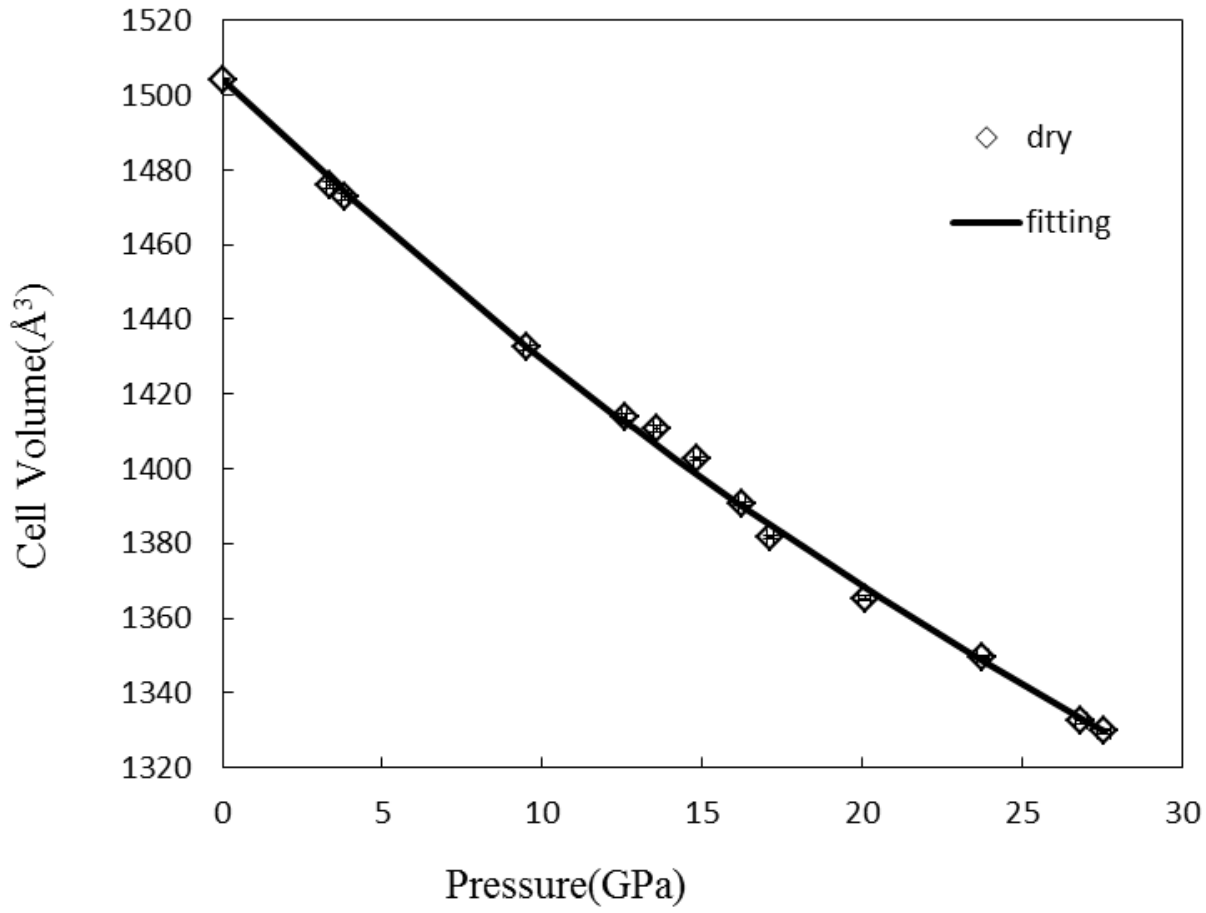

Figure 6.2 Unit cell volume as a function of dry pyrope, error bar is too small 


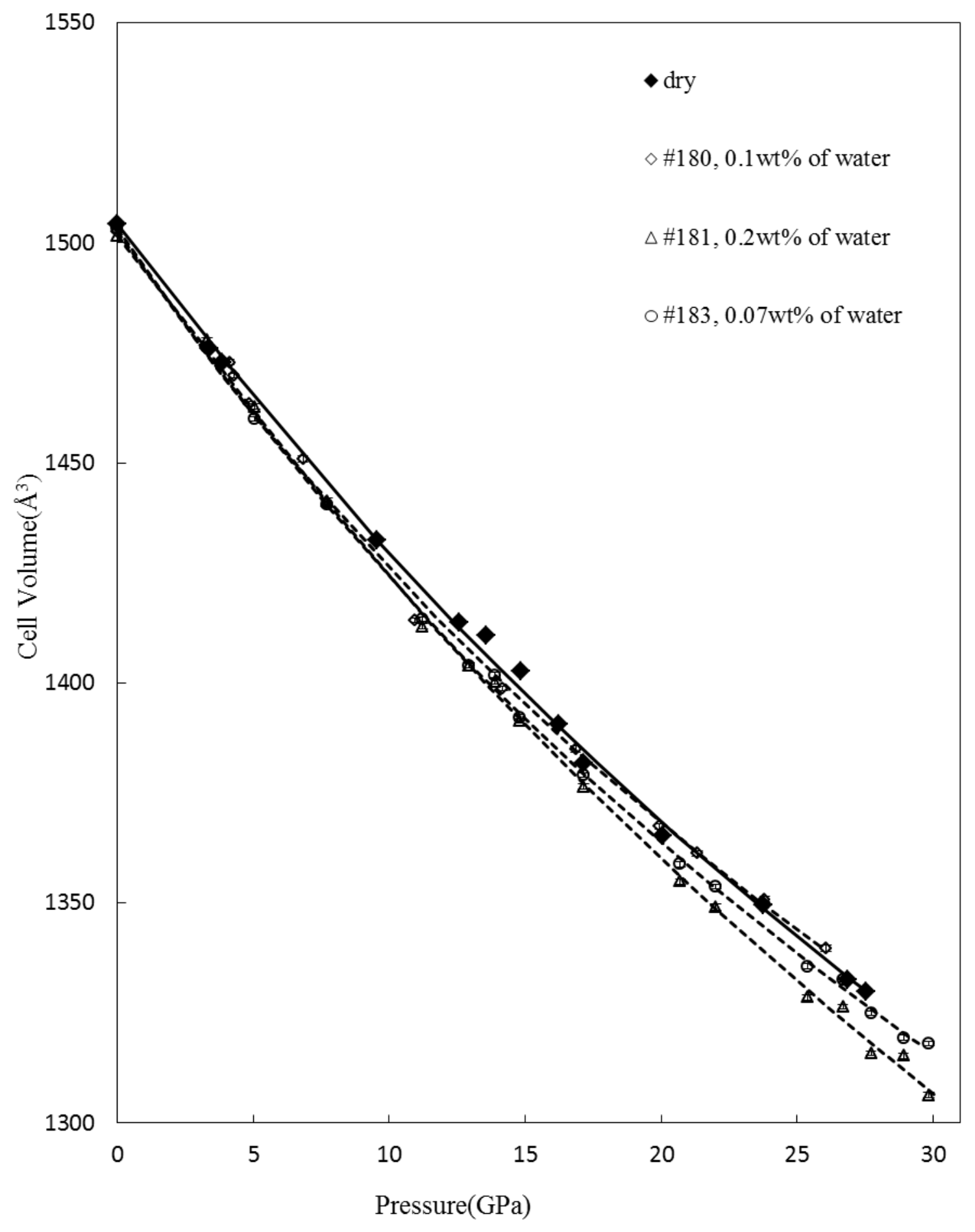


Figure 6.3 Comparison of EOS fitting between dry and hydrous samples. Solid line represents dry pyrope and dash lines are for hydrous samples; error bars are smaller than symbols.
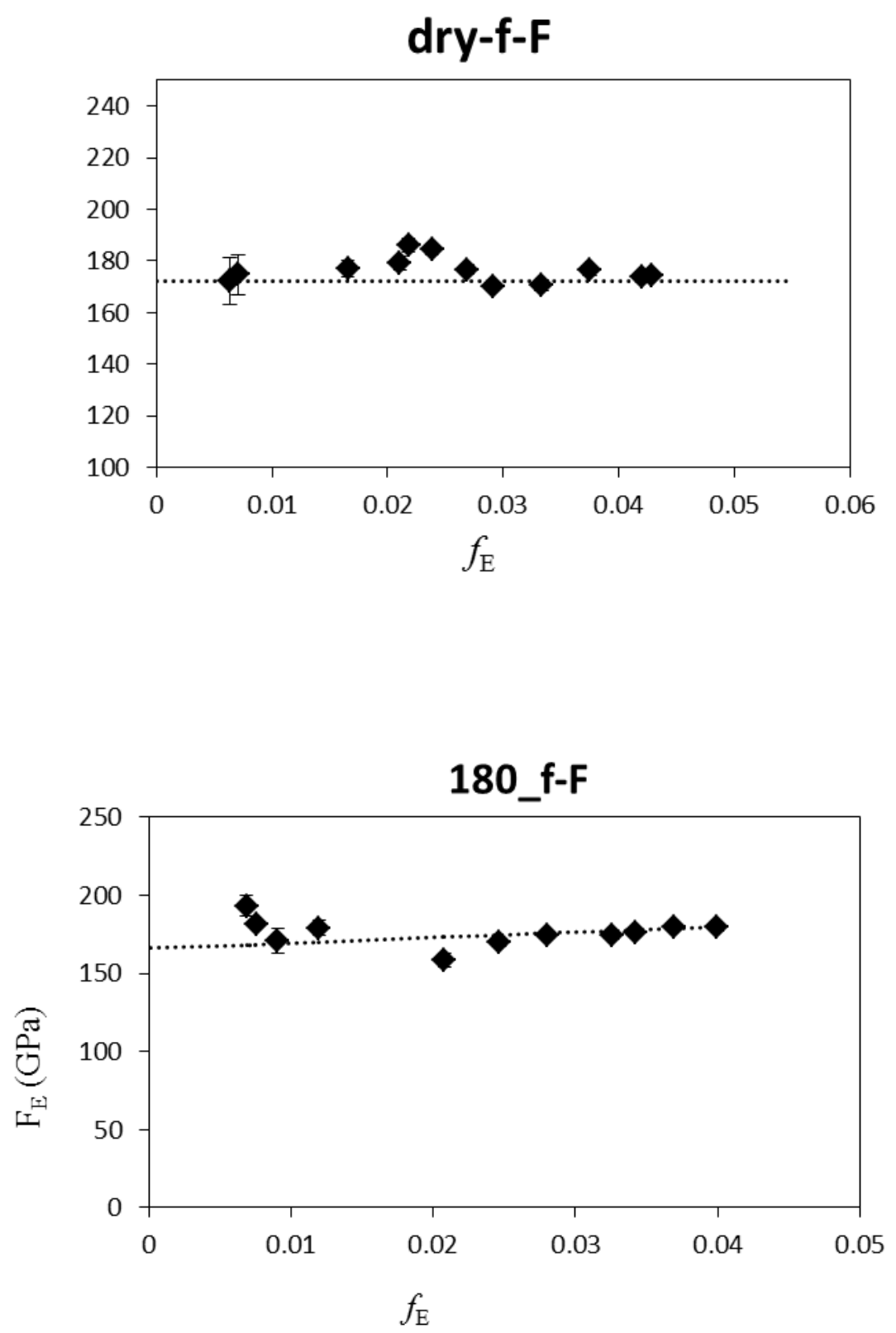


\section{1_f-F}
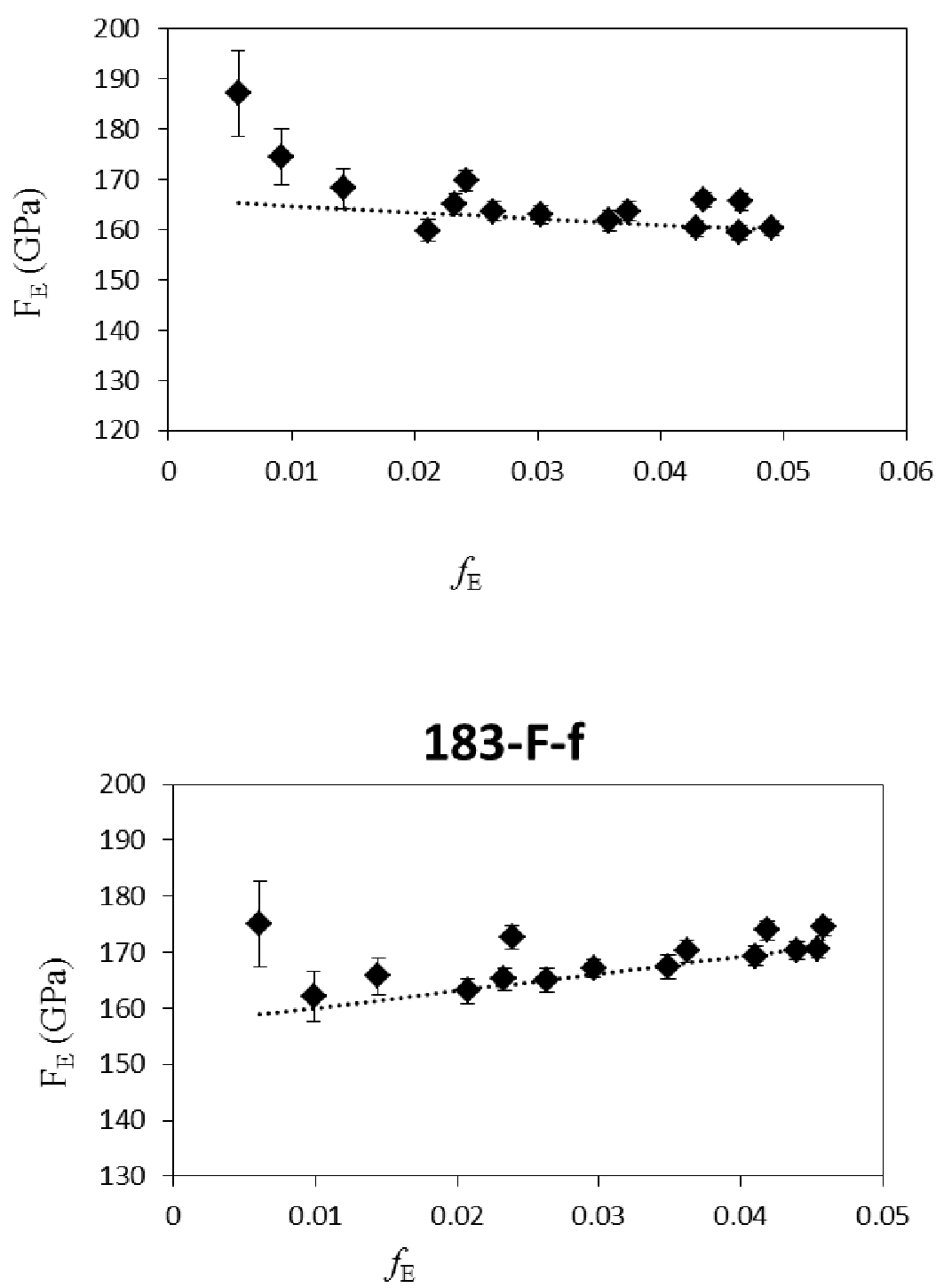

Figure 6.4 Birch-normalized pressure $\left(\mathrm{F}_{\mathrm{E}}\right)$ as a function of Euler finite strain $\left(\mathrm{f}_{\mathrm{E}}\right)$ plots for dry pyrope and hydrous samples $(180,181,183)$. The slope of dash lines represent $\mathrm{K}^{\prime}$ 


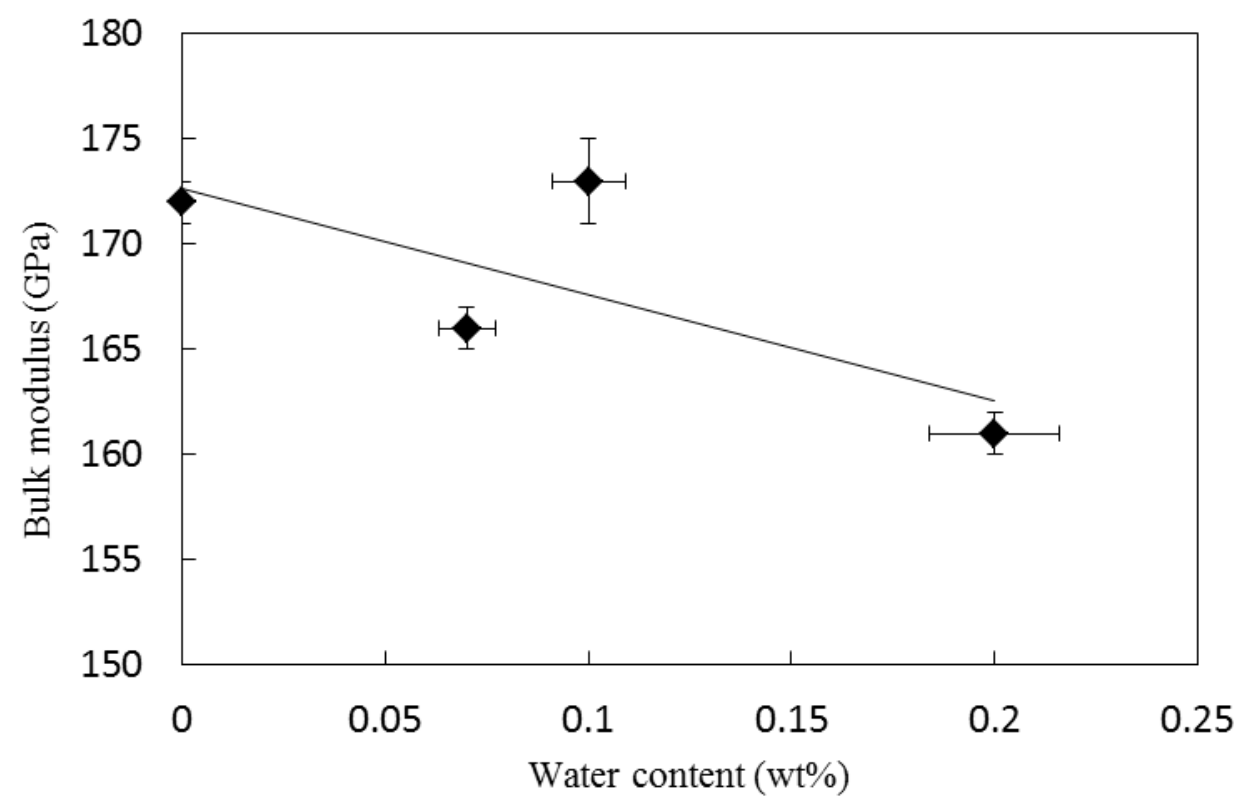

Figure 6.5 Bulk modulus of hydrous pyrope as a function of water content using fitting results at $\mathrm{K}^{\prime}=4.4$

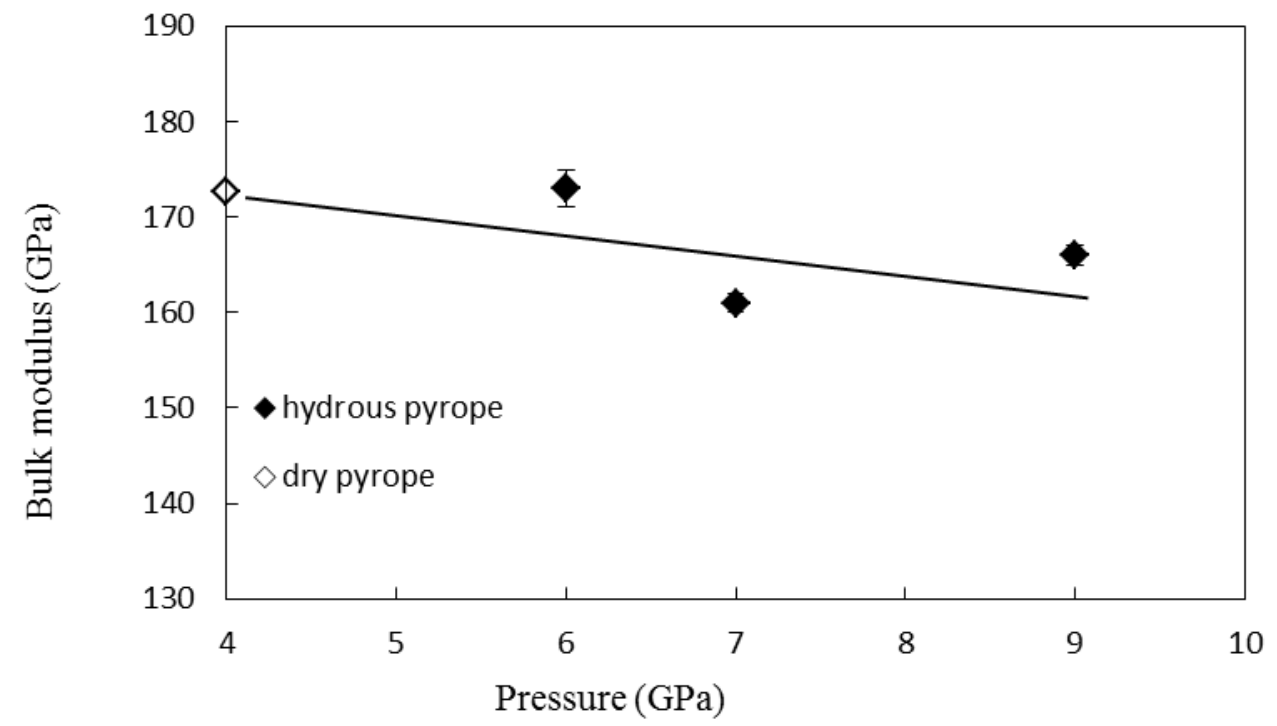

Figure 6.6 Bulk modulus plotted as a function of pressure under water saturated environment. Empty marker is dry pyrope, black marker are hydrous samples 


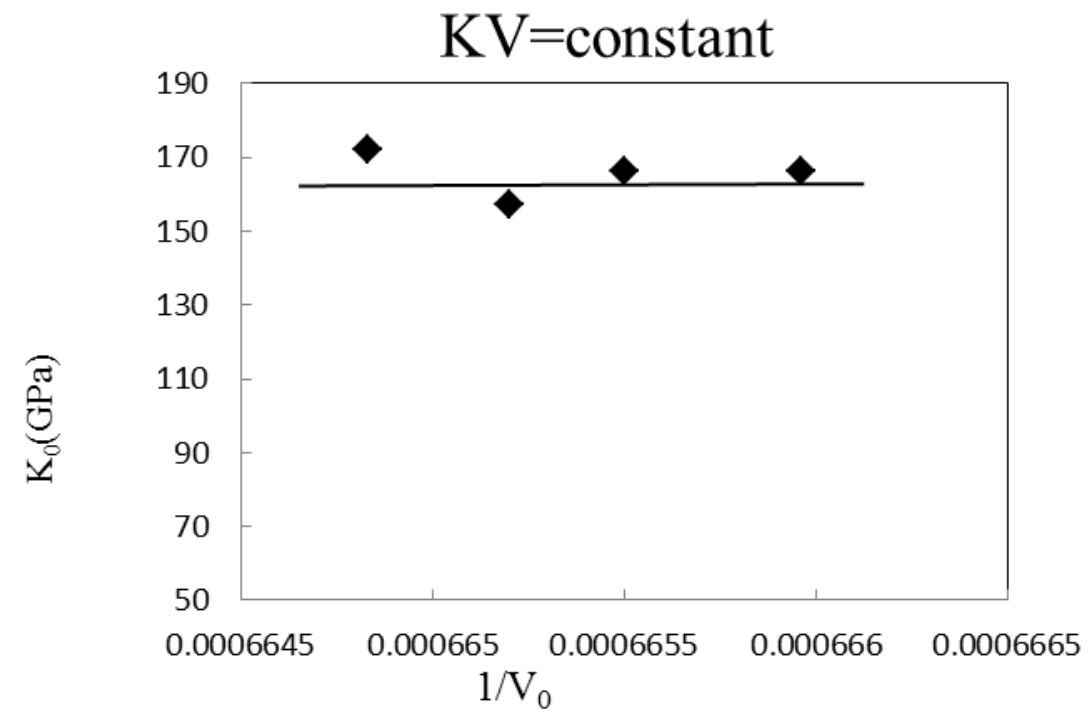

Figure 6.7 Bulk modulus versus $1 / \mathrm{V}_{0}$ for dry and hydrous pyrope

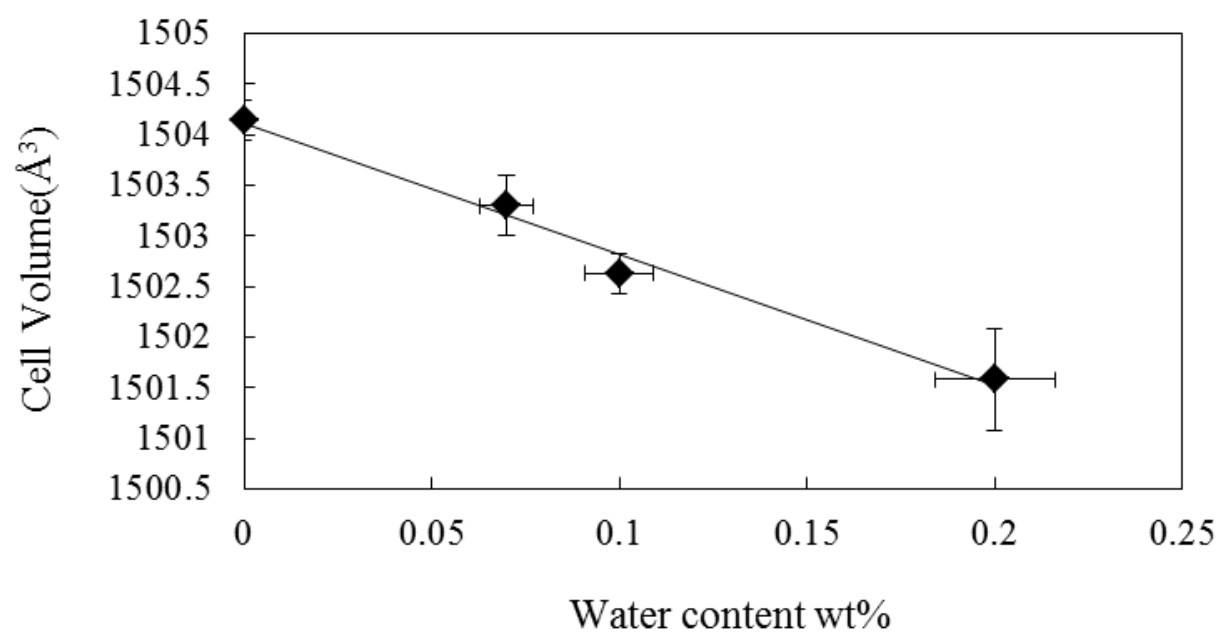

Figure 6.8 Unit cell volume as a function of water content in each sample. 


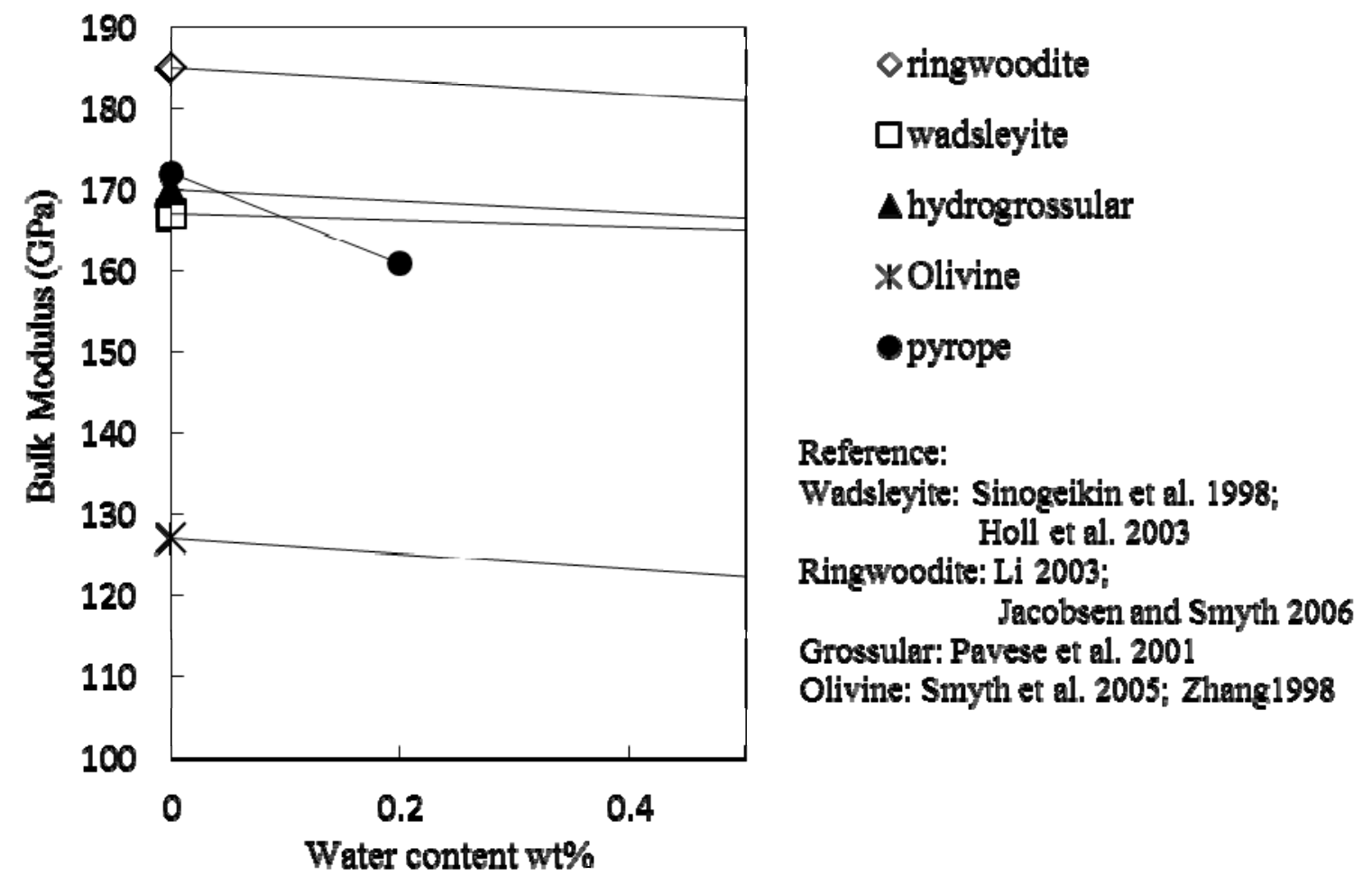

Figure 6.9 Bulk modulus as a function of water content is plotted in various nominally anhydrous minerals. 


\section{Chapter 7}

\section{Summary and further work}

The main goal of this dissertation is to investigate the influence of two factors, chemical composition and water, on the bulk modulus of pyrope. This was done with high-pressure equipment and synchrotron X-ray facilities. Multi-anvil press was used to synthesize all the garnet solid solution samples and hydrous pyrope crystals. Diamond anvil cells were employed for all the bulk moduli measurements with in situ X-ray diffractions in synchrotron.

Mineral physics is essential to analyze seismic velocities from the Earth's interior. The velocities change while travelling through different minerals of various compositions. Pyrope is stable from the mantle to the transition zone with a large volume percentage in the mantle. Because of that, it is of importance in studying seismic velocities in the mantle. In other words, any variation in properties of pyrope will contribute to the seismic velocity changes. The bulk modulus is studied because seismic velocities in minerals are determined by their density and bulk moduli. Therefore, study of seismic velocities in pyrope of various compositions becomes a bulk modulus investigation of pyrope. To determine how chemical compositions of pyrope influence its bulk modulus, one will need pure garnet end member samples and pure solid solutions. Previous research has been done on many natural solid solutions, which are not pure phases and contain a variety of elements. Such data are not good to define a single chemical influence (eg. Fe) on the bulk modulus of pyrope. In the binary systems of pyrope and other end members, such as garnets in the pyrope-majorite join, there are bulk modulus 
data on this join. However, in the pyrope-almandine join, no synthetic solid solution data is available yet. This study was a systematic investigation on the pyrope-almandine binary system. A relation between the bulk modulus and the almandine mole fraction $(n)$ was derived to be $K_{0}=170+15 \mathrm{n}$. We concluded that this system is close to an ideal mixing model, which agrees with Geiger et al., (1997), who studied volume mixing and thermodynamic parameters of garnet in the pyrope-almandine join.

Water has attracted much attention of scientists to study its trace levels in nominally anhydrous minerals; however, there was significant influence in properties. Pyrope is not expected to be a large water carrier in the mantle compared with the other minerals, such as ringwoodite, wadsleyite, which can take a few percentages of water into the structure. Previous studies showed that tenths of $w t \%$ of water can be incorporated into the structure. Due to its low water content, not many experimental data are available in pyrope. We studied pyrope grown at pressures from $4 \mathrm{Gpa}$ to $12 \mathrm{GPa}$ and $1000^{\circ} \mathrm{C}$ under the water-saturated environment. Water solubility was examined as a function of pressure. At $4-7 \mathrm{GPa}$, it increased with pressures and reached a $0.2 \mathrm{wt} \%$ of water content at $7 \mathrm{GPa}$. At $9 \mathrm{GPa}$, water in pyrope dropped to $0.07 \mathrm{wt} \%$. From IR spectra, we observed hydrogarnet substitution from 4-7GPa, which showed a peak at $3630 \mathrm{~cm}^{-1}$. This is the same type of substitution mechanism as in hydrous grossular. At 9 and $12 \mathrm{GPa}$, new peaks appeared at $3572 \mathrm{~cm}^{-1}$ and $3504 \mathrm{~cm}^{-1}$, which indicates that a new substitution mechanism may be employed by hydrous pyrope.

We also observed the water weakening effect on the bulk moduli of pyrope single crystals. The three hydrous pyrope bulk moduli were measured to be $166 \mathrm{GPa}, 173 \mathrm{GPa}$ 
and $161 \mathrm{GPa}$ with water contents of $0.07 \mathrm{wt} \%, 0.1 \mathrm{wt} \%$ and $0.2 \mathrm{wt} \%$, respectively. A trend has been defined for the bulk modulus with water content: $1 \mathrm{wt} \%$ of water lowers $12 \mathrm{GPa}$ of the bulk modulus at the water range $0-0.2 \mathrm{wt} \%$.

The significance of this water effect study is that we observed new OH stretching peaks, which may represent a new substitution mechanism in pyrope, other than hydrogarnet substitution. The other is the bulk modulus reduction by incorporated water, which is more significant than we expected and is supported by a comparative study of two samples with $0.07 \mathrm{wt} \%$ and $0.2 \mathrm{wt} \%$ of water, respectively. The two samples showed a 5GPa bulk modulus difference with the same K'. The cubic to tetragonal structure change also suggests that water incorporation in pyrope is more complicated than hydrogarnet substitution. Water content in pyrope reached the highest solubility $(0.3 \mathrm{wt} \%)$ after structure change. Water may be the cause of this structure change. The tetragonal garnets are not common but do exist in nature. Therefore, further study is planned to characterize the compositions of hydrous pyrope by a micron probe to find out which element is off the nominal composition ratios and is likely to be replaced by the $\mathrm{OH}$ hydroxyl. Besides, a structure refinement of hydrous pyrope at $12 \mathrm{GPa}$ is needed to determine its accurate space group. 


\section{REFERENCES}

Ackermann, L, Cemič, L, \& Langer, K. (1983). Hydrogarnet substitution in pyrope: a possible location for "water" in the mantle. Earth and Planetary Science Letters, 62(2), 208-214.

Allmann, Rudolf, \& Hinek, Roland. (2007). The introduction of structure types into the Inorganic Crystal Structure Database ICSD. Acta Crystallographica Section A: Foundations of Crystallography, 63(5), 412-417.

Anderson, Don L. (1989). Theory of the Earth.

Andrut, Michael, Wildner, Manfred, \& Beran, Anton. (2002). The crystal chemistry of birefringent natural uvarovites. Part IV. OH defect incorporation mechanisms in non-cubic garnets derived from polarized IR spectroscopy. European journal of mineralogy, 14(6), 1019-1026.

Angel, Ross J. (2000). Equations of state. Reviews in mineralogy and geochemistry, 4l(1), $35-59$.

Bell, David R, Ihinger, Phillip D, \& Rossman, George R. (1995). Quantitative analysis of trace $\mathrm{OH}$ in garnet and pyroxenes. American Mineralogist, 80(5), 465-474.

Bell, David R, \& Rossman, George R. (1992). Water in Earth's mantle: The role of nominally anhydrous minerals. Science, 255(5050), 1391-1397.

Bell, David R, Rossman, George R, Maldener, Joachim, Endisch, Denis, \& Rauch, Friedel. (2004). Hydroxide in kyanite: A quantitative determination of the absolute amount and calibration of the IR spectrum. American Mineralogist, 89(7), 998-1003.

Beran, A, Langer, K, \& Andrut, M. (1993). Single crystal infrared spectra in the range of $\mathrm{OH}$ fundamentals of paragenetic garnet, omphacite and kyanite in an eklogitic mantle xenolith. Mineralogy and Petrology, 48(2-4), 257-268.

Chen, Ganglin, Cooke, JA, Gwanmesia, Gabriel D, \& Liebermann, Robert C. (1999). Elastic wave velocities of $\mathrm{Mg}_{3} \mathrm{Al}_{2} \mathrm{Si}_{3} \mathrm{O}_{12}$-pyrope garnet to $10 \mathrm{GPa}$. American Mineralogist, 84, 384-388.

Chen, Jiuhua, Liu, Haozhe, \& Girard, Jennifer. (2011). Comparative in situ X-ray diffraction study of San Carlos olivine: Influence of water on the $410 \mathrm{~km}$ seismic velocity jump in Earth's mantle. American Mineralogist, 96(5-6), 697-702. 
Cho, Herman, \& Rossman, George R. (1993). Single-crystal NMR studies of lowconcentration hydrous species in minerals; grossular garnet. American Mineralogist, 78(11-12), 1149-1164.

Conrad, Pamela G, Zha, Chang-Sheng, Mao, Ho-Kwang, \& Hemley, Russell J. (1999). The high-pressure, single-crystal elasticity of pyrope, grossular, and andradite. American Mineralogist, 84, 374-383.

Dai, Lidong, \& Karato, Shun-ichiro. (2009). Electrical conductivity of pyrope-rich garnet at high temperature and high pressure. Physics of the Earth and Planetary Interiors, 176(1), 83-88.

Dera, Przemyslaw, Zhuravlev, Kirill, Prakapenka, Vitali, Rivers, Mark L, Finkelstein, Gregory J, Grubor-Urosevic, Ognjen, . . . Downs, Robert T. (2013). High pressure single-crystal micro X-ray diffraction analysis with GSE_ADA/RSV software. High Pressure Research(ahead-of-print), 1-19.

Dziewonski, Adam M, \& Anderson, Don L. (1981). Preliminary reference Earth model. Physics of the earth and planetary interiors, 25(4), 297-356.

Fan, Dawei W, Zhou, Wenge G, Liu, Congqiang Q, Liu, Yonggang G, Wan, Fang, Xing, Yinsuo S, . . Xie, Hongsen S. (2009). The thermal equation of state of ( $\mathrm{Fe} 0$. $86 \mathrm{Mg} 0.07 \mathrm{Mn} 0.07) 3 \mathrm{Al} 2 \mathrm{Si} 3 \mathrm{O} 12$ almandine. Mineralogical Magazine, 73(1), 95102.

G.R., Rossman. (1996). Studies of OH in nominally anhydrous minerals. Physics and Chemistry of Minerals, 23(4-5), 299-304.

Geiger, CA, Newton, RC, \& Kleppa, OJ. (1987). Enthalpy of mixing of synthetic almandine-grossular and almandine-pyrope garnets from high-temperature solution calorimetry. Geochimica et Cosmochimica Acta, 51(6), 1755-1763.

Geiger, Charles A. (2013). Garnet: A key phase in nature, the laboratory, and technology. Elements, 9(6), 447-452.

Geiger, Charles A, Dachs, Edgar, \& Benisek, Artur. (2012). Thermodynamic behavior and properties of katoite (hydrogrossular): A calorimetric study. American Mineralogist, 97(7), 1252-1255.

Geiger, Charles A, \& Feenstra, Anne. (1997). Molar volumes of mixing of almandinepyrope and almandine-spessartine garnets and the crystal chemistry and thermodynamic-mixing properties of the aluminosilicate garnets. American Mineralogist, 82(5), 571-581.

Geiger, Charles A, Langer, Klaus, Bell, David R, Rossman, George R, \& Winkler, Bjoern. (1991). The hydroxide component in synthetic pyrope. American Mineralogist, 76(1-2), 49-59. 
Grew, Edward S, Locock, Andrew J, Mills, Stuart J, Galuskina, Irina O, Galuskin, Evgeny V, \& Hålenius, Ulf. (2013). Nomenclature of the garnet supergroup. American Mineralogist, 98(4), 785-811.

Gwanmesia, G, Liu, J, Chen, G, Kesson, S, Rigden, SM, \& Liebermann, RC. (2000). Elasticity of the pyrope (Mg3Al2Si3O12)-majorite (MgSiO3) garnets solid solution. Physics and Chemistry of Minerals, 27(7), 445-452.

Gwanmesia, G, Wang, Liping, Triplett, Richard, \& Liebermann, Robert C. (2009). Pressure and temperature dependence of the elasticity of pyrope-majorite $\left[\mathrm{Py}_{60} \mathrm{Mj}_{40}\right.$ and $\left.\mathrm{Py}_{50} \mathrm{Mj}_{50}\right]$ garnets solid solution measured by ultrasonic interferometry technique. Physics of the Earth and Planetary Interiors, 174, 105112.

Harris, Jeff, Hutchison, Mark T, Hursthouse, Mike, Light, Mark, \& Harte, Ben. (1997). A new tetragonal silicate mineral occurring as inclusions in lower-mantle diamonds. Nature, 387(6632), 486-488.

Hazen, RM, Downs, RT, Conrad, PG, Finger, LW, \& Gasparik, T. (1994). Comparative compressibilities of majorite-type garnets. Physics and Chemistry of Minerals, 21(5), 344-349.

Holl, Christopher M, Smyth, Joseph R, Jacobsen, Steven D, \& Frost, Daniel J. (2008). Effects of hydration on the structure and compressibility of wadsleyite, $\beta$ $\left(\mathrm{Mg}_{2} \mathrm{SiO}_{4}\right)$. American Mineralogist, 93(4), 598-607.

Hong, Xinguo, Chen, Zhiqiang, \& Duffy, Thomas S. (2012). Absolute X-ray energy calibration over a wide energy range using a diffraction-based iterative method. Review of Scientific Instruments, 83(6), 063901-063901-063910.

Hunter, BA. (1997). Rietica for Windows v. 1.7. 7. ANSTO, Sydney, Australia.

Irifune, T, Sekine, T, Ringwood, AE, \& Hibberson, WO. (1986). The eclogite-garnetite transformation at high pressure and some geophysical implications. Earth and Planetary Science Letters, 77(2), 245-256.

Ita, Joel, \& Stixrude, Lars. (1992). Petrology, elasticity, and composition of the mantle transition zone. Journal of Geophysical Research: Solid Earth (1978-2012), 97(B5), 6849-6866.

Jacobsen, Steven D. (2006). Effect of water on the equation of state of nominally anhydrous minerals. Reviews in mineralogy and geochemistry, 62(1), 321-342. 
Jacobsen, Steven D, Jiang, Fuming, Mao, Zhu, Duffy, Thomas S, Smyth, Joseph R, Holl, Christopher M, \& Frost, Daniel J. (2008). Effects of hydration on the elastic properties of olivine. Geophysical Research Letters, 35(14).

Jiang, Fuming, Speziale, Sergio, \& Duffy, Thomas S. (2004). Single-crystal elasticity of grossular-and almandine-rich garnets to $11 \mathrm{GPa}$ by Brillouin scattering. Journal of Geophysical Research: Solid Earth (1978-2012), 109(B10).

Johnson, Elizabeth A, \& Rossman, George R. (2004). A survey of hydrous species and concentrations in igneous feldspars. American Mineralogist, 89(4), 586-600.

Kantor, I, Prakapenka, V, Kantor, A, Dera, P, Kurnosov, A, Sinogeikin, S, . . . Dubrovinsky, L. (2012). BX90: A new diamond anvil cell design for X-ray diffraction and optical measurements. Review of Scientific Instruments, 83(12), 125102-125102-125106.

Katayama, Ikuo, Nakashima, Satoru, \& Yurimoto, Hisayoshi. (2006). Water content in natural eclogite and implication for water transport into the deep upper mantle. Lithos, 86(3), 245-259.

Kennett, BLN, Engdahl, ER, \& Buland, R. (1995). Constraints on seismic velocities in the Earth from traveltimes. Geophysical Journal International, 122(1), 108-124.

Keppler, Hans, \& Bolfan-Casanova, Nathalie. (2006). Thermodynamics of water solubility and partitioning. Reviews in mineralogy and geochemistry, 62(1), 193230.

Khomenko, VM, Langer, K, Beran, A, Koch-Müller, M, \& Fehr, T. (1994). Titanium substitution and $\mathrm{OH}$-bearing defects in hydrothermally grown pyrope crystals. Physics and chemistry of minerals, 20(7), 483-488.

Kudoh, Y, Kuribayashi, T, Mizobata, H, \& Ohtani, E. (2000). Structure and cation disorder of hydrous ringwoodite, $\gamma-\mathrm{Mg}_{1 .}{ }_{89} \mathrm{Si}_{0 .}{ }_{98} \mathrm{H}_{0 .}{ }_{30} \mathrm{O}_{4}$. Physics and Chemistry of Minerals, 27(7), 474-479.

Lager, GA, Armbruster, Thomas, \& Faber, J. (1987). Neutron and X-ray diffraction study of hydrogarnet Ca 3 Al 2 (O 4 H 4) 3. American Mineralogist, 72(7-8), 756-765.

Lager, George A, Downs, Robert T, Origlieri, Marcus, \& Garoutte, Rebecca. (2002). High-pressure single-crystal X-ray diffraction study of katoite hydrogarnet: Evidence for a phase transition from Ia3d $\rightarrow$ I $\overline{43} \mathrm{~d}$ symmetry at $5 \mathrm{GPa}$. American Mineralogist, 87(5-6), 642-647.

Lager, George A, Marshall, William G, Liu, Zhenxian, \& Downs, Robert T. (2005). Reexamination of the hydrogarnet structure at high pressure using neutron powder diffraction and infrared spectroscopy. American Mineralogist, 90(4), 639-644. 
Leger, JM, Redon, AM, \& Chateau, C. (1990). Compressions of synthetic pyrope, spessartine and uvarovite garnets up to $25 \mathrm{GPa}$. Physics and Chemistry of Minerals, 17(2), 161-167.

Li, Li, Brodholt, John, \& Alfè, Dario. (2009). Structure and elasticity of hydrous ringwoodite: A first principle investigation. Physics of the Earth and Planetary Interiors, 177(3), 103-115.

Li, Li, Weidner, Donald J, Brodholt, John, Alfè, Dario, \& Price, G David. (2011). Ab initio molecular dynamic simulation on the elasticity of $\mathrm{Mg} 3 \mathrm{Al} 2 \mathrm{Si} 3 \mathrm{O} 12$ pyrope. Journal of Earth Science, 22(2), 169-175.

Libowitzky, Eugen, \& Beran, Anton. (2006). The structure of hydrous species in nominally anhydrous minerals: information from polarized IR spectroscopy. Reviews in mineralogy and geochemistry, 62(1), 29-52.

Lu, Ren, \& Keppler, Hans. (1997). Water solubility in pyrope to 100 kbar. Contributions to Mineralogy and Petrology, 129(1), 35-42.

Manghnani, MH, Amulele, G, Smyth, JR, Holl, CM, Chen, G, Prakapenka, V, \& Frost, DJ. (2005). Equation of state of hydrous Fo90 ringwoodite to $45 \mathrm{GPa}$ by synchrotron powder diffraction. Mineralogical Magazine, 69(3), 317-323.

Mao, HK, Xu, J-A, \& Bell, PM. (1986). Calibration of the ruby pressure gauge to 800 kbar under quasi-hydrostatic conditions. Journal of Geophysical Research: Solid Earth (1978-2012), 91(B5), 4673-4676.

Mao, Z, Jacobsen, SD, Jiang, F, Smyth, JR, Holl, CM, \& Duffy, TS. (2008). Elasticity of hydrous wadsleyite to $12 \mathrm{GPa}$ : Implications for Earth's transition zone. Geophysical Research Letters, 35(21).

Mao, Z, Jacobsen, SD, Jiang, F, Smyth, JR, Holl, CM, Frost, DJ, \& Duffy, TS. (2010). Velocity crossover between hydrous and anhydrous forsterite at high pressures. Earth and Planetary Science Letters, 293(3), 250-258.

Maruyama, Shigenori, Isozaki, Y, Nakashima, S, \& Windley, BF. (2001). History of the Earth and life. Geochemistry and the origin of life, Universal Academic Press, Tokyo, Japan, 285-325.

Matsyuk, SS, Langer, K, \& Hösch, A. (1998). Hydroxyl defects in garnets from mantle xenoliths in kimberlites of the Siberian platform. Contributions to Mineralogy and Petrology, 132(2), 163-179. 
Mei, S, \& Kohlstedt, DL. (2000). Influence of water on plastic deformation of olivine aggregates: 2. Dislocation creep regime. Journal of Geophysical Research: Solid Earth (1978-2012), 105(B9), 21471-21481.

Mierdel, Katrin, Keppler, Hans, Smyth, Joseph R, \& Langenhorst, Falko. (2007). Water solubility in aluminous orthopyroxene and the origin of Earth's asthenosphere. Science, 315(5810), 364-368.

Mookherjee, Mainak, \& Karato, Shun-ichiro. (2010). Solubility of water in pyrope-rich garnet at high pressures and temperature. Geophysical Research Letters, 37(3), L03310.

Nishihara, Yu, Aoki, Ichiro, Takahashi, Eiichi, Matsukage, Kyoko N, \& Funakoshi, Kenichi. (2005). Thermal equation of state of majorite with MORB composition. Physics of the Earth and Planetary Interiors, 148(1), 73-84.

Ohtani, Eiji. (2005). Water in the mantle. Elements, 1(1), 25-30.

Ohtani, Eiji, Litasov, Konstantin, Hosoya, Tomofumi, Kubo, Tomoaki, \& Kondo, Tadashi. (2004). Water transport into the deep mantle and formation of a hydrous transition zone. Physics of the Earth and Planetary Interiors, 143, 255-269.

Olijnyk, H, Paris, E, Geiger, CA, \& Lager, GA. (1991). Compressional study of katoite [Ca3Al2 (O4H4) 3] and grossular garnet. Journal of Geophysical Research: Solid Earth (1978-2012), 96(B9), 14313-14318.

O'Neill, Bridget, Bass, Jay D, \& Rossman, George R. (1993). Elastic properties of hydrogrossular garnet and implications for water in the upper mantle. Journal of Geophysical Research: Solid Earth (1978-2012), 98(B11), 20031-20037.

O'Neill, Bridget, Bass, Jay D, Rossman, George R, Geiger, Charles A, \& Langer, Klaus. (1991). Elastic properties of pyrope. Physics and Chemistry of Minerals, 17(7), 617-621.

O'Neill, Bridget, Bass, Jay D, Smyth, Joe R, \& Vaughan, Michael T. (1989). Elasticity of a grossular-pyrope-almandine garnet. Journal of Geophysical Research, 94(B12), $17819-17817,17824$.

Orlando, R, Torres, FJ, Pascale, F, Ugliengo, P, Zicovich-Wilson, C, \& Dovesi, R. (2006). Vibrational spectrum of katoite $\mathrm{Ca}_{3} \mathrm{Al}_{2}\left[(\mathrm{OH})_{4}\right]_{3}$ : a periodic ab initio study. The Journal of Physical Chemistry B, 110(2), 692-701.

Paterson, MS. (1982). The determination of hydroxyl by infrared-absorption in quartz, silicate-glasses and similar materials. Bulletin de Minéralogie, 105(1), 20-29. 
Peacock, Simon A. (1990). Fluid processes in subduction zones. Science, 248(4953), 329-337.

Rauch, Markus, \& Keppler, Hans. (2002). Water solubility in orthopyroxene. Contributions to Mineralogy and Petrology, 143(5), 525-536.

Ricolleau, Angèle, Perrillat, Jean-Philippe, Fiquet, Guillaume, Daniel, Isabelle, Matas, Jan, Addad, Ahmed, ... Guignot, Nicolas. (2010). Phase relations and equation of state of a natural MORB: Implications for the density profile of subducted oceanic crust in the Earth's lower mantle. Journal of Geophysical Research: Solid Earth (1978-2012), 115(B8).

Rigden, Sally M, Gwanmesia, Gabriel D, \& Liebermann, Robert C. (1994). Elastic wave velocities of a pyrope-majorite garnet to $3 \mathrm{GPa}$. Physics of the Earth and Planetary Interiors, 86(1), 35-44.

Ringwood, AE. (1991). Phase transformations and their bearing on the constitution and dynamics of the mantle. Geochimica et Cosmochimica Acta, 55(8), 2083-2110.

Ringwood, AE, \& Green, DH. (1966). An experimental investigation of the gabbroeclogite transformation and some geophysical implications. Tectonophysics, 3(5), $383-427$.

Ross, NL, \& Chaplin, TD. (2003). Compressibility of $\mathrm{CaZrO}<\mathrm{sub}>3</ \mathrm{sub}>$ perovskite: Comparison with Ca-oxide perovskites. Journal of Solid State Chemistry, 172(1), $123-126$.

Rossman, George R. (1996). Studies of OH in nominally anhydrous minerals. Physics and Chemistry of Minerals, 23(4-5), 299-304.

Rossman, George R. (2006). Analytical methods for measuring water in nominally anhydrous minerals. Reviews in mineralogy and geochemistry, 62(1), 1-28.

Rossman, George R, \& Aines, Roger D. (1991). The hydrous components in garnets; grossular-hydrogrossular. American Mineralogist, 76(7-8), 1153-1164.

Shen, Yongrong, Kumar, Ravhi S, Pravica, Michael, \& Nicol, Malcolm F. (2004). Characteristics of silicone fluid as a pressure transmitting medium in diamond anvil cells. Review of scientific instruments, 75(11), 4450-4454.

Sinogeikin, Stanislav V, \& Bass, Jay D. (2000). Single-crystal elasticity of pyrope and $\mathrm{MgO}$ to $20 \mathrm{GPa}$ by Brillouin scattering in the diamond cell. Physics of the Earth and Planetary Interiors, 120(1), 43-62. 
Sinogeikin, Stanislav V, \& Bass, Jay D. (2002). Elasticity of pyrope and majorite-pyrope solid solutions to high temperatures. Earth and Planetary Science Letters, 203(1), $549-555$.

Sinogeikin, Stanislav V, Bass, Jay D, \& Katsura, Tomoo. (2003). Single-crystal elasticity of ringwoodite to high pressures and high temperatures: implications for $520 \mathrm{~km}$ seismic discontinuity. Physics of the Earth and Planetary Interiors, 136(1), 41-66.

Smyth, Joseph R. (1987). 0-Mg2SiO4: A potential host for water in the mantle? American Mineralogist, 72, 1051-1055.

Smyth, Joseph R, Holl, Christopher M, Frost, Daniel J, Jacobsen, Steven D, Langenhorst, Falko, \& Mccammon, Catherine A. (2003). Structural systematics of hydrous ringwoodite and water in Earth's interior. American Mineralogist, 88(10), 14021407.

Suzuki, Isao, \& Anderson, Orson L. (1983). Elasticity and thermal expansion of a natural garnet up to 1,000 K. Journal of Physics of the Earth, 31(2), 125-138.

Sykes, Dan, Rossman, George R, Veblen, David R, \& Grew, Edward S. (1994). Enhanced $\mathrm{H}$ and $\mathrm{F}$ incorporation in borian olivine. American Mineralogist, 79(910), 904-908.

Takahashi, Taro, \& Liu, Lin-Gun. (1970). Compression of ferromagnesian garnets and the effect of solid solutions on the bulk modulus. Journal of Geophysical Research, 75(29), 5757-5766.

Wang, Jingyun, Sinogeikin, Stanislav V, Inoue, Toru, \& Bass, Jay D. (2003). Elastic properties of hydrous ringwoodite. American Mineralogist, 88(10), 1608-1611.

Wang, Liping, Zhang, Youxue, \& Essene, Eric J. (1996). Diffusion of the hydrous component in pyrope. American Mineralogist, 81(5), 706-718.

Wang, Yanbin, Weidner, Donald J, Zhang, Jianzhong, Gwanrnesia, Gabriel D, \& Liebermann, Robert C. (1998). Thermal equation of state of garnets along the pyrope-majorite join. Physics of the Earth and Planetary Interiors, 105(1), 59-71.

Wang, Zichao, \& Ji, Shaocheng. (2001). Elasticity of six polycrystalline silicate garnets at pressure up to 3.0 GPa. American Mineralogist, 86(10), 1209-1218.

Williams, Quentin, \& Hemley, Russell J. (2001). Hydrogen in the deep Earth. Annual Review of Earth and Planetary Sciences, 29(1), 365-418.

Withers, Anthony C, Wood, Bernard J, \& Carroll, Michael R. (1998). The OH content of pyrope at high pressure. Chemical Geology, 147(1-2), 161-171. 
Wood, Bernard J, Kiseeva, Ekaterina S, \& Matzen, Andrew K. (2013). Garnet in the Earth's Mantle. Elements, 9(6), 421-426.

Xu, Lili, Mei, Shenghua, Dixon, Nathaniel, Jin, Zhenmin, Suzuki, Ayako M, \& Kohlstedt, David L. (2013). Effect of water on rheological properties of garnet at high temperatures and pressures. Earth and Planetary Science Letters, 379, 158-165.

Yagi, T, Akaogi, M, Shimomura, Osamu, Tamai, Hiroshi, \& Akimoto, Syun-iti. (1987). High pressure and high temperature equations of state of majorite. High-Pressure Research in Mineral Physics, Geophys. Monogr. Ser, 39, 141-147.

Yagi, T, Uchiyama, Y, Akaogi, M, \& Ito, E. (1992). Isothermal compression curve of $\mathrm{MgSiO}<\mathrm{sub}>3</$ sub $>$ tetragonal garnet. Physics of the Earth and Planetary Interiors, 74(1), 1-7.

Zhang, Li, Ahsbahs, H, \& Kutoglu, A. (1998). Hydrostatic compression and crystal structure of pyrope to $33 \mathrm{GPa}$. Physics and Chemistry of Minerals, 25(4), 301-307.

Zhang, Li, Ahsbahs, H, Kutoglu, A, \& Geiger, CA. (1999). Single-crystal hydrostatic compression of synthetic pyrope, almandine, spessartine, grossular and andradite garnets at high pressures. Physics and Chemistry of Minerals, 27(1), 52-58.

Zou, Yongtao, Gréaux, Steeve, Irifune, Tetsuo, Whitaker, Matthew L, Shinmei, Toru, \& Higo, Yuji. (2012). Thermal equation of state of Mg3Al2Si3O12 pyrope garnet up to $19 \mathrm{GPa}$ and 1,700 K. Physics and Chemistry of Minerals, 39(7), 589-598. 


\section{APPENDICES}

Appendix 1: Crust and upper mantle of PREM including directional velocities, anisotropic elastic constants and equivalent isotropic velocities.

Appendix 2: Elastic properties of mantle minerals (Duffy and Anderson, 1988)

The two tables are cited from the book:

Anderson, Don L. Theory of the Earth. Boston: Blackwell Scientific Publications, 1989. http://resolver.caltech.edu/CaltechBOOK:1989.001 
Appendix 1: Crust and upper mantle of PREM including directional velocities, anisotropic elastic constants and equivalent isotropic velocities.

Crust and Upper Mantle of PREM Including Directional Velocities, Anisotropic Elastic

Constants and "Equivalent" Isotropic Velocities. Evaluated at Reference Periods

of $1 \mathrm{~s}$ (top) and $200 \mathrm{~s}$ (bottom).

\begin{tabular}{|c|c|c|c|c|c|c|c|c|c|c|c|c|c|c|c|c|}
\hline $\begin{array}{l}\text { Radius } \\
(\mathbf{k m})\end{array}$ & $\begin{array}{l}\text { Depth } \\
(\mathrm{km})\end{array}$ & $\begin{array}{l}\text { Density } \\
\left(\mathrm{g} / \mathrm{cm}^{3}\right)\end{array}$ & $\begin{array}{c}V_{P V} \\
(\mathrm{~km} / \mathrm{s})\end{array}$ & $\begin{array}{c}V_{P H} \\
(\mathrm{~km} / \mathrm{s})\end{array}$ & $\begin{array}{c}V_{S V} \\
(\mathbf{k m} / \mathbf{s})\end{array}$ & $\begin{array}{c}V_{S H} \\
(\mathrm{~km} / \mathrm{s})\end{array}$ & $\eta$ & $Q_{\bar{\mu}}$ & $Q_{\mathrm{K}}$ & $\begin{array}{c}A \\
\text { (kbar) }\end{array}$ & $\begin{array}{c}C \\
\text { (kbar) }\end{array}$ & $\begin{array}{c}L \\
\text { (kbar)( }\end{array}$ & N & $\begin{array}{c}F \\
\text { (kbar) }\end{array}$ & $\begin{array}{c}V_{\mathrm{p}} \\
(\mathrm{km} / \mathrm{s})\end{array}$ & $\begin{array}{c}V_{\mathrm{s}} \\
(\mathrm{km} / \mathrm{s})\end{array}$ \\
\hline 6151.0 & 220.0 & 3.35950 & 7.80050 & 8.04862 & 4.44110 & 4.43629 & 0.97654 & 80 & 57822 & 2176 & 2044 & 663 & 661 & 831 & 7.98970 & 4.41885 \\
\hline 6171.0 & 200.0 & 3.36167 & 7.82315 & 8.06310 & 4.43649 & 4.45423 & 0.96877 & 80 & 57822 & 2186 & 2057 & 662 & 667 & 835 & 8.00235 & 4.42580 \\
\hline 6191.0 & 180.0 & 36384 & .84581 & 8.07760 & 4,43189 & 4.47218 & 0.96099 & 80 & 57822 & 2195 & 2071 & 661 & 673 & 839 & 8.01494 & 4.43285 \\
\hline 6211.0 & 160.0 & 3.36602 & 7.86847 & 8.09209 & 4.42728 & 4.49013 & 0.95321 & 80 & 57822 & 2204 & 2084 & 660 & 679 & 843 & 8.02747 & 4.44000 \\
\hline 6231.0 & 140.0 & .36819 & 7.89113 & 8.10659 & 4.42267 & 4.50807 & 0.94543 & 80 & 57822 & 2213 & 2097 & 659 & 685 & 847 & 8.03992 & 4.44724 \\
\hline 6251.0 & 120.0 & 3.37036 & 7.91378 & 8.12108 & 4.41806 & 4.52602 & 0.93765 & 80 & 57822 & 2223 & 2111 & 658 & 690 & 851 & 8.05231 & 4.45458 \\
\hline 6271.0 & 100.0 & 3.37254 & 7.93644 & 8.13558 & 4.41345 & 4.54397 & 0.92987 & 80 & 57822 & 2232 & 2124 & 657 & 696 & 854 & 8.06463 & 4.46201 \\
\hline 6291.0 & 80.0 & .37471 & 7.95909 & 8.15006 & 4.40885 & 4.56191 & 0.92210 & 80 & 57822 & 2242 & 2138 & 656 & 702 & 857 & 8.07688 & 4.46953 \\
\hline 6291.0 & 80.0 & 3.37471 & 7.95911 & 8.150 & 4.4 & 4.56193 & 0.92209 & 600 & 57822 & 2242 & 2138 & 656 & 702 & 857 & 8.07689 & 4.46954 \\
\hline 6311.0 & 60.0 & 37688 & 7.98176 & 8.16 & & 887 & 0.91432 & 600 & 57822 & 2251 & 2151 & 655 & 708 & 860 & 8.08907 & 4.47715 \\
\hline 6331.0 & 40.0 & 3.37906 & 8.00442 & 8.17906 & 4.39963 & 4.59782 & 0.90654 & 600 & 57822 & 2260 & 2165 & 654 & 714 & 863 & 8.10119 & 4.48486 \\
\hline 6346.6 & 24.4 & .38076 & 8.02212 & 8.19038 & 603 & 4.61184 & 0.90047 & 600 & 57822 & 2268 & 2176 & 653 & 719 & 866 & 8.11061 & 4.49094 \\
\hline 6346.6 & 24,4 & 90000 & 6.80000 & 6.80 & 000 & 3.90000 & 000 & 600 & 57822 & 1341 & 1341 & 441 & 441 & 459 & 6.80000 & 3.90000 \\
\hline 6356.0 & 15.0 & 2.90000 & 6.80000 & 6.80000 & 3.90000 & 3.90000 & 1.00000 & 600 & 57822 & 1341 & 1341 & 441 & 441 & 459 & 6.80000 & 3.90000 \\
\hline 6356.0 & 15.0 & 60000 & 5.80 & $5.8 \mathrm{C}$ & 3.20000 & 3.20000 & 1.00000 & 600 & 57822 & 875 & 875 & 266 & 266 & 342 & 5.80000 & 3.20000 \\
\hline 6368.0 & 3.0 & 2.60000 & 5.80000 & 5.80000 & 3.20000 & 3.20000 & 1.00000 & 600 & 57822 & 875 & 875 & 266 & 266 & 342 & 5.80000 & 3.20000 \\
\hline 6368.0 & 3.0 & 1.02000 & 1.45000 & 1.45000 & 0. & 0. & 1.00000 & 0 & 57822 & 21 & 21 & 0 & 0 & 21 & 1.45000 & 0. \\
\hline 6371.0 & 0. & 1.02000 & 1.45000 & 1.45000 & 0. & 0. & 1.00000 & 0 & 57822 & 21 & 21 & 0 & 0 & 21 & 1.45000 & 0. \\
\hline 6151.0 & 220.0 & 5950 & 7.72930 & & & & & & & & & & & & & \\
\hline 6171.0 & 200.0 & 36167 & 7.75230 & 7.9 & & 4.3 & & 80 & & 2148 & 2020 & 634 & 639 & 853 & 7.93236 & 4.33212 \\
\hline 6191.0 & 180.0 & 36384 & 7.77531 & 8.00786 & 4.33 & 4.37 & 0.960 & 80 & 57822 & & & 633 & 645 & 856 & -457 & 4.33934 \\
\hline 6211.0 & 160.0 & 3.36602 & 7.79831 & 8.02192 & 4.33395 & 4.39547 & 0.95321 & 80 & 57822 & 2166 & 2047 & 632 & 650 & 859 & 7.95673 & 4.34665 \\
\hline 6231.0 & 140.0 & 3.36819 & 7.82132 & 8.03598 & 4.32943 & 4.41304 & 0.945 & 80 & 57822 & 2175 & 2060 & 631 & 656 & 863 & 7.96882 & 4.35406 \\
\hline 6251.0 & 120.0 & 3.37036 & 7.84432 & 8.05004 & 4.32492 & 4.43061 & 0.93765 & 80 & 57822 & 2184 & 2074 & 630 & 662 & 866 & 7.98084 & 4.36155 \\
\hline 6271.0 & 100.0 & 3.37254 & 7.86732 & 8.06410 & 4.32041 & 4.44818 & 0.92987 & 80 & 57822 & 2193 & 2087 & 630 & 667 & 869 & 7.99279 & 4.36914 \\
\hline 6291.0 & 80.0 & 3.37471 & 7.89031 & 8.07815 & 4.31590 & 4.46574 & 0.92210 & 80 & 57822 & 2202 & 2101 & 629 & 673 & 871 & 8.00468 & 4.37682 \\
\hline 6291.0 & 80.0 & 3.37471 & 7.94982 & 8.14037 & 4.39645 & 4.54911 & 0.92209 & 600 & 57822 & 2236 & 2133 & 652 & 698 & 859 & 8.06715 & 4.45717 \\
\hline 6311.0 & 60.0 & 3.37688 & 7.97251 & 8.15480 & 4.39186 & 4.56700 & 0.91432 & 600 & 57822 & 2246 & 2146 & 651 & 704 & 862 & 8.07928 & 4.46480 \\
\hline 6331.0 & 40.0 & 3.37906 & 7.99522 & 8.16924 & 4.38726 & 4.58490 & 0.90654 & 600 & 57822 & 2255 & 2160 & 650 & 710 & 865 & 8.09135 & 4.47253 \\
\hline 6346.6 & 24.4 & 3.38076 & 8.01295 & 8.18051 & 4.38368 & 4.59887 & 0.90047 & 600 & 57822 & 2262 & 2171 & 650 & 715 & 867 & 8.10074 & 4.47863 \\
\hline 6346.6 & 24.4 & 2.90000 & 6.79151 & 6.79151 & 3.88904 & 3.88904 & 1.00000 & 600 & 57822 & 1338 & 1338 & 439 & 439 & 460 & 6.79151 & 3.88904 \\
\hline 6356.0 & 15.0 & 2.90000 & 6.79151 & 6.79151 & 3.88904 & 3.88904 & 1.00000 & 600 & 57822 & 1338 & 1338 & 439 & 439 & 460 & 6.79151 & 3.88904 \\
\hline 6356.0 & 15.0 & 2.60000 & 5.79328 & 5.79328 & 3.19101 & 3.19101 & 1.00000 & 600 & 57822 & 873 & 873 & 265 & 265 & 343 & 5.79328 & 3.19101 \\
\hline 6368.0 & 3.0 & 2.60000 & 5.79328 & 5.79328 & 3.19101 & 3.19101 & 1.00000 & 600 & 57822 & 873 & 873 & 265 & 265 & 343 & 5.79328 & 3.19101 \\
\hline 6368.0 & 3.0 & 1.02000 & 1.44996 & 1.44996 & 0. & 0. & 1.00000 & 0 & 57822 & 21 & 21 & 0 & 0 & 21 & 1.44996 & 0. \\
\hline 6371.0 & 0. & 1.02000 & 1.44996 & 1.44996 & 0. & 0. & 1.00000 & 0 & 57822 & 21 & 21 & 0 & 0 & 21 & 1.44996 & 0. \\
\hline
\end{tabular}

Dziewonski, A. M. and D. L. Anderson (1981)Preliminary Reference Earth Model, Phys. Earth Planet.

Inter., 25, 297-356 
Appendix 2: Elastic properties of mantle minerals (Duffy and Anderson, 1988)

Elastic Properties of Mantle Minerals (Duffy and Anderson, 1988)

\begin{tabular}{|c|c|c|c|c|c|c|c|}
\hline $\begin{array}{c}\text { Formula } \\
\text { (structure) }\end{array}$ & $\begin{array}{l}\text { Density }{ }^{1} \\
\left(\mathrm{~g} / \mathrm{cm}^{3}\right)\end{array}$ & $\begin{array}{c}\boldsymbol{K}_{\boldsymbol{s}} \\
(\mathbf{G P a})\end{array}$ & $\underset{(\mathbf{G P a})}{\boldsymbol{G}}$ & $K_{s}^{\prime}$ & $G^{r}$ & $\begin{array}{c}-\dot{K}_{\mathbf{S}} \\
(\mathbf{G P a} / \mathbf{K})\end{array}$ & $\begin{array}{c}-G \\
(\mathbf{G P a} / \mathbf{K})\end{array}$ \\
\hline $\begin{array}{l}\text { (Mg,Fe) }{ }_{2} \mathrm{SiO}_{4} \\
\text { (olivine) }\end{array}$ & $\begin{array}{l}3.222(2)+ \\
1.182 x_{\mathrm{Fe}}\end{array}$ & $129(2)^{2}$ & $\begin{array}{l}82(1)- \\
31(1) x_{\mathrm{Fe}}^{2}\end{array}$ & $5.1(3)^{3}$ & $1.8(1)^{3}$ & $0.016(1)^{4}$ & $0.013(1)^{5}$ \\
\hline $\begin{array}{l}(\mathrm{Mg}, \mathrm{Fe})_{2} \mathrm{SiO}_{4} \\
(\beta \text {-spinel })\end{array}$ & $\begin{array}{l}3.472(5)+ \\
1.24(9) x_{\mathrm{Fe}}\end{array}$ & $174(1)^{6}$ & $\begin{array}{l}114(1)- \\
41 x_{\mathrm{Fe}}^{7}\end{array}$ & 4.9 & 1.8 & 0.018 & 0.014 \\
\hline $\begin{array}{l}(\mathrm{Mg}, \mathrm{Fe})_{2} \mathrm{SiO}_{4} \\
\text { (y-spinel) }\end{array}$ & $\begin{array}{l}3.548(1)+ \\
1.30 x_{\mathrm{Fe}}\end{array}$ & $184(1)^{8}$ & $\begin{array}{l}119(1)- \\
41 x_{\mathrm{fe}}^{\mathrm{B}}\end{array}$ & 4.8 & 1.8 & 0.017 & 0.014 \\
\hline $\begin{array}{l}(\mathrm{Mg}, \mathrm{Fe}) \mathrm{SiO}_{3} \\
\text { (orthopyroxene) }\end{array}$ & $\begin{array}{l}3.204(5)+ \\
0.799(5) x_{\mathrm{Fe}}\end{array}$ & $104(4)^{9}$ & $\begin{array}{l}77(1)- \\
24(1) x_{\mathrm{Fe}}^{9}\end{array}$ & 5.0 & 2.0 & 0.012 & 0.011 \\
\hline $\begin{array}{l}\mathrm{CaMgSi}_{2} \mathrm{O}_{6} \\
\text { (clinopyroxene) }\end{array}$ & $3.277(5)^{10}$ & $113(1)^{11}$ & $67(2)^{11}$ & $4.5(1.8)^{12}$ & 1.7 & 0.013 & 0.010 \\
\hline $\begin{array}{l}\mathrm{NaAlSi}_{2} \mathrm{O}_{6} \\
\text { (clinopyroxene) }\end{array}$ & $3.32(2)^{10}$ & $143(2)^{13}$ & $84(2)^{13}$ & 4.5 & 1.7 & 0.016 & 0.013 \\
\hline $\begin{array}{l}\text { (Mg,Fe)O } \\
\text { (magnesiowustite) }\end{array}$ & $\begin{array}{l}3.583(1)+ \\
2.28(1) x_{\mathrm{Fe}}\end{array}$ & $\begin{array}{l}163(1)- \\
8(5) x_{\mathrm{Ft}}^{14}\end{array}$ & $\begin{array}{l}131(1)- \\
77(5) x_{\mathrm{Fe}}^{14}\end{array}$ & $4.2(3)^{11}$ & $2.5(1)^{11}$ & $0.016(3)^{11}$ & $0.024(4)^{11}$ \\
\hline $\begin{array}{l}\mathrm{Al}_{2} \mathrm{O}_{3} \\
\text { (corundum) }\end{array}$ & $3.988(2)^{10}$ & $251(3)^{11}$ & $162(2)^{11}$ & $4.3(1)^{11}$ & $1.8(1)^{11}$ & $0.014(3)^{11}$ & $0.019(1)^{11}$ \\
\hline $\begin{array}{l}\mathrm{SiO}_{2} \\
\text { (stishovite) }\end{array}$ & $4.289(3)$ & $316(4)^{11}$ & $220(3)^{11}$ & 4.0 & 1.8 & 0.027 & 0.018 \\
\hline $\begin{array}{l}(\mathrm{Mg}, \mathrm{Fe})_{3} \mathrm{Al}_{2} \mathrm{Si}_{3} \mathrm{O}_{12} \\
\text { (garnet) }\end{array}$ & $\begin{array}{l}3.562(2)+ \\
0.758(3) x_{\mathrm{Fe}}\end{array}$ & $\begin{array}{l}175(1)+ \\
1(1) x_{\mathrm{R}}^{11}\end{array}$ & $\begin{array}{l}90(1)+ \\
8(1) x_{\mathrm{Fe}}^{11}\end{array}$ & $4.9(5)^{11}$ & $1.4(1)^{\prime \prime}$ & $0.021(2)^{11}$ & $0.010(1)^{11}$ \\
\hline $\begin{array}{l}\mathrm{Ca}_{3}(\mathrm{Al}, \mathrm{Fe})_{2} \mathrm{Si}_{3} \mathrm{O}_{12} \\
\text { (garnet) }\end{array}$ & $\begin{array}{l}3.595(2)+ \\
0.265(1) x_{\mathrm{Re}}^{10}\end{array}$ & $\begin{array}{l}169(2)- \\
11(2) x_{\mathrm{Fe}}^{15}\end{array}$ & $\begin{array}{l}104(1)- \\
14(1) x_{\mathrm{Fe}}^{15}\end{array}$ & 4.9 & 1.6 & $0.016^{16}$ & $0.015^{16}$ \\
\hline $\begin{array}{l}(\mathrm{Mg}, \mathrm{Fe}) \mathrm{SiO}_{3} \\
\text { (ilmenite) }\end{array}$ & $\begin{array}{l}3.810(4)+ \\
1.10(5) x_{\mathrm{Fe}}\end{array}$ & $212(4)^{17}$ & $\begin{array}{l}132(9)- \\
41 x_{\mathrm{Fe}}^{17}\end{array}$ & 4.3 & 1.7 & 0.017 & 0.017 \\
\hline $\begin{array}{l}\text { (Mg, } \mathrm{Fe}) \mathrm{SiO}_{3} \\
\text { (perovskite) }\end{array}$ & $\begin{array}{l}4.104(7)+ \\
1.07(6) x_{\mathrm{Fe}}\end{array}$ & $266(6)^{18}$ & 153 & $3.9(4)^{18}$ & 2.0 & 0.031 & 0.028 \\
\hline $\begin{array}{l}\mathrm{CaSiO}_{3} \\
\text { (perovskite) }\end{array}$ & $4.13(11)^{19}$ & 227 & 125 & 3.9 & 1.9 & 0.027 & 0.023 \\
\hline $\begin{array}{l}(\mathrm{Mg}, \mathrm{Fe})_{4} \mathrm{Si}_{4} \mathrm{O}_{12} \\
\text { (majorite) }\end{array}$ & $\begin{array}{l}3.518(3)+ \\
0.973(7) x_{\mathrm{Fe}}\end{array}$ & $\begin{array}{l}175+ \\
1 x_{\mathrm{Fe}}^{20}\end{array}$ & $\begin{array}{l}90+ \\
8 x_{\mathrm{fe}}^{20}\end{array}$ & 4.9 & 1.4 & 0.021 & 0.010 \\
\hline $\begin{array}{l}\mathrm{Ca}_{2} \mathrm{Mg}_{2} \mathrm{Si}_{4} \mathrm{O}_{12} \\
\text { (majorite) }\end{array}$ & $3.53^{21}$ & 165 & 104 & 4.9 & 1.6 & 0.016 & 0.015 \\
\hline $\begin{array}{l}\mathrm{Na}_{2} \mathrm{Al}_{2} \mathrm{Si}_{4} \mathrm{O}_{12} \\
\text { (majorite) }\end{array}$ & $4.00^{21}$ & 200 & 127 & 4.9 & 1.6 & 0.016 & 0.015 \\
\hline
\end{tabular}

(1) All densities from Jeanloz and Thompson (1983) except where indicated; $x_{\mathrm{Fe}}$ is molar fraction of Fe endmember.

(2) Graham and others (1982), Schwab and Graham (1983), Suzuki and others (1983), Sumino and Anderson(1984), and Yeganeh-Haeri and Vaughan (1984).

(3) Schwab and Graham (1983), Sumino and Anderson (1984)

(4) Suzuki and others (1983), Sumino and Anderson (1984); $\dot{K}=\partial K / \partial T$.

(5) Schwab and Graham (1983), Suzuki and others (1983), Sumino and Anderson (1984); G = $\partial G / \partial T$.

(6) Sawamoto and others (1984).

(7) Sawamoto and others (1984). The effect of Fe on the modulus is from Weidner and others (1984).

(8) Weidner and others (1984).

(9) Sumino and Anderson (1984), Bass and Weidner(1984), Duffy and Vaughan (1986).

(10) Robie and others (1966).

(11) Sumino and Anderson (1984)

(12) Levine and Prewitt (1981).

(13) Kandelin and Weidner (1984)

(14) Sumino and Anderson (1984).

(15) Halleck (1973), Bass (1986)

(16) Isaak and Anderson (1987).

(17) Weidner and Ito (1985)

(18) Knittle and Jeanloz (1987)

(19) Bass (1984)

(20) Inferred from Weidner and others (1987).

(21) Estimated by Bass and Anderson (1984). 
VITA

2004- 2008

SHU HUANG

Jiangxi, China

B.S. in Materials Science and Engineering

China University of Geoscience,

Beijing, China

2008- 2014

Doctoral Candidate

Materials Science and Engineering

Florida International University

Miami, FL

Teaching Assistant

Florida International University

\section{PUBLICATIONS AND PRESENTATIONS}

\section{PUBLICATIONS:}

Huang, S., \& Chen, J. Water Solubility in Synthetic pyrope at High Temperature and High Pressure up to $12 \mathrm{GPa}$. (in preparation)

Huang, S., \& Chen, J. (2014). Equation of state of pyrope-almandine solid solution measured using a diamond anvil cell and in situ synchrotron X-ray diffraction. Physics of the Earth and Planetary Interiors, 228, 88-91.

Chen, J., Yu, T., Huang, S., Girard, J., \& Liu, X. (2014). et al. Compressibility of liquid FeS measured using X-ray radiograph imaging. Physics of the Earth and Planetary Interiors, 228, 294-299.

Mao, Z., Lin, J. F., Huang, S., Chen, J., Xiao, Y., \& Chow, P. (2013). Synchrotron Mössbauer study of Fe-bearing pyrope at high pressures and temperatures. American Mineralogist, 98(7), 1146-1152.

Yu, T., Chen, J., Ehm, L., Huang, S., Guo, Q., Luo, S. N., \& Parise, J. (2012). Study of liquid gallium at high pressure using synchrotron X-ray. Journal of Applied Physics, 111(11), 112629. 


\section{PRESENTATIONS:}

Shu Huang, Jiuhua Chen. "Synthesis of Hydrous Pyrope at High Temperature and Pressure." The Study of Matter at Extreme Conditions (SMEC) meeting. Eastern Caribbean, March 23-30. 2013.

Shu Huang, Jiuhua Chen. "Water Solubility of Synthetic Pyrope at High Temperature and Pressure up to 12GPa." Abstract\# MR23B-2407. Abstract proceedings of American Geophysical Union (AGU) Fall meeting 2012, Eos Trans. AGU.

Zhu Mao, Jung-Fu Lin, Shu Huang, Jiuhua Chen, Yuming Xiao, Paul Chow. "Synchrotron Mössbauer Study of Fe-bearing Pyrope at High Pressures and Temperatures." Abstract\#43B-2319. Abstract proceedings of American Geophysical Union (AGU) Fall meeting 2012, Eos Trans. AGU.

Shu Huang, Jiuhua Chen. "Equation of State of Garnet Solid Solution Using in situ Synchrotron X-ray Diffraction." COMPRES annual meeting, Lake Tahoe, CA, June, 2012.

Shu Huang, Jiuhua Chen. "Equation of State of Garnet Solid Solution along almandinepyrope join measured in diamond anvil cell.” TMS meeting. Orlando, FL, March 2012.

Shu Huang, Jiuhua Chen. "Equation of Garnet $\mathrm{Fe}_{2.4} \mathrm{Mg}_{0.6} \mathrm{Al}_{2} \mathrm{Si}_{3} \mathrm{O}_{12}$ Using in situ Synchrotron X-ray Diffraction.” $A G U$, San Francisco, CA. Dec. 2011.

Shu Huang, CIDER 2011 Summer School "Dynamics of Mountain building." UC Berkeley, CA. June-July 2011.

Jiuhua Chen, Jennifer Girard, Shu Huang. "High Pressure and Temperature Equation of State of NiO up to 8GPa and 1400K." AGU fall meeting. MR41A-2094. Dec. 2011

Shu Huang, Jiuhua Chen. "Equation of State of Garnet $\mathrm{Mg}_{2.4} \mathrm{Fe}_{0.6} \mathrm{Al}_{2} \mathrm{Si}_{3} \mathrm{O}_{12}$ at $\mathrm{Ambient}$ Conditions." COMPRES annual meeting. Williamsburg. VA. Jun. 2011. 